2015

\title{
MODELING AND ANALYSIS OF REACTIVITY CONTROLLED COMPRESSION IGNITION (RCCI) COMBUSTION
}

Mohammadreza Nazemi

Michigan Technological University

Follow this and additional works at: https://digitalcommons.mtu.edu/etds

Part of the Automotive Engineering Commons

Copyright 2015 Mohammadreza Nazemi

\section{Recommended Citation}

Nazemi, Mohammadreza, "MODELING AND ANALYSIS OF REACTIVITY CONTROLLED COMPRESSION IGNITION (RCCI) COMBUSTION", Master's Thesis, Michigan Technological University, 2015.

https://doi.org/10.37099/mtu.dc.etds/956

Follow this and additional works at: https://digitalcommons.mtu.edu/etds

Part of the Automotive Engineering Commons 


\title{
MODELING AND ANALYSIS OF REACTIVITY CONTROLLED COMPRESSION IGNITION (RCCI) COMBUSTION
}

\author{
By
}

Mohammadreza Nazemi

\begin{abstract}
A THESIS
Submitted in partial fulfillment of the requirements for the degree of MASTER OF SCIENCE

In Mechanical Engineering
\end{abstract}

MICHIGAN TECHNOLOGICAL UNIVERSITY

2015

(c) 2015 Mohammadreza Nazemi 

This thesis has been approved in partial fulfillment of the requirements for the Degree of MASTER OF SCIENCE in Mechanical Engineering.

Department of Mechanical Engineering-Engineering Mechanics

Thesis Advisor: Dr. Mahdi Shahbakhti

Committee Member: Dr. Scott Miers

Committee Member: Dr. Sunil Mehendale

Department Chair: Dr. William Predebon 

Develop an attitude of gratitude, and give thanks for everything that happens to you, knowing that every step forward is a step toward achieving something bigger and better than your current situation.

- Brian Tracy 



\section{Contents}

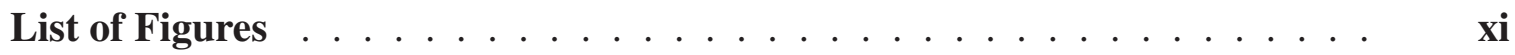

List of Tables . . . . . . . . . . . . . . . . . . . . . . .

Acknowledgments ...................... xix

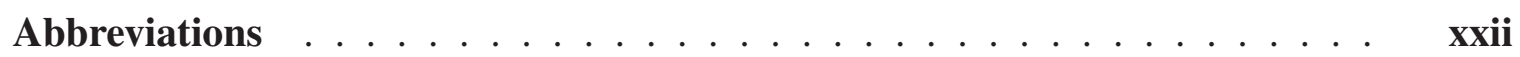

Nomenclature .......................

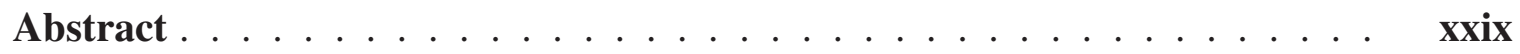

1 Introduction ........................ 1

1.1 Motivation and Background . . . . . . . . . . . . . 1

1.2 Literature Review . . . . . . . . . . . . . . . . 3

1.2.1 HCCI Combustion ................. 5

1.2.2 PPCI and PCCI Combustion Strategies . . . . . . . . . . 7

1.2.3 RCCI Combustion .................. 9

1.3 Technical approach and scope of this thesis ........... 11

1.4 Organization of thesis $\ldots \ldots \ldots \ldots$ 
2 Zero-Dimensional Model Development . . . . . . . . . . . . . . 15

2.1 Engine Specifications . . . . . . . . . . . . . . . . 17

2.2 Model Description . . . . . . . . . . . . . . . . 18

2.3 Results and Discussion ..................... 23

3 Multi-Dimensional/CFD Model Development . . . . . . . . . . . . . 25

3.1 CFD Model Description . . . . . . . . . . . . . 25

$3.1 .1 \quad$ Spray Model . . . . . . . . . . . . . . . . 28

3.1.2 Combustion model ................... 32

3.1.3 Emission models .................... 33

3.1.4 Turbulence Model . . . . . . . . . . . . . . . 35

3.2 Model Validation . . . . . . . . . . . . . . . 37

4 Combustion and Performance Analysis- Effects of Fuel Injection

Parameters ........................ 45

4.1 Premixed Ratio $(\mathrm{PR}) \quad \ldots \ldots \ldots \ldots$

4.2 Injection Pressure . . . . . . . . . . . . . 58

4.3 Start of Injection Timing . . . . . . . . . . . . 68

4.4 Spray Angle . . . . . . . . . . . . . . . . 82

4.5 Summary of injection system parameters . . . . . . . . . . . 95

5 Summary and Conclusion . . . . . . . . . . . . . . . . . 97

5.1 Summary of thesis contributions . . . . . . . . . . . . . 98 
5.2 Future Work . . . . . . . . . . . . . . . . . 100

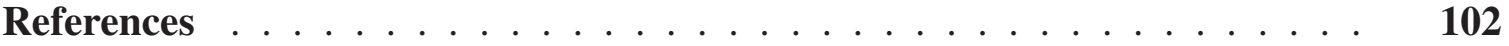

A Calculations of gross and net work . . . . . . . . . . . . . . 115

B MS Publications . . . . . . . . . . . . . . . . . . . . . . . 117

C Geometric/CFD Model of EML's LTC engine . . . . . . . . . . . . . . . . 119

D Calculations for standard limit of HC and CO emissions . . . . . . . . 126

E Thesis files summary . . . . . . . . . . . . . . . . . 128

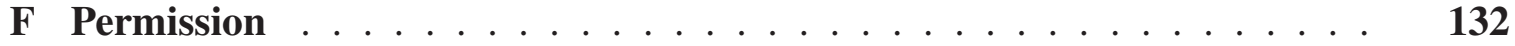





\section{List of Figures}

1.1 Soot and $\mathrm{NO}_{\mathrm{x}}$ regions in $\phi$-T space. Adapted from [1]. . . . . . . . . . 4

1.2 Background of main fuel injection system parameters in the literature . 13

1.3 Thesis organization $\ldots \ldots \ldots \ldots$. . . . . . . . . . . . . . 14

2.1 Varying scale thermo-kinetic combustion models for RCCI engines . . . 17

2.2 Three step simulation path to simulate RCCI cycle . . . . . . . . . . . 19

3.1 Two step simulation path in CFD platform . . . . . . . . . . 26

3.2 a) Geometry used for computational study b) piston shape for the GM diesel

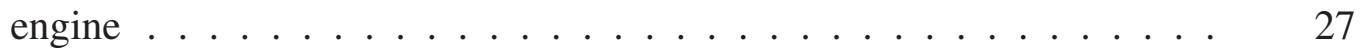

3.3 Injected fuel spray corresponding to case ain Table 2.3 with maximum injection pressure of 480 bar. . . . . . . . . . . . . . . 28

3.4 Pressure trace validation for the engine operating condition corresponding to case ain Table $2.3 \ldots \ldots \ldots$. . . . . . . . . . . . . . 38

3.5 Heat Release Rate (HRR) validation for the engine operating condition corresponding to case ain Table $2.3 \ldots \ldots$. . . . . . . . . . 39

3.6 Pressure trace validation for the engine operating condition corresponding to case bin Table $2.3 \ldots \ldots$. . . . . . . . . . . . . . . 40 
3.7 Heat Release Rate (HRR) validation for the engine operating condition corresponding to case bin Table $2.3 \ldots \ldots \ldots$

3.8 Pressure trace validation for the engine operating condition corresponding to case cin Table $2.3 \ldots \ldots \ldots \ldots$

3.9 Heat Release Rate (HRR) validation for the engine operating condition corresponding to case cin Table $2.3 \ldots \ldots \ldots$

4.1 Effects of Premixed Ratio (PR) on in-cylinder pressure for engine operating condition corresponding to case ain Table $2.3 \ldots \ldots$. . . . . . .

4.2 Effects of Premixed Ratio (PR) on Heat Release Rate (HRR) for engine operating condition corresponding to case ain Table $2.3 \ldots \ldots$

4.3 Effects of Premixed Ratio (PR) on combustion phasing (CA10, CA50, CA90, BD) for engine operating condition corresponding to case ain Table $2.3 \ldots \ldots \ldots \ldots \ldots \ldots \ldots$

4.4 Effects of Premixed Ratio (PR) on engine-out emissions including HC, CO, $\mathrm{NO}_{\mathrm{x}}$ and soot for engine operating condition corresponding to case ain Table $2.3 \ldots \ldots \ldots \ldots \ldots \ldots \ldots$

4.5 Effects of Premixed Ratio (PR) on mean in-cylinder temperature for engine operating condition corresponding to case ain Table $2.3 \ldots \ldots$

4.6 Effects of Premixed Ratio (PR) on combustion efficiency, IMEP $\mathrm{g}$ and $\mathrm{IMEP}_{\mathrm{n}}$ for engine operating condition corresponding to $\underline{\text { case ain }}$ Table 2.3 
4.7 Effects of Premixed Ratio (PR) on $\eta_{\text {ind.-g }}$ and $\eta_{\text {ind.-n}}$ for engine operating condition corresponding to case ain Table $2.3 \ldots \ldots 56$

4.8 Effects of Premixed Ratio (PR) on PPRR and ringing intensity for engine operating condition corresponding to case ain Table $2.3 \ldots \ldots$

4.9 Effects of injection pressure on in-cylinder pressure for engine operating condition corresponding to case ain Table $2.3 \ldots$. . . . . . . . . . 60

4.10 Cylinder temperature cut planes at 4 crank angles for each of the injection pressure for engine operating condition corresponding to case ain Table 2.3. Fuel parcels are shown by green color pentagons. . . . . . .

4.11 Equivalence ratio cut planes at 4 crank angles for each of the injection pressure for engine operating condition corresponding to case ain Table $2.3 \ldots \ldots \ldots \ldots \ldots \ldots \ldots \ldots$

4.12 Effects of injection pressure on Heat Release Rate (HRR) for engine operating condition corresponding to case ain Table $2.3 \ldots \ldots$

4.13 Effects of injection pressure on combustion phasing (CA10, CA50, CA90, BD) for engine operating condition corresponding to case ain Table 2.3

4.14 Effects of injection pressure on engine-out emissions including $\mathrm{HC}, \mathrm{CO}$, $\mathrm{NO}_{\mathrm{x}}$ and soot for engine operating condition corresponding to case ain Table $2.3 \ldots \ldots \ldots \ldots \ldots \ldots \ldots$

4.15 Effects of injection pressure on combustion efficiency, $\mathrm{IMEP}_{\mathrm{g}}$ and $\mathrm{IMEP}_{\mathrm{n}}$ for engine operating condition corresponding to case ain Table 2.3 . . 
4.16 Effects of injection pressure on $\eta_{\text {ind.-g }}$ and $\eta_{\text {ind.-n}}$ for engine operating condition corresponding to case ain Table $2.3 \ldots \ldots$. . . . . . . .

4.17 Effects of injection pressure on PPRR and ringing intensity for engine operating condition corresponding to case ain Table $2.3 \ldots . . \ldots 68$

4.18 Effects of SOI timing sweep on in-cylinder pressure for engine operating condition corresponding to case ain Table $2.3 \ldots \ldots \ldots$

4.19 Equivalence ratio cut planes at 4 crank angles for each of the SOI timings (deg. aTDC) for engine operating condition corresponding to case ain Table $2.3 \ldots \ldots \ldots \ldots \ldots \ldots \ldots$

4.20 Effects of SOI timing sweep on Heat Release Rate (HRR) for engine operating condition corresponding to case ain Table $2.3 \ldots \ldots$

4.21 Effects of SOI timing sweep on mean in-cylinder gas temperature for engine operating condition corresponding to case ain Table $2.3 \ldots .$.

4.22 Cylinder temperature cut planes at 4 crank angles for each of the SOI timings (deg. aTDC) for engine operating condition corresponding to case ain Table 2.3. Fuel parcels are shown by green color pentagons. .

4.23 Effects of SOI timing sweep on combustion phasing (CA10, CA50, CA90, BD) for engine operating condition corresponding to case ain Table 2.3

4.24 Effects of SOI timing sweep on engine-out emissions including $\mathrm{HC}, \mathrm{CO}$, $\mathrm{NO}_{\mathrm{x}}$ and soot for engine operating condition corresponding to case ain Table $2.3 \ldots \ldots \ldots \ldots \ldots \ldots$ 
4.25 Effects of SOI timing sweep on max. in-cylinder gas temperature for engine operating condition corresponding to case ain Table $2.3 \ldots 78$

4.26 Effects of SOI timing sweep on combustion efficiency, IMEP gnd $_{\text {IMEP }}$ for engine operating condition corresponding to case ain Table 2.3 . .

4.27 Effects of SOI timing sweep on $\eta_{\text {ind.-g}}$ and $\eta_{\text {ind.- }}$ for engine operating condition corresponding to case ain Table $2.3 \ldots \ldots . . . . . .$.

4.28 Effects of SOI timing sweep on PPRR and ringing intensity for engine operating condition corresponding to case ain Table $2.3 \ldots \ldots$

4.29 Fuel parcels spray from the engine's seven-hole injector at injection pressure of 480 bar. . . . . . . . . . . . . . . .

4.30 Different spray angles for the engine sector studied in this thesis . . . .

4.31 Effects of spray angle on in-cylinder pressure for engine operating condition corresponding to case ain Table $2.3 \ldots \ldots . . . . .$.

4.32 Effects of spray angle on Heat Release Rate (HRR) for engine operating condition corresponding to case ain Table $2.3 \ldots \ldots . . . . .$.

4.33 Cylinder temperature cut planes at 4 crank angles for each of the studied spray angles for engine operating condition corresponding to case ain Table 2.3. Fuel parcels are shown by green color pentagons. . . . . . .

4.34 Effects of spray angle on combustion phasing (CA10, CA50, CA90, BD) for engine operating condition corresponding to case ain Table 2.3 . . 
4.35 Effects of spray angle on engine-out emissions including $\mathrm{HC}, \mathrm{CO}, \mathrm{NO}_{\mathrm{x}}$ and soot for engine operating condition corresponding to case ain Table $2.3 \quad 90$

4.36 Effects of spray angle on max. in-cylinder gas temperature for engine operating condition corresponding to case ain Table $2.3 \ldots . . . . .991$

4.37 Effects of spray angle on combustion efficiency, $\mathrm{IMEP}_{\mathrm{g}}$ and $\mathrm{IMEP}_{\mathrm{n}}$ for engine operating condition corresponding to case ain Table $2.3 \ldots .$.

4.38 Effects of spray angle on $\eta_{i n d .-g}$ and $\eta_{i n d .-n}$ for engine operating condition corresponding to case ain Table $2.3 \ldots \ldots 93$

4.39 Effects of spray angle on PPRR and ringing intensity for engine operating condition corresponding to case ain Table $2.3 \ldots \ldots \ldots$

4.40 Classification of fuel injection system parameters based on engine performance metrics in Table 4.1. . . . . . . . . . . . . . . 96

A.1 Pressure trace validation for the engine operating condition corresponding to case cin Table $2.3 \ldots \ldots \ldots$. . . . . . . . . . . . . . . 116

C.1 Stock and new piston top designs [2] . . . . . . . . . . . . . 120

C.2 3D model of the GM Ecotec LHU engine with stock piston. . . . . . . . 122

C.3 Motoring in-cylinder pressure with stock piston in simulation . . . . . 123

C.4 3D model of the GM Ecotec LHU engine with new piston. . . . . . . . 124

C.5 Motoring in-cylinder pressure with new piston in simulation . . . . . 125 


\section{List of Tables}

2.1 Specifications of GM Z19DTH Diesel Engine converted for RCCI operation $[3] . \ldots \ldots \ldots \ldots \ldots \ldots \ldots \ldots \ldots \ldots \ldots \ldots$

2.2 Constants used in the Woschni correlation . . . . . . . . . . . 22

2.3 Engine operating conditions of the experimental data used to validate the single-zone model at $1500 \mathrm{rpm} . \ldots \ldots \ldots$. . . . . . . . . 23

2.4 Surface temperatures selected for simulations in this thesis $\ldots \ldots .23$

2.5 Comparison between experimental (Exp.) and simulated (Sim.) SOC . . 24

3.1 Summary of key spray processes used in the CONVERGE code . . . 29

3.2 Comparison between experimental (Exp.) and simulated (Sim.) combustion phasing (CA10, CA50, CA90, BD) $\ldots \ldots \ldots \ldots$

3.3 Comparison between experimental (Exp.) and simulated (Sim.) engine-out emissions $\left(\mathrm{NO}_{\mathrm{x}}, \mathrm{HC}, \mathrm{CO}\right) \ldots \ldots \ldots \ldots \ldots \ldots$

4.1 Classification of RCCI engine points to find optimum injection system

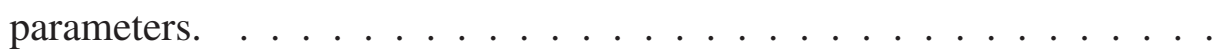

C.1 Engine specifications (GM Ecotec LHU A20NFT) . . . . . . . . . . 
C.2 Differences in creating the geometric/3D model of the engine with stock

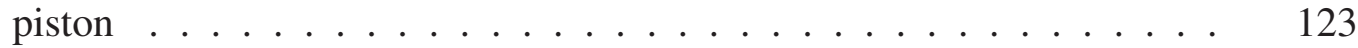

C.3 Differences in creating the geometric/3D model of the engine with new

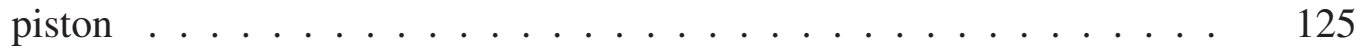

E.1 Experimental data files . . . . . . . . . . . . . . . 128

E.2 CHEMKIN ${ }^{\circledR}-\mathrm{PRO}$ and CONVERGE ${ }^{\mathrm{TM}}$ files . . . . . . . . . . . 129

E.3 Matlab figure (.fig) files for Chapter $3 \ldots \ldots$. . . . . . . . . 129

E.4 Matlab figure (.fig) files for Chapter 4 and Appendix A . . . . . . 130

E.5 Image files for Chapters 1, 3 and Appendix C . . . . . . . . . 131

E.6 Visio figures . . . . . . . . . . . . . . . . . 131 


\section{Acknowledgments}

I wish to take this opportunity to thank all those who have made a contribution to this work.

First, I would like to thank my parents for providing me this opportunity to pursue my MS

degree in the US. I also thank my parents and sister for their promising suggestions and advise whenever I consult with them.

Second, I wish to thank my advisor Dr. Mahdi Shahbakhti for giving me this opportunity to join his research group and work under his supervision. I am also thankful to Dr. Scott Miers and Dr. Sunil Mehendale for accepting to become my committee members.

Third, I want to thank my dear friend Bahram Seifi for his friendship and spending a great two years together.

Fourth, I want to acknowledge all past and current EML members specifically Meysam Razmara and Mehran Bidarvatan for their help and guidance during the whole two years.

I am also grateful to Seyfi Polat, Kamran Pourghasemi and Hrishikesh Saigaonkar for their help and collaboration during my masters.

Fifth, I want to acknowledge Prof. Rolf Reitz, Dr. Yifeng Wu and Anand Nageswaran Brahath From UW-Madison Engine Research Center for providing the RCCI experimental 
data as well as their guidance and technical support during this work.

Last but not least, I wish to thank Dr. Sameera Wijeyakulasuriya from Convergent Science Inc., Eric O’Connell, Kim Connolly and Kevin Colburn from CEI Inc. for their help, guidance and support whenever I had problems with CONVERGE and EnSight software during this work. 



\section{Abbreviations}

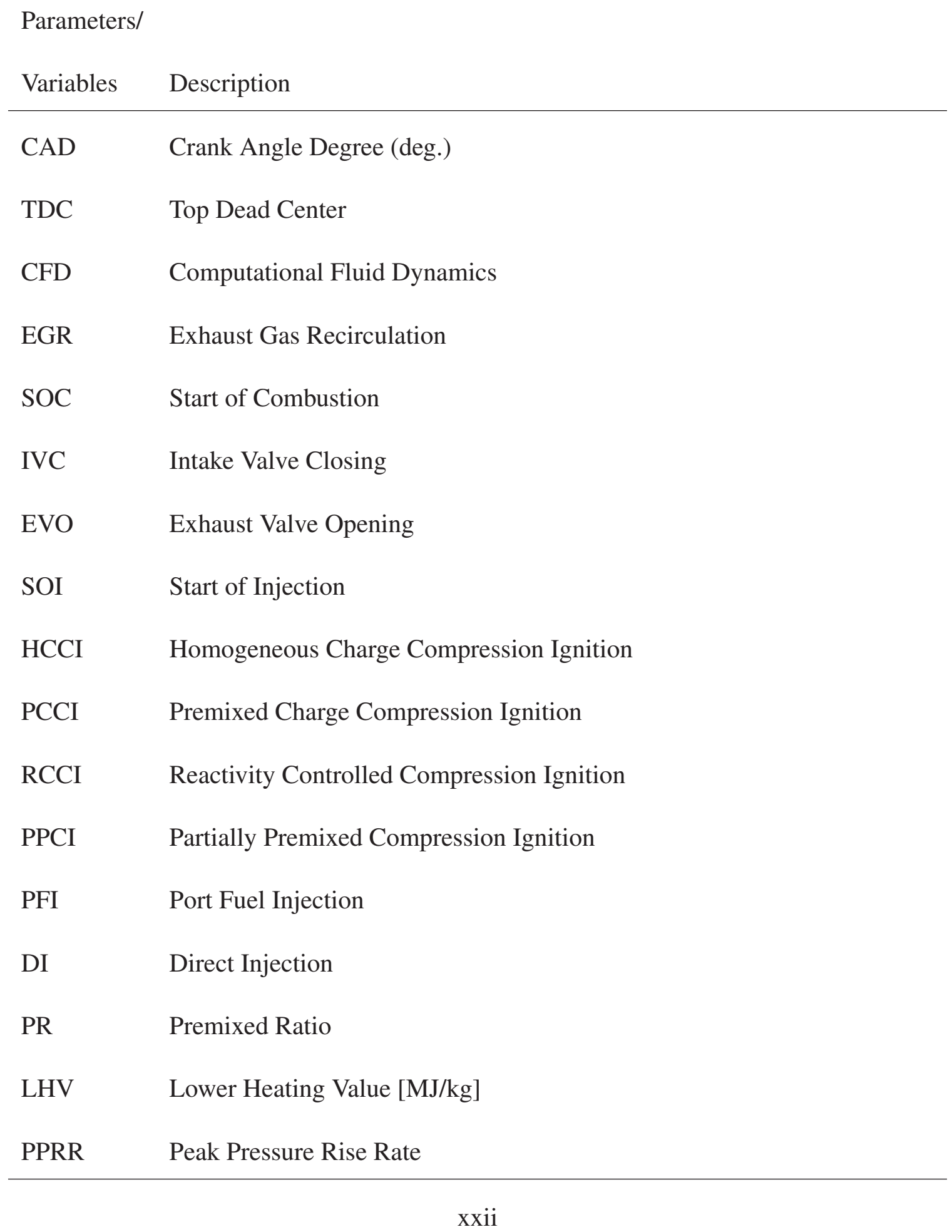




\author{
RI Ringing Intensity \\ IMEP Indicated Mean Effective Pressure [bar] \\ $C A_{X} \quad$ Crank angle for $\mathrm{X} \%$ burnt fuel [CAD aTDC] \\ SZM Single Zone Model \\ MZM Multi Zone Model \\ BD Burn Duration \\ DOE Design of Experiment
}





\section{Nomenclature}

\begin{tabular}{|c|c|}
\hline Variables & Description \\
\hline $\mathrm{C}_{\mathrm{p}}$ & Constant-pressure specific heat capacity $\left[\frac{\mathrm{J}}{\mathrm{kg} . \mathrm{K}}\right]$ \\
\hline $\mathrm{C}_{\mathrm{v}}$ & Constant-volume specific heat capacity $\left[\frac{\mathrm{J}}{\mathrm{kg} \cdot \mathrm{K}}\right]$ \\
\hline$\gamma$ & Specific heat ratio [-] \\
\hline$R$ & Gas constant $\left[\frac{\mathrm{J}}{\mathrm{kg} \cdot \mathrm{K}}\right]$ \\
\hline$R_{u}$ & Universal gas constant $\left[\frac{\mathrm{J}}{\mathrm{kmol} . \mathrm{K}}\right]$ \\
\hline$Q_{\text {wall }}$ & Convective heat loss to the cylinder wall [W] \\
\hline h & Convective heat transfer coefficient $\left[\frac{\mathrm{W}}{\mathrm{m}^{2} . \mathrm{K}}\right]$ \\
\hline $\mathrm{T}$ & Temperature $[\mathrm{K}]$ \\
\hline $\mathrm{T}_{\text {wall }}$ & Wall temperature $[\mathrm{K}]$ \\
\hline $\mathrm{P}$ & Pressure $[\mathrm{Pa}]$ \\
\hline $\mathrm{Nu}_{\mathrm{h}}$ & Nusselt number [-] \\
\hline $\operatorname{Re}$ & Reynolds number [-] \\
\hline $\operatorname{Pr}$ & Prandtl number [-] \\
\hline $\mathrm{D}$ & Diameter $[\mathrm{m}]$ \\
\hline$\rho$ & Mixture density $\left[\frac{\mathrm{kg}}{\mathrm{m}^{3}}\right]$ \\
\hline$\lambda$ & Gas conductivity $\left[\frac{\mathrm{W}}{\mathrm{m} \cdot \mathrm{K}}\right]$ \\
\hline$\omega$ & Gas velocity $\left[\frac{\mathrm{m}}{\mathrm{s}}\right]$ \\
\hline
\end{tabular}




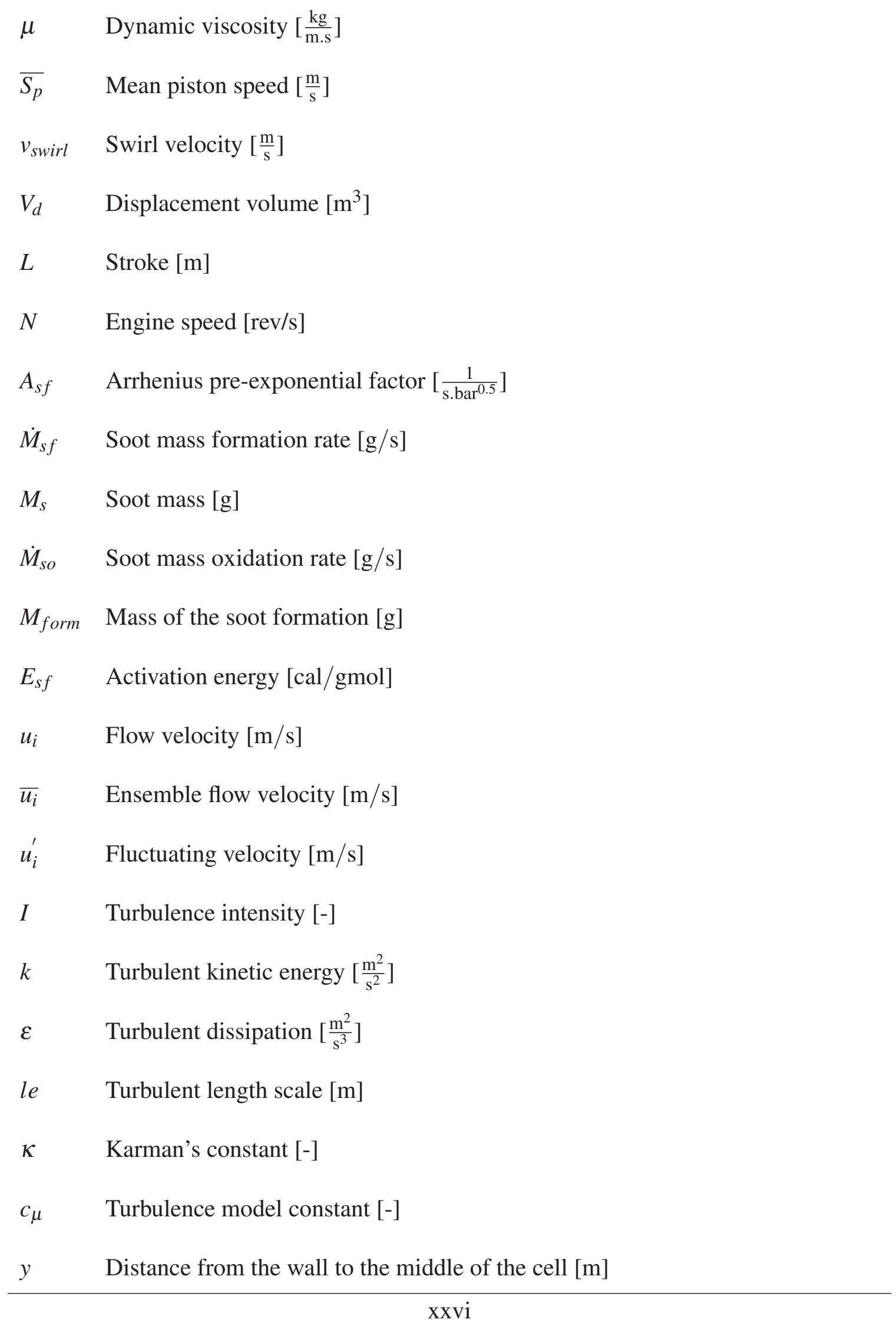




$\begin{array}{ll}\eta_{c} & \text { Combustion efficiency [-] } \\ \sum R H R & \text { Integrated value of heat release [J] } \\ Q_{\text {in }} & \text { Total amount of heat release by fuel [J] } \\ m_{\text {gasoline }} & \text { Mass of gasoline [mg] } \\ m_{\text {diesel }} & \text { Mass of diesel [mg] } \\ \eta_{\text {ind.-g }} & \text { Gross indicated efficiency [-] } \\ \eta_{\text {ind.-n }} & \text { Net indicated efficiency [-] } \\ \eta_{t h-g} & \text { Gross thermal efficiency [-] } \\ \eta_{t h-n} & \text { Net thermal efficiency [-] } \\ A F R & \text { Mass of air to mass of fuel ratio [-] } \\ R I & \left.\text { Ringing intensity [MW } / \mathrm{m}^{2}\right] \\ (d P / d t)_{\text {max }} & \text { Maximum pressure rise rate }[\mathrm{kPa} / \mathrm{ms}] \\ p_{\text {max }} & \text { Maximum cylinder pressure [pa] } \\ & \text { Maximum cylinder temperature [K] }\end{array}$





\section{Abstract}

Homogeneous Charge Compression Ignition (HCCI) and Premixed Charge Compression Ignition (PCCI) combustion strategies are promising methods for achieving low engine-out $\mathrm{NO}_{\mathrm{x}}$ and soot emissions as well as high indicated efficiency. However, these combustion strategies have difficulties with controlling the rate of heat release and lack of an adequate combustion phasing control mechanism. A dual-fuel Reactivity Controlled Compression Ignition (RCCI) combustion strategy will address these issues due to the existence of precise means for controlling the heat release rate and combustion phasing. In the RCCI strategy two fuels with different reactivity (auto-ignition characteristics, e.g., gasoline and diesel) are blended inside the combustion chamber. Combustion phasing is controlled by the relative ratios of these two fuels and the combustion duration is controlled by the local equivalence ratio gradient between the two fuels. This thesis focuses on development of RCCI engine combustion model and understanding the effects of key parameters controlling RCCI engine combustion. This thesis includes three major modeling and analysis contributions.

In the fist part, a computationally efficient modeling platform is developed and validated against the experimental data. The model is able to predict start of combustion (SOC) with average error around 1 Crank Angle Degree (CAD). However, due to premixed nature of air-fuel mixture and considering the whole combustion chamber as one uniform zone, 
the model overpredicts peak in-cylinder pressure and therefore is not capable of predicting crank angle for 50 percent mass of fuel burned (CA50) and Burn Duration (BD) .

Proper operation of RCCI engines requires an in-depth understanding of the interactions between fluid flows, turbulent mixing and chemical kinetics. In the second part of this thesis, a detailed 3D/Computational Fluid Dynamics (CFD) combustion model in commercial CFD code called CONVERGE is developed and validated against experimental data. In-cylinder pressure trace, combustion phasing and emissions (e.g., $\mathrm{NO}_{\mathrm{x}}, \mathrm{HC}$ and $\mathrm{CO}$ ) are shown to be in good agreement with experimental data for different operating conditions.

In the last part, the effects of fuel injection system parameters on the performance and emissions characteristics of an RCCI engine are discussed. The injection system parameters include Premixed Ratio (PR), injection pressure, Start of Injection (SOI) timing and spray angle. The CFD model is then used to suggest an injection strategy capable of achieving optimized RCCI engine operation. 


\section{Chapter 1}

\section{Introduction}

\subsection{Motivation and Background}

Combustion has been the essential means of heating, food preparation, and material processing for several thousand years [4] and combustion of liquid hydrocarbons is the primary source of energy that is utilized in transportation systems. However, even with its long history, a detailed understanding of the interactions between fluid flow, mixing, and chemical kinetics is not well understood and requires further consideration. Since most of the transportation systems are equipped with Internal Combustion (IC) engines where the difficulties associated with turbulent combustion are combined by interactions with complex flow fields and multi-phase mixtures. In addition, mechanical work extraction 
considerations and the use of complex turbo-machinery systems to increase efficiency make the analysis of IC engines more complex.

Rising and unstable fuel costs and a focus on reduction of emissions necessitate the need for increasing efficiency from the IC engines. This need for increasing efficiency makes the diesel or compression ignition (CI) engine under consideration due to its higher thermal efficiency in comparison to spark-ignited (SI) engines. Although the fuel efficiency of CI engines is typically higher than that of SI engines, controlling $\mathrm{NO}_{\mathrm{x}}$ and soot emissions is a big concern. Under conventional CI operation, parts of the combustion chamber cross rich and lean-high temperature regions, forming soot and $\mathrm{NO}_{\mathrm{x}}$, respectively. Soot can be decreased with a Diesel Particulate Filter (DPF) effectively; however, DPFs require continuous regeneration (i.e., removal of collected soot), which increases fuel consumption. Additionally, since diesel engines typically operate under lean mixture condition, the exhaust oxygen concentrations are too high to convert $\mathrm{NO}_{\mathrm{x}}$ to nitrogen using a three-way catalyst (TWC). Several efforts have been done to operate CI engines under stoichiometric mixture condition such that a TWC can be used for $\mathrm{NO}_{\mathrm{x}}$ reduction [5]; however, these efforts generally yielded poor fuel efficiency; thus removing the CI engines benefits over the SI engines. In addition to stoichiometric-TWC $\mathrm{NO}_{\mathrm{x}}$ reduction, technologies for $\mathrm{NO}_{\mathrm{x}}$ aftertreatment consistent with lean operation are available. Sample technologies include lean $\mathrm{NO}_{\mathrm{x}}$ traps (LNT) and Selective Catalytic Reduction (SCR). An LNT is basically a TWC reformulated to improve storage of $\mathrm{NO}_{\mathrm{x}}$ during lean operation. LNTs provide $\mathrm{NO}_{\mathrm{x}}$ reduction similar to conventional TWC where $\mathrm{NO}_{\mathrm{x}}$ is converted to $\mathrm{N}_{2}$ through reactions 
with products of rich combustion including $\mathrm{CO}, \mathrm{HC}$, and $\mathrm{H}_{2}$ [6]. An engine operating with LNT for $\mathrm{NO}_{\mathrm{x}}$ reduction must periodically operate on rich mixture condition to reduce the stored $\mathrm{NO}_{\mathrm{x}}$; as a result, fuel efficiency is reduced. In contrast to LNT technology, SCR technology can be applied for $\mathrm{NO}_{\mathrm{x}}$ reduction without the need to operate rich condition; therefore, the fuel efficiency benefits of the lean burn CI engines, are conserved. However, similar to the required periodic rich operation of LNT technology, SCR technology requires to reduce agent (i.e., urea). The urea is stored on the vehicle and is injected into the exhaust system, resulting no useful work; therefore, the consumed urea applied for $\mathrm{NO}_{\mathrm{x}}$ reduction

can increase fuel consumption. Based on the work of Johnson [7], urea consumption can be estimated at $1 \%$ of the fuel consumption per $\mathrm{g} / \mathrm{kW}-\mathrm{hr}$ reduction in $\mathrm{NO}_{\mathrm{x}}$ emissions.

Considering the above discussion, it is necessary to maximize overall engine efficiency by minimizing the need for aftertreatment systems. Accordingly, reduction of $\mathrm{NO}_{\mathrm{x}}$ and soot in the cylinder has been studied by many researchers. This study presents development and analysis of an advanced combustion strategy capable of achieving near zero $\mathrm{NO}_{\mathrm{x}}$ and soot emissions in the cylinder.

\subsection{Literature Review}

To understand what conditions yield $\mathrm{NO}_{\mathrm{x}}$ and soot emissions, a plot of "local" equivalence $\operatorname{ratio}(\phi)$ versus "local" temperature is shown in Figure 1.1. 


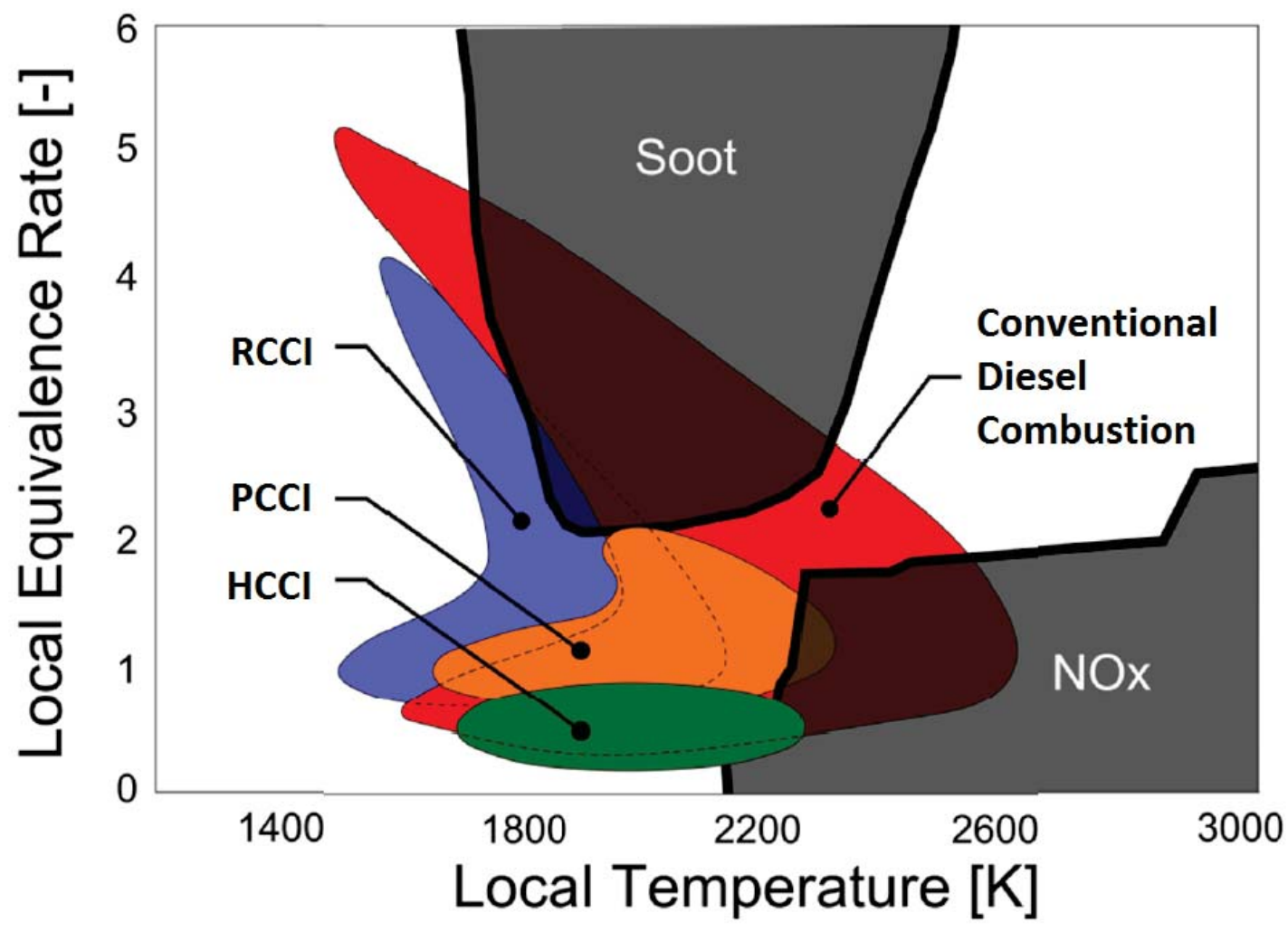

Figure 1.1: Soot and $\mathrm{NO}_{\mathrm{x}}$ regions in $\phi$-T space. Adapted from [1].

It can be observed that there are two distinct zones for soot and $\mathrm{NO}_{\mathrm{x}}$ emissions formation: at stoichiometric mixture condition $(\phi=1)$, there is a diffusion flame (i.e., mixing-controlled burning) that results in high $\mathrm{NO}_{\mathrm{x}}$ formation rates, while $2<\phi<3$ with $\mathrm{T}=2000 \mathrm{~K}$, results in unacceptably high soot formation rates [1]. In an effort to simultaneously reduce $\mathrm{NO}_{\mathrm{x}}$ and soot emissions, many advanced combustion strategies have been proposed. The goal of these strategies is to develop a combustion process that avoids high temperatures (i.e., the $\mathrm{NO}_{\mathrm{x}}$ production regime) as well as rich mixture (i.e., the soot production regime) conditions. The strategies presented here typically considers all or most of the fuel to be 
premixed to remove locally rich regions in the combustion chamber. The premixed fuel can be achieved by injecting through port fuel or direct injections early in the intake and compression strokes and/or several injection events containing small amounts of fuel.

\subsubsection{HCCI Combustion}

The homogeneous charge compression ignition (HCCI) concept has been the topic of much research and development work. This strategy uses a fully premixed charge of fuel and air, which is compressed until reaches auto-ignition, where the charge undergoes a volumetric combustion process. In this combustion strategy, the fuel is injected through PFI system. Theoretically, this lean, low temperature combustion process can avoid both the high $\mathrm{NO}_{\mathrm{x}}$ and soot production regions, as shown in Figure 1.1. However, due to the volumetric combustion process, very high peak cylinder pressure and Peak Pressure Rise Rate (PPRR) values are caused, resulting in high levels of combustion noise and knock. In addition, the peak cylinder pressure values as well as their phasing relative to the piston position can lead to damage to the engine design and components. In the late 1970's Onishi et al. [8] initiates the research on this concept by studying on a two-stroke engine. In their strategy, the scavenging process was utilized to increase the temperature of the air/fuel charge until autoignition of the charge was achieved. In the early 1980's, Najt and Foster [9] studied the application of the HCCI to four-stroke engines. They successfully expanded the lean flammability limit of their engine's operating regime, and observed that fuel oxidation 
kinetics could be sufficiently controlled in a way the engine could operate in HCCI combustion mode. Thring [10] further studied HCCI combustion in four-stroke engines and determined that, under the right operating conditions (e.g., EGR rates between 13-30\% and intake temperatures greater than $370^{\circ} \mathrm{C}$ ), HCCI combustion processes are comparable with typical diesel engines in fuel efficiency. Despite of its lean and low temperature combustion process and consequently near-zero $\mathrm{NO}_{\mathrm{x}}$ and soot emissions as well as high thermal efficiencies, the HCCI combustion conserves some major drawbacks which affect market penetration of this mode of combustion. This strategy is too sensitive to oscillations in parameters such as intake temperature, equivalence ratio, and cyclic variability. The HCCI combustion strategy has difficulty with control of the ignition timing and the rate of heat release due to not having definite means of control actuation such as spark plug in SI engines or diesel injection timing in the CI engines. In the SI engine the rate of heat release is controlled by finite turbulent flame propagation while in the CI engines the rate of heat release is controlled by the rate of fuel injection. Because HCCI combustion depends on a premixed mixture of air and fuel, the fuel injection(s) is/are typically very early in the compression stroke. Therefore there is enough time for the fuel and intake air to mix. Injection of fuel early in the cycle results in a long ignition delay period (i.e; the time between the end of injection and initiation of combustion). Therefore, the injection stage and the combustion process are not linked [11]. Further, the HCCI combustion strategy depends on chemical kinetics to initiate auto-ignition of the mixture. In an effort to gain control over ignition timing, Olsson et al. $[12,13,14]$ examined combination of fuels that 
have a large reactivity gradient. By changing the ratio between the high and low-reactivity fuels (e.g., iso-octane/n-heptane and ethanol/n-heptane), it was observed that more control over the combustion process is possible. However, the experiments were restricted in load due to losses imposed by the turbocharger. Exhaust gas temperatures in HCCI are significantly lower in comparison to other combustion strategies, so high levels of boost were unreachable. Nonetheless, the experiments yielded results with very low $\mathrm{NO}_{\mathrm{x}}$, and combustion efficiency values above $95 \%$, even at high-load points and when EGR was used. However, efficient low-load operation is still a big challenge for HCCI and HCCI-like combustion strategies.

In an effort to increase controllability of the HCCI engine over ignition timing and the rate of heat release, another combustion strategy called Premixed Charge Compression Ignition (PCCI) have been proposed that utilizes early direct injection of fuel in the compression stroke.

\subsubsection{PPCI and PCCI Combustion Strategies}

In these combustion strategies, a direct fuel injection system is utilized. Based on the level of homogeneity of the air-fuel mixture, PCCI combustion strategy uses early direct injection while PPCI applies late direct injection of fuel to prepare partially premixed mixture of air and fuel. Single or dual fuel can be used in these combustion strategies. 
Noehre et al. [15] tested a conventional diesel engine at 8, 12, and, 15 bar gross IMEP using partially premixed diesel fuel. They observed that the $\mathrm{NO}_{\mathrm{x}}$-soot compromise which is typical in Conventional Diesel Combustion (CDC) can be avoided in this partially premixed compression ignition (PPCI) combustion strategy, but at the cost of a decrease in combustion efficiency. By using high levels of EGR (e.g., 60\%), the $\mathrm{NO}_{\mathrm{x}}$ emission is near zero and the soot emission values decrease dramatically. However these high EGR levels resulted in combustion efficiency values below $90 \%$.

Manente et al. at Lund University [16, 17, 18] developed strategies for operating a heavy-duty diesel engine with gasoline by using two direct injections, high boost, and nearly 50\% EGR. At 18 bar gross IMEP, they achieved soot emissions values in the range of 1-2 filter smoke number (FSN), $\mathrm{NO}_{\mathrm{x}}$ below $0.3 \mathrm{~g} / \mathrm{kW}$-hr, gross indicated efficiency above $50 \%$ and maximum pressure rise rate values around $15 \mathrm{bar} / \mathrm{deg}$. They operated their engine over a wide load range (approximately 5-26 bar IMEP) with fuels that had approximately the same boiling point as gasoline. Gross indicated efficiency values for these fuels were above 50\%. A genetic algorithm optimization by Dempsey and Reitz [19] examined strategies for PPCI operation of a heavy-duty engine with gasoline at mid and high loads. Both load conditions showed low $\mathrm{NO}_{\mathrm{x}}$ emissions and gross indicated thermal efficiency values of 50\%. However, while low soot and PPRR were achieved at mid load, achieving low soot and PPRR was challenging at high load conditions. Although PPCI combustion strategies result in high thermal efficiency and low emissions values, maintaining low PPRR values is a big challenge, particularly at high load condition. In an effort for slowing the 
rate of heat release, Inagaki et al. [20] found that by changing the in-cylinder fuel blending of gasoline and diesel, ignition timing can be controlled. It was understood that an injection timing around $-30^{\circ}$ aTDC resulted in milder combustion rates than those showed by single fuel HCCI combustion strategies. It was concluded that there is a tradeoff with the injection timing where injections later than $-30^{\circ}$ aTDC result in unacceptably high $\mathrm{NO}_{\mathrm{x}}$ emissions while injections earlier than $-30^{\circ}$ aTDC result in very high pressure rise rates.

\subsubsection{RCCI Combustion}

Based on studies of Bessonette et al. [21] and Inagaki et al. [20], Kokjohn and Reitz et al. [22, 23, 24] a clean and highly efficient dual fuel combustion strategy in a heavy-duty single cylinder engine using gasoline and diesel fuels was developed. It was found that early diesel injection timings cause the high pressure rise rates to decrease dramatically, which allowed the development of a new in-cylinder fuel blending strategy called Reactivity Controlled Compression Ignition (RCCI) [25]. In this approach, gasoline is injected through the port fuel injection system, creating a homogeneous air-fuel charge during compression stroke. Next, fuel is injected through the direct injection system to introduce a stratification of reactivity zones within the cylinder. A dual-fuel RCCI concept improves other modes of LTC engines such as HCCI or PCCI by offering precise means for controlling the heat release rate and combustion phasing. In the RCCI strategy two fuels with different reactivity (auto-ignition characteristics) are blended inside the 
combustion chamber. Combustion phasing is controlled by the relative ratios of these two fuels and the combustion duration is controlled by spatial stratification between the two fuels [25]. RCCI results by Kokjohn and Reitz et al. [22, 23, 24] showed high thermal efficiency as well as very low $\mathrm{NO}_{\mathrm{x}}$ and soot emissions over a wide engine load range from 4 bar IMEP to 14.5 bar IMEP using gasoline and diesel fuels in the RCCI combustion strategy. By using EGR at the high load operating conditions, $\mathrm{NO}_{\mathrm{x}}$ emission and combustion noise values were kept as low as possible. However, extension to loads beyond 14.5 bar IMEP with gasoline/diesel has been shown to be difficult because of PPRR limitation and EGR rate requirements. The use of various other fuels and additives with different reactivity for use in the RCCI combustion strategy was explored in different studies [26, 27]. Computational studies by Adhikary et al. [26] showed that the use of 87-octane number gasoline surrogate fuel in a light-duty engine results in very low $\mathrm{NO}_{\mathrm{x}}$ emission values at full-load engine operating conditions. Experiments were conducted on a light-duty engine by Kaddatz et al. [27] using E10 (i.e., 10\% ethanol in gasoline)/E10+EHN (2-Ethylhexyl nitrate cetane improver). They [27] could achieve engine operation at 5.5 bar IMEP and 9 bar IMEP with very low $\mathrm{NO}_{\mathrm{x}}$ and soot emissions values, as well as gross thermal efficiencies near 50\%. This study [27] also showed the fuel-flexibility of the RCCI combustion strategy by achieving similar results with different fuels where low $\mathrm{NO}_{\mathrm{x}}$ and soot emissions as well as high thermal efficiencies were observed with either gasoline/diesel or gasoline/gasoline+cetane improver. These experiments also showed that RCCI operation is possible in practical applications where use of a single base fuel tank 
is desirable. By using gasoline/gasoline+EHN, a small separate tank will be needed for the cetane-improving additive. The additional tank will be significantly smaller than the gasoline tank (e.g., 3\% EHN was used in Kaddatz [27] study). Study by Splitter et al. [28] on a heavy duty engine showed that in RCCI combustion using combinations of ethanol (E85)/diesel and gasoline/gasoline+DTBP (Di-tert-butyl peroxide cetane improver) leads to high gross indicated thermal efficiency values (well over 50\%), clean and quiet combustion, $\mathrm{NO}_{\mathrm{x}}$ and soot emissions values well below US $2010 \mathrm{HD}$ regulations, and PPRR values between 5 and $10 \mathrm{bar} / \mathrm{deg}$ for all engine loads.

\subsection{Technical approach and scope of this thesis}

Understanding of RCCI combustion is necessary to optimize engine operation. To this end, simulation models play a key role to provide insight into RCCI combustion. Simulation models with different dimensions have been proposed for thermo-kinetic modeling of RCCI engine. A OD multi-zone model to predict RCCI combustion was developed by Eichmeier et. al [29]. This model could predict ignition and combustion of RCCI engine. In general, 1D engine cycle simulation tools such as $\mathrm{GT}^{\circledR}{ }^{\mathrm{P}}$ - POWER are valuable to facilitate the development process of RCCI combustion strategy. However, up until now there is no combustion model that is solely able to predict RCCI combustion [29] and therefore engine cycle simulation offers limited contribution to the development of optimum RCCI

combustion strategies. Studies carried out in $[30,31,32]$ used a 3D/CFD model for the 
RCCI cycle simulation. KIVA-3V code was used for the CFD part. The simulation results showed that around 52\% gross indicated efficiency could be achieved while meeting $\mathrm{NO}_{\mathrm{x}}$ emission regulations. In addition, the results showed that RCCI improves fuel consumption by around $4 \%$ in comparison to conventional diesel combustion. In an effort to improve accuracy of the RCCI models, in this thesis, a OD single zone model from CHEMKIN ${ }^{\circledR}$ - PRO is developed to predict SOC in the RCCI engine. Next, a detailed 3D/CFD combustion model is developed in CONVERGE ${ }^{\mathrm{TM}}$ and is coupled with $\mathrm{GT}^{\circledR}$ - POWER to simulate the closed part of the RCCI engine cycle. The simulation results of the CFD model are comparable with the experimental data as will be discussed in chapter 3.

Figure 1.2 shows studies carried out to investigate the effects of fuel injection parameters on combustion and performance of diesel, dual fuel and RCCI engines. To the best of author's knowledge there is no comprehensive study to investigate the impacts of injection pressure and spray angle on the combustion and performance of RCCI engines. This thesis intends to address them in details. The effects of SOI timings sweep on emissions and BMEP have been discussed in $[33,34]$. However a detailed study of the effects of SOI timings sweep on combustion and performance of RCCI engines is missing and will be presented in this thesis. 


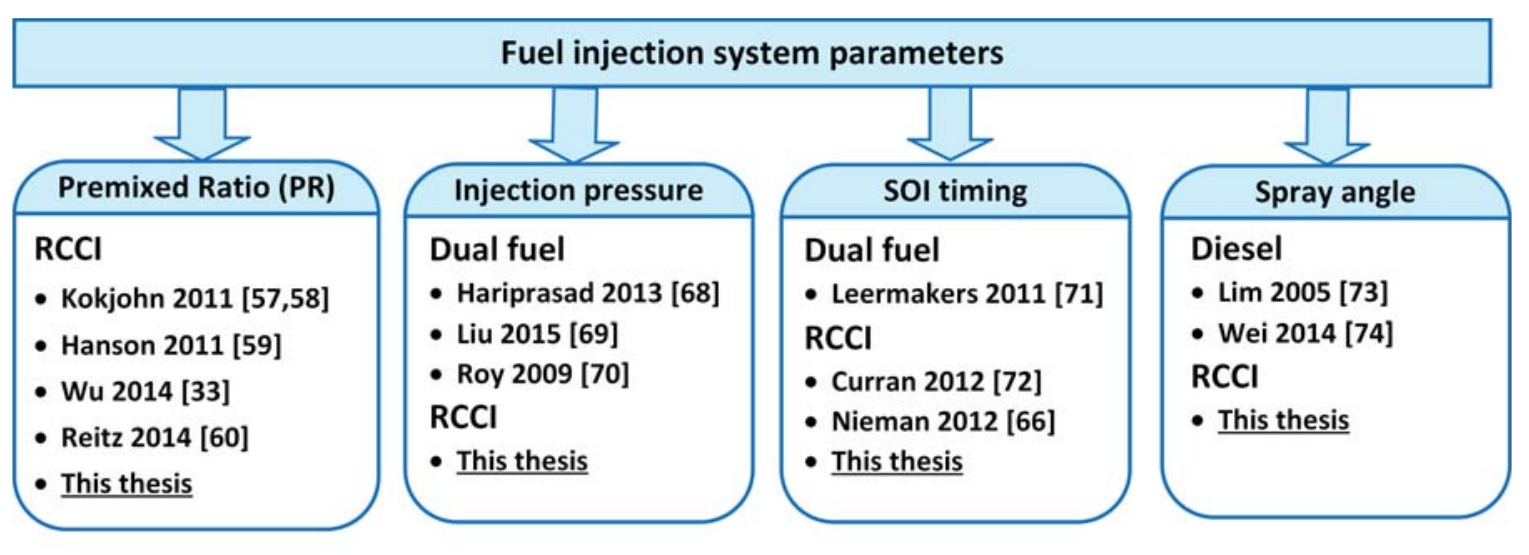

Figure 1.2: Background of main fuel injection system parameters in the literature

\subsection{Organization of thesis}

This thesis is organized in five chapters as shown in Figure 1.3. Chapter 2 includes development of a zero-dimensional model to predict SOC (i.e., CA10) in an RCCI engine. In Chapter 3, a 3D/CFD combustion model is developed and validated with RCCI experimental data. The effects of fuel injection system parameters on combustion and performance of the RCCI engine will be discussed in chapter 4. Finally, summary and conclusions along with recommendations for future work are presented in chapter 5. 


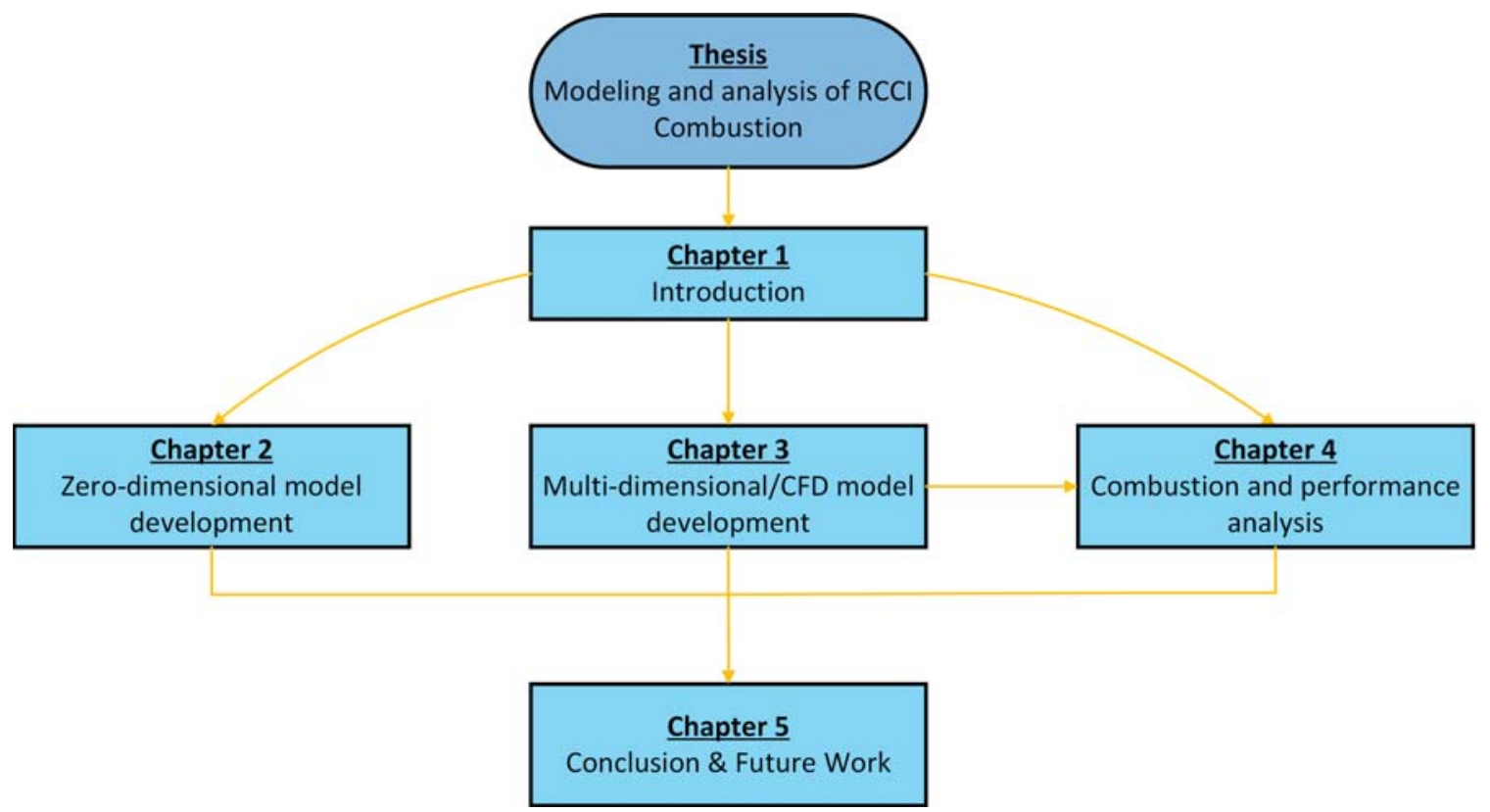

Figure 1.3: Thesis organization 


\section{Chapter 2}

\section{Zero-Dimensional Model Development}

In this chapter a zero-dimensional computationally efficient combustion model is developed for RCCI combustion. The model is capable of predicting Start of Combustion (SOC) accurately.

Figure 2.1 shows different thermo-kinetic combustion models that can be utilized for simulating the RCCI engine cycle. It is clear that using CFD combustion model with detailed chemical mechanism is highly expensive in terms of computational time while using Single Zone Model (SZM) with simplified chemical mechanism is the most computationally efficient approach for modeling and analysis of RCCI engine combustion. A multi-zone thermo-kinetic combustion model using simplified chemical mechanism was developed by Eichmeier et. al [29] to predict RCCI engine combustion. In extensive studies 
done by ERC $[30,31,32]$ a KIVA-3V CFD model with simplified chemical mechanism was developed to characterize the combustion and performance of RCCI engines. In this thesis, a single zone combustion model with detailed chemical mechanism (A) is developed to predict SOC in the RCCI engine. Using SZM with simplified chemical mechanism does not decrease computational time significantly however decreases the accuracy of the model. The difference in simulation time of SZM with simplified chemical mechanism and detailed chemical mechanism is less than 2 minutes in an Intel Core i5 processor with 4 GB RAM. Next, A 3D/CFD model with simplified chemical mechanism (B) is developed to understand combustion and performance characteristics of an RCCI engine.Using CFD model with detailed chemical mechanism increases computational time drastically which takes a couple of days for each simulation to run even with high computing cluster resources. 


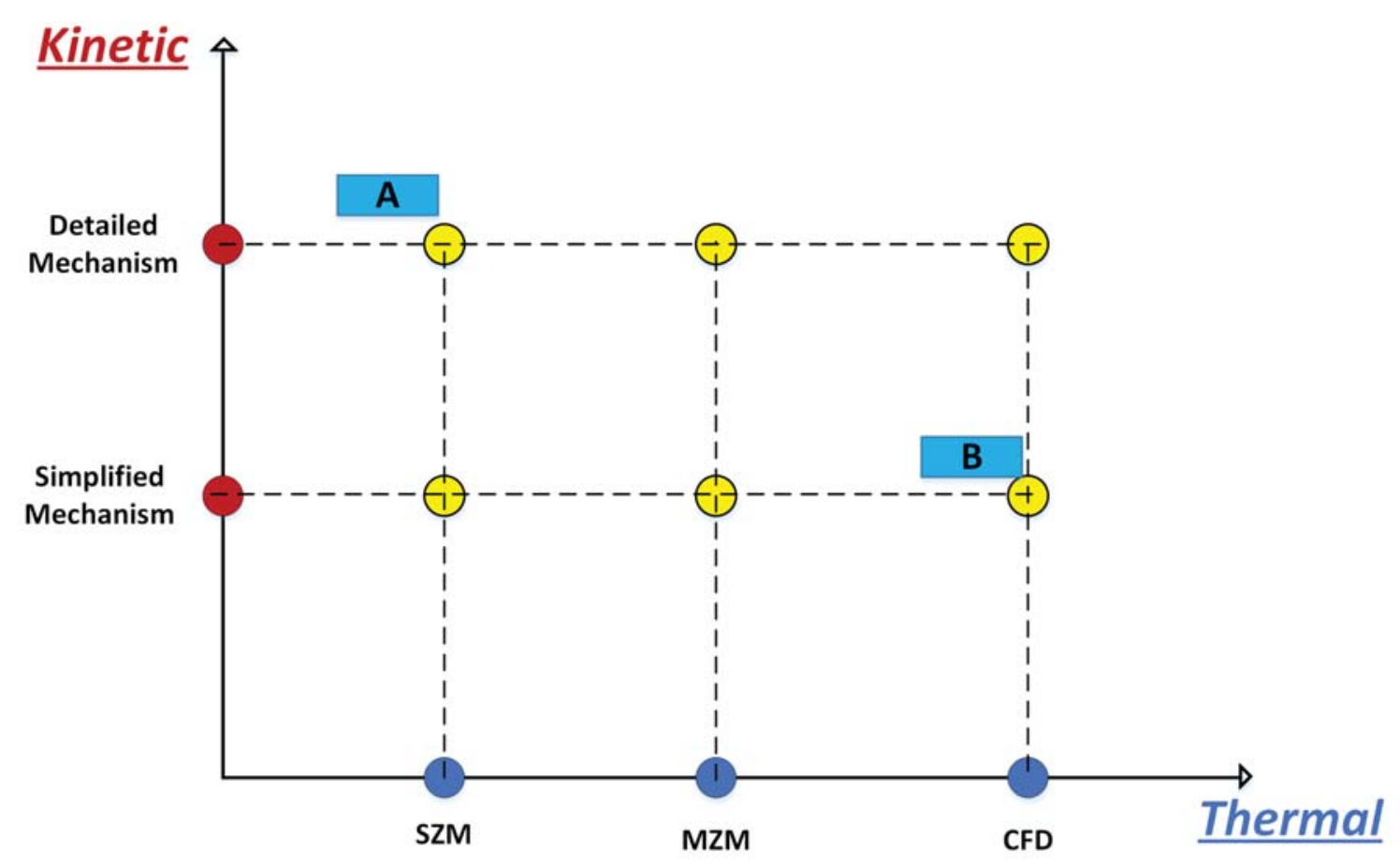

Figure 2.1: Varying scale thermo-kinetic combustion models for RCCI engines

\subsection{Engine Specifications}

In this thesis, an RCCI engine from [3] is simulated and validated against experimental data. The RCCI engine is based on a General Motors Z19DTH 1.9 liters 4-cylinder diesel engine. This engine meets Euro- 4 emission regulations and has been equipped to a common rail fuel injection system, cooled EGR, Variable Geometry Turbocharger (VGT) and variable swirl port design. PFI injectors were added to the intake manifold for RCCI operation [3]. The BOSCH ETAS electronic control unit (ECU) was replaced with an engine control 
module from DRIVVEN with the purpose of calibration and control of the engine. A low pressure EGR system was added to the engine to ensure greater flexibility and control of the air system [3]. Table 2.1 shows the specifications of the RCCI engine in this thesis.

Table 2.1

Specifications of GM Z19DTH Diesel Engine converted for RCCI operation [3].

\begin{tabular}{cc}
\hline \hline Parameter & Value \\
\hline \hline Bore & $82 \mathrm{~mm}$ \\
Stroke & $90.4 \mathrm{~mm}$ \\
Compression ratio & $17.5: 1$ \\
Displacement volume & $1.9 \mathrm{~L}$ \\
Cylinder Configuration & Inline $4 / 4$ valves per cylinder \\
IVC ( ${ }^{\circ}$ aTDC) & -132 \\
EVO ( ${ }^{\circ}$ aTDC) & 112 \\
Common Rail Injectors & Bosch CRIP2-MI \\
& $148^{\circ}$ spray included angle \\
& 480 bar fuel injection pressure \\
Port Fuel Injectors & Delphi \\
& $400 \mathrm{kPa}$ fuel pressure \\
\hline
\end{tabular}

\subsection{Model Description}

A zero-dimensioanl closed homogeneous reactor model from $\mathrm{CHEMKIN}^{\circledR}-\mathrm{PRO}$ is developed for predicting SOC. Experimental data from a 4 cylinder RCCI engine [3] is used to validate the model for different operating conditions. 


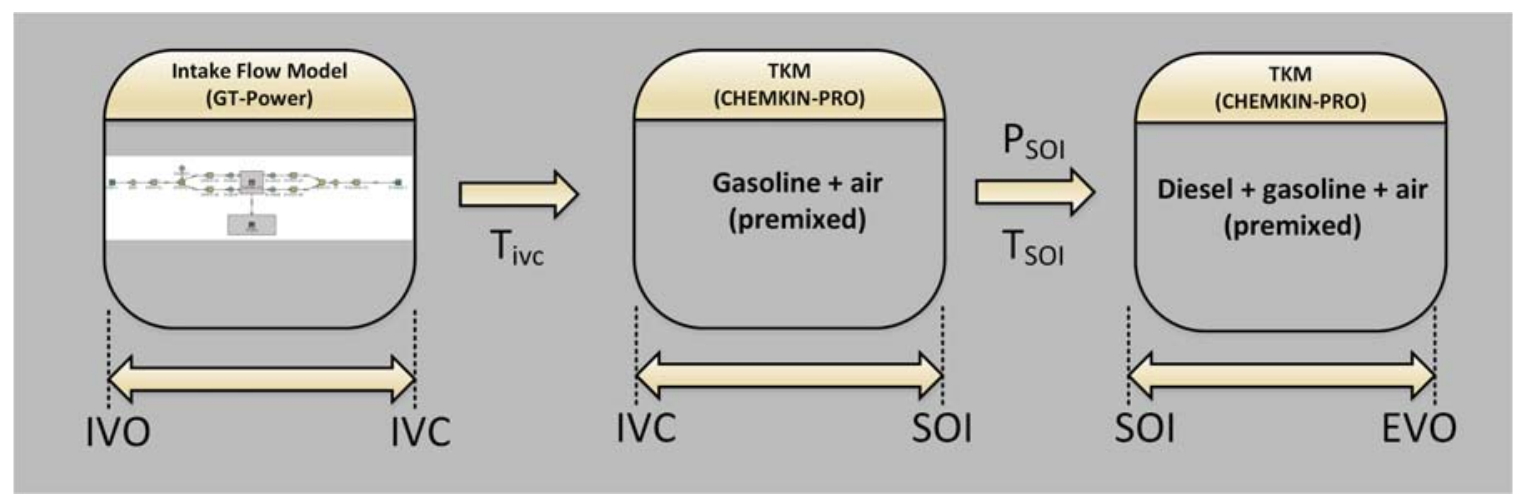

Figure 2.2: Three step simulation path to simulate RCCI cycle

As shown in Figure 2.2 a three-stage modeling approach is designed to simulate the closed cycle model from IVC up to EVO from single zone combustion model in CHEMKIN $^{\circledR}-$ PRO.

The RCCI engine model is developed in $\mathrm{GT}^{\circledR}-$ POWER to determine cylinder temperature at IVC. The IVC conditions are then fed into CHEMKIN ${ }^{\circledR}-$ PRO for single zone combustion modeling.

The combustion model uses a detailed chemical mechanism for iso-octane and n-heptane including 1034 species and 4236 reactions from Lawrence Livermore National Laboratory (LLNL) [35] as representatives for gasoline and diesel, respectively.

Heat transfer is modeled by using the Woschni heat transfer correlation [36] for IC engines. Convective heat loss $Q_{\text {wall }}$ from the in-cylinder gas mixture to the cylinder wall is 
determined by:

$$
Q_{\text {wall }}=h A\left(T-T_{\text {wall }}\right)
$$

where $T_{\text {wall }}$ is the wall temperature, $A$ is the wall surface area and $h$ is the convective heat transfer coefficient obtained based on the following equation [37]:

$$
N u_{h}=a R e^{b} \operatorname{Pr}^{c}
$$

where $N u, \quad R e$ and $\operatorname{Pr}$ are the Nusselt, Reynolds and Prandtl numbers. $a, b, c$ are constants. For the Woschni correlation $N u$ for heat transfer is defined by the following equation:

$$
N u_{h}=\frac{h D}{\lambda}
$$

where $D$ represents the cylinder bore diameter and $\lambda$ is the gas conductivity.

Reynolds number based on mean piston speed is defined by:

$$
R e=\frac{D w \rho}{\mu}
$$

where $\rho$ is the mixture density and $\mu$ is the dynamic viscosity of the fluid. The average gas 
velocity (w) is determined by [37]:

$$
w=\left[C_{11}+C_{12} \frac{v_{\text {swirl }}}{\overline{S_{p}}}\right] \overline{S_{p}}+C_{2} \frac{V_{d} T_{i}}{P_{i} V_{i}}\left(P-P_{\text {motored }}\right)
$$

In Equation (2.5), the terms $C_{11}, C_{12}$ and $C_{2}$ are modeling parameters. $v_{\text {swirl }}$ is the swirl velocity, $V_{d}$ is the displacement volume, $P_{\text {motored }}$ is the motored cylinder pressure and $T_{i}$, $P_{i}, V_{i}$ are the initial temperature, pressure and volume of the cylinder at IVC. $\overline{S_{p}}$ represents the mean piston speed which is calculated by the following equation:

$$
\overline{S_{p}}=2 L N
$$

where $L$ is the stroke and $N$ is the engine speed.

The motored cylinder pressure is the pressure associated with an isentropic compression, in which the pressure and volume ratios are related by a specific heat ratio $\gamma$.

$$
\frac{P_{\text {motored }}}{P_{\text {ref }}}=\left(\frac{V}{V_{\text {ref }}}\right)^{\gamma}
$$

where $P_{r e f}$ and $V_{r e f}$ are the reference pressure and volume.

Prandtl number is defined by the following equation:

$$
\operatorname{Pr}=\frac{C_{p} \mu}{\lambda}
$$


where $C_{p}$ is the constant pressure specific heat capacity.

Table 2.2 shows constants used in the single zone RCCI model in this thesis.

Table 2.2

Constants used in the Woschni correlation

\begin{tabular}{lr}
\hline \hline Constant & Value \\
\hline \hline HT coefficient a & 0.035 \\
HT coefficient b & 0.8 \\
HT coefficient c & 0 \\
Coefficient $C_{11}$ & 2.2 \\
Coefficient $C_{12}$ & 0 \\
Coefficient $C_{2}$ & 0.00324 \\
Prandtl number & 0.7 \\
\hline
\end{tabular}

In this RCCI model, the closed engine cycle from IVC to EVO is divided into two parts. The first part from IVC to SOI is modeled by considering the mixture of gasoline and air. In order to take into account diesel fuel when injected directly into the cylinder, diesel fuel is added to cylinder mixture composition starting from SOI and it is assumed that gasoline and diesel are well premixed at the SOI timing. The RCCI model is validated for three different engine operating conditions listed in Table 2.3. Experimental engine data is taken from [3]. AFR is defined by the following equation:

$$
A F R=\left(\frac{m_{\text {air }}}{m_{\text {fuel }}}\right)
$$

where $m_{f u e l}$ is the total amount of fuel including gasoline and diesel fuels. Low diesel injection pressure for three different cases in Table 2.3 is because of small required amount 
of diesel fuel and its too short injection duration. Injection pulse width is limited by minimum injector opening and closing time.

Table 2.3

Engine operating conditions of the experimental data used to validate the single-zone model at $1500 \mathrm{rpm}$.

\begin{tabular}{cccccccc}
\hline \hline $\begin{array}{c}\text { Case } \\
\#\end{array}$ & $\begin{array}{c}\text { BMEP } \\
(\text { bar })\end{array}$ & $\begin{array}{c}\text { EGR } \\
\text { Ratio } \\
(\%)\end{array}$ & $\begin{array}{c}\text { Diesel } \\
\text { SOI } \\
\left({ }^{\circ} \text { aTDC }\right)\end{array}$ & $\begin{array}{c}\text { Diesel } \\
\text { Injection } \\
\text { Pressure (bar) }\end{array}$ & $\begin{array}{c}\text { Diesel } \\
\text { Injected Mass } \\
(\text { mg/cycle })\end{array}$ & $\begin{array}{c}\text { Gasoline } \\
\text { Mass } \\
(\mathrm{mg} / \text { cycle })\end{array}$ & $\begin{array}{c}\text { AFR } \\
(\text { mass })\end{array}$ \\
\hline \hline $\mathrm{a}$ & 4 & 4.2 & -53 & 480 & 2.41 & 10.58 & 35 \\
$\mathrm{~b}$ & 2 & 50 & -43 & 410 & 3.35 & 4.67 & 27 \\
$\mathrm{c}$ & 1 & 52 & -39 & 380 & 3.26 & 2.44 & 36 \\
\hline
\end{tabular}

The surface temperatures including wall, piston and head are presented in Table 2.4.

Table 2.4

Surface temperatures selected for simulations in this thesis

\begin{tabular}{lr}
\hline \hline Parameter & Value \\
\hline \hline Wall temperature $(\mathrm{K})$ & 390 \\
Head temperature $(\mathrm{K})$ & 440 \\
Piston temperature $(\mathrm{K})$ & 440 \\
\hline
\end{tabular}

\subsection{Results and Discussion}

Table 2.5 shows experimental and simulated SOC (i.e., CA10) for three different operating conditions in Table 2.3. There is a good agreement between experiment data and results from the RCCI model for predicting SOC with an average error around $1 \mathrm{CAD}$. The simulation time for each engine cycle is around 2 minutes in an Intel Core i5 processor with 4 GB RAM. 


\section{Table 2.5}

Comparison between experimental (Exp.) and simulated (Sim.) SOC

\begin{tabular}{|c|c|c|}
\hline \multirow{2}{*}{ Case \# } & \multicolumn{2}{|c|}{$\begin{array}{c}\text { SOC }(\text { CA10) } \\
\left({ }^{\circ} \text { aTDC }_{\mathrm{f}}\right)\end{array}$} \\
\cline { 2 - 3 } & Exp. & Sim. \\
\hline a & 0.3 & 0.0 \\
\hline b & -3.8 & -2.1 \\
\hline c & -6.6 & -5.5 \\
\hline
\end{tabular}

This computationally efficient single zone model in CHEMKIN ${ }^{\circledR}-$ PRO can predict SOC (CA10) accurately. However due its premixed nature and considering the whole combustion chamber as one uniform zone without any crevices, the entire air-fuel mixture in the combustion chamber combusts simultaneously. Therefore this model overpredicts peak pressure and has a very short BD (i.e., CA90-CA10) [38, 39, 40]. This limits the accuracy of the model for predicting CA50 (Crank angle for 50\% burnt fuel) and also predicting performance metrics of the RCCI engine. To predict combustion and performance metrics of the RCCI engine a detailed combustion model needs to be developed. Chapter 3 presents a new multi-dimensional model for predicting combustion and performance of the RCCI engine. 


\section{Chapter 3}

\section{Multi-Dimensional/CFD Model}

\section{Development}

In this chapter, a new CFD model is developed to predict combustion and performance metrics of the RCCI engine. Important physical models for RCCI combustion are explained. and proper models are selected for the RCCI CFD model. Computations are performed using the commercially available CFD software called CONVERGE ${ }^{\mathrm{TM}}$.

\subsection{CFD Model Description}

Figure 3.1 shows the approach used to develop closed cycle model from IVC up to EVO. 


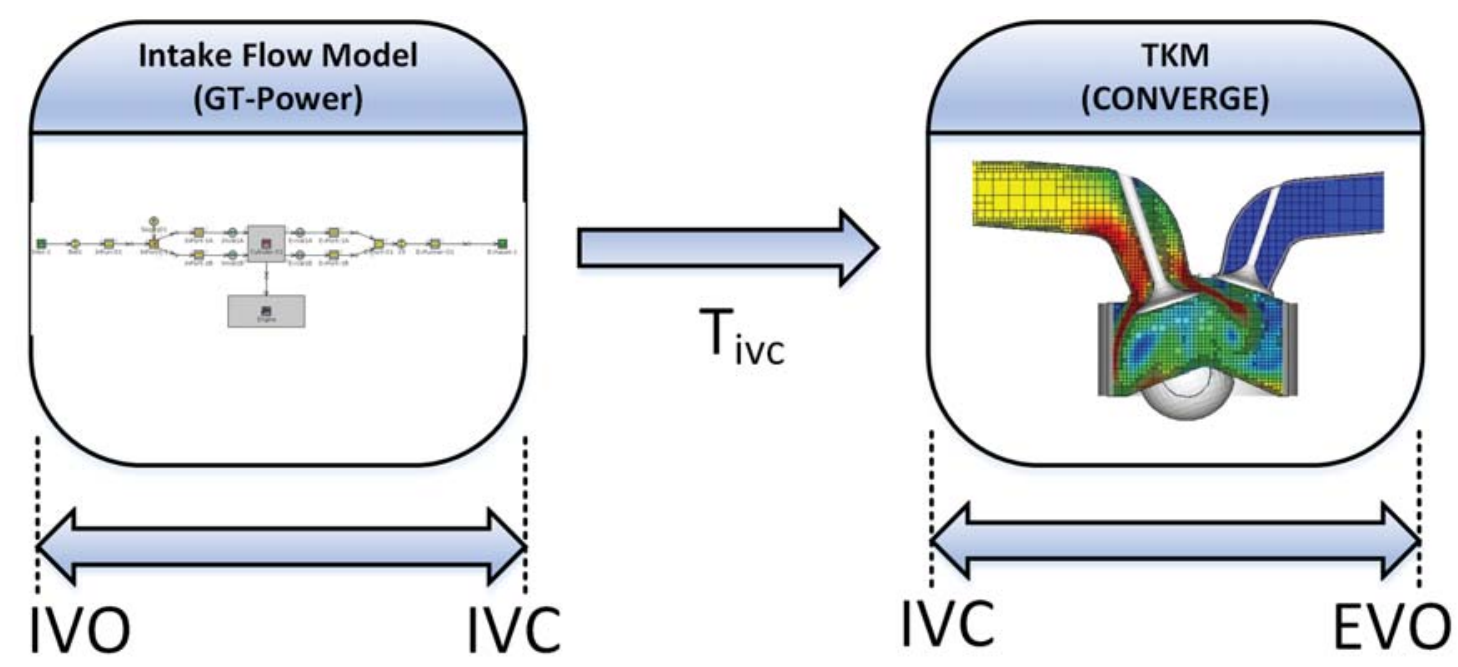

Figure 3.1: Two step simulation path in CFD platform

The first step from IVO to IVC is done in $\mathrm{GT}^{\circledR}$ - POWER to determine the IVC temperature [3]. The IVC conditions are then fed into CONVERGE for detailed combustion modeling for the closed part of the engine cycle from IVC to EVO. CONVERGE is a CFD program that removes the grid generation congestion from the simulation process. CONVERGE automatically generates a perfectly orthogonal, structured grid at runtime, based on simple, user-defined grid control parameters. This runtime grid generation method completely eliminates the need to manually generate a grid. CONVERGE has the capability to handle a large number of species and chemical reactions, as well as transient liquid sprays, and laminar or turbulent flows.

The engine specifications are the same as those in chapter 2 (see Table 2.1). Figure 3.2 shows the geometry used for CFD analysis as well as shape of the GM diesel engine piston. 
The 51.4 degree sector mesh, shown in Figure 3.2-a, is made up of 120,000 cells at IVC with a grid resolution of $1 \times 1 \times 1 \mathrm{~mm}$ at the start of simulation. The crevice volume is considered as a separate region in this analysis.

(a)

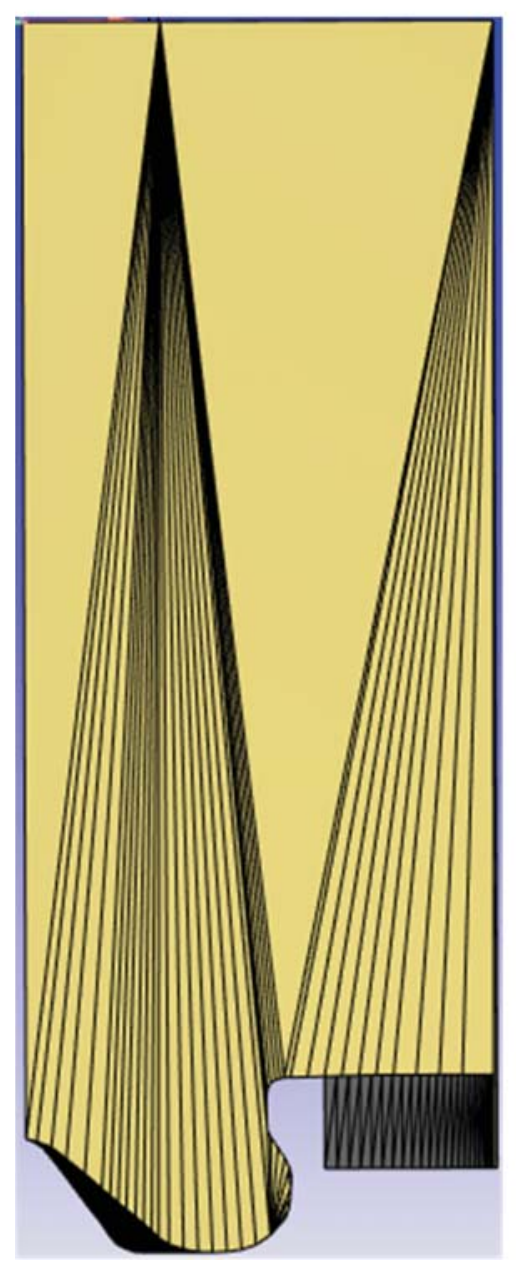

(b)

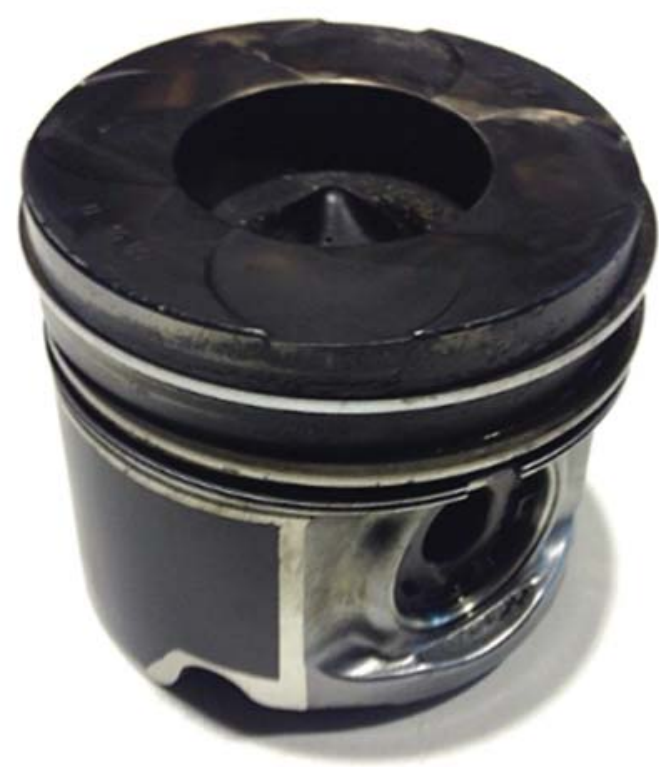

Figure 3.2: a) Geometry used for computational study b) piston shape for the GM diesel engine 


\subsubsection{Spray Model}

This subsection describes the physical models included in the CONVERGE code for spray modeling and phase discretization. To calculate the spray in a simulation, fuel droplet parcels have been introduced into the domain at the injector location at a specified rate shape. Figure 3.3 shows the rate shape of the diesel fuel injected into the cylinder. The injection duration is around 2.2 CAD for the case (a) in Table 2.3 with injection pressure of 480 bar.

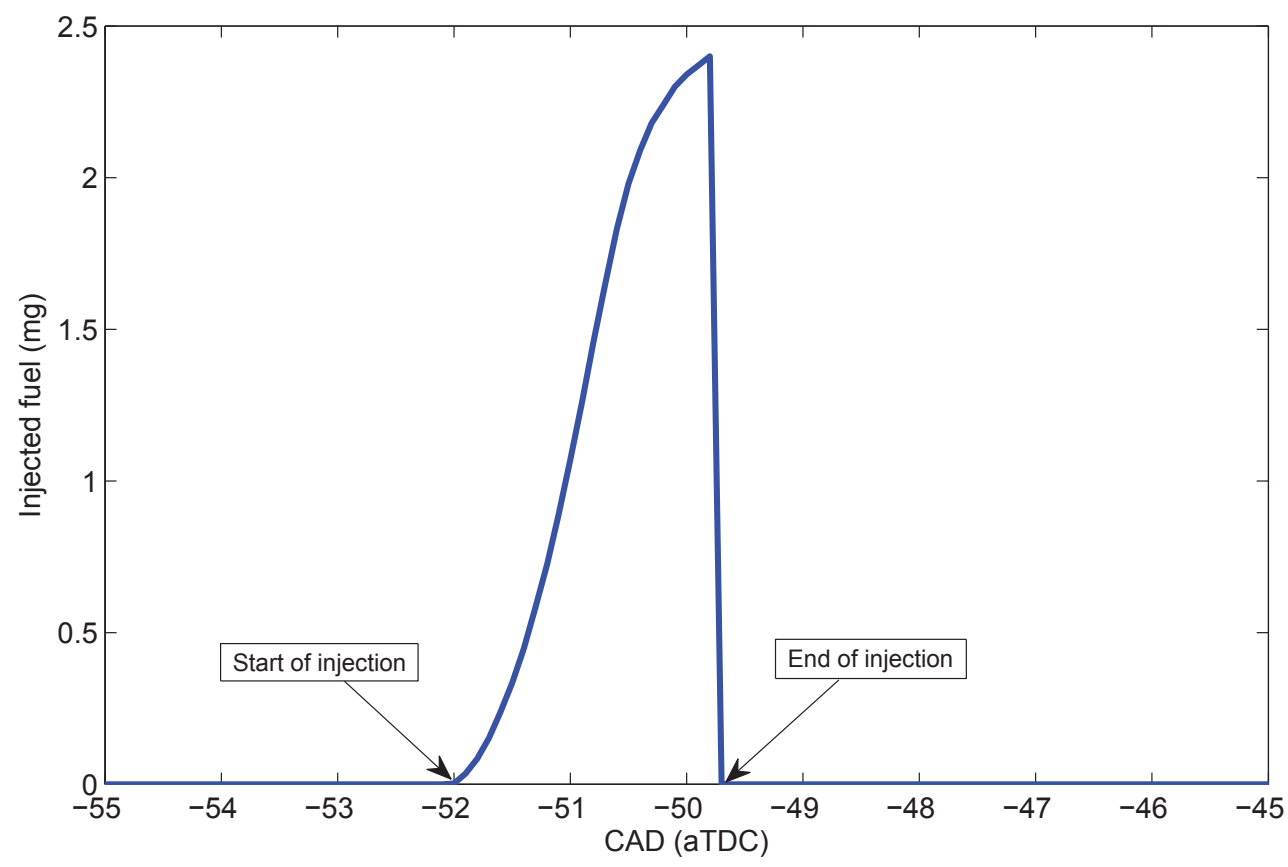

Figure 3.3: Injected fuel spray corresponding to $\underline{\text { case } a}$ in Table 2.3 with maximum injection pressure of 480 bar.

Parcels represent a group of identical fuel droplets with same radius, velocity and 
temperature. Parcels are used to represent the entire spray field. By using the concept of drop parcels, computational time of a simulation including spray considerably decreases. Spray droplets undergo several stages from the time of injection until the time of vaporization of fuel. Table 3.1 provides a summary of the main physical droplet processes that are used in the CFD RCCI simulations. It should be noted that some physical models have been chosen by recommendation of combustion experts from Convergent Science Inc. at CONVERGE workshop held at Madison during July 27-30, 2014.

Table 3.1

Summary of key spray processes used in the CONVERGE code

\begin{tabular}{ll}
\hline \hline Spray model physical process & Model \\
\hline \hline Liquid injection & Blob injection model \\
Spray breakup & Modified KH-RT models \\
Drop drag & Dynamic drag models \\
Collision model & NTC model \\
Collision outcomes model & Post collision outcomes \\
Drop turbulent dispersion & O'Rourke model \\
Drop/wall interaction & Wall film model \\
Evaporation model & Multi-component vaporization \\
\hline
\end{tabular}

In the Blob injection model [41] the diameter of an injected drop is set equal to its 
corresponding nozzle's hole size. The dynamic drag model determines the droplet drag coefficient dynamically, accounting for variations in the drop shape through a drop distortion parameter. The values of the drop distortion parameter are determined from the Taylor Analogy Breakup (TAB) model. The details of the TAB model is found in [42]. The atomization of the liquid blobs and subsequent droplets is simulated with models based on the Kelvin-Helmholtz (KH) and Rayleigh-Taylor (RT) instability mechanisms with the use of a breakup length [43]. This model is the combination of KH [41] and RT [44] that includes the effects of aerodynamics, cavitation, and turbulence on primary spray breakup.

The No Time Counter (NTC) method is used to consider drops collision [45]. An alternative to the O'Rourke numerical collision scheme [46] is the NTC method. The NTC method is based on techniques used in gas dynamics for Direct Simulation Monte Carlo (DSMC) calculations. This model has been shown to be faster and more accurate than O'Rourke's model under certain conditions. The NTC method involves stochastic (randomly determined) sub-sampling of the parcels within each cell. This potentially results in much faster collision calculations. Unlike O'Rourke's method, which requires an additional computational cost that increases with the square of the number of parcels, the NTC method has a linear cost. O'Rourke's method assumes that multiple collisions can occur between parcels and this process is governed by a Poisson distribution. However, the Poisson distribution is not correct unless collision has no consequences for the parcels. Since collisions change parcels' velocities, size, and number, the method of repeated sampling used by the NTC method generates more accurate answers [45]. Post collision 
outcomes is simulated by using Post and Abraham model [47]. In addition to the grazing collision and coalescence outcomes which are addressed in O'Rourke's model [46], stretching separation and reflexive separation are considered in Post collision outcomes model based on experimental results of hydrocarbon drops. O'Rourke's model [46] is utilized to simulate the droplet turbulent dispersion where the effects of the turbulent flow on spray drops are considered by adding a fluctuating velocity $u_{i}^{\prime}$ to the gas velocity $u_{i}$. A particle-based wall film [48] model is used for modeling the interaction of liquid droplets with solid surfaces. The model uses a hybrid approach for wall film modeling: some calculations are performed assuming individual particle-based quantities, while other calculations utilize film-based quantities. The film momentum equation is used to model liquid film transport. Film separation can occur if wall film particles flow over a sharp corner. The separation criterion is applied to determine if film separation takes place. The model is capable to determine when a drop splashes.

When the liquid spray is injected into the computational domain, a model is needed to convert the liquid into gaseous vapor. The time rate of change of droplet radius due to vaporization is calculated from the Frossling correlation [49]. In addition, the rate of heat conduction to the drop surface per unit area is given by the Ranz-Marshall correlation [50]. Parcels and liquid film may consist of many components. Multi-component vaporization model in CONVERGE handles multi-component vaporization where all of the multi-component liquid species will evaporate into the base species. 


\subsubsection{Combustion model}

This part explains about chemistry and combustion models that are applied in the RCCI engine simulations.

In order to include detailed chemistry in combustion applications, the SAGE model [51] is used in this study. This approach allows to use detailed chemical kinetics in combustion simulations. The SAGE model uses the CVODES solver (solves initial value problems for ordinary differential equation, ODE systems) package. The combustion of different fuels can be modeled by changing the mechanism (e.g., there are mechanisms for iso-octane, n-heptane, natural gas, etc.). The detailed chemistry solver, SAGE, calculates the reaction rates for each elementary reaction while the CFD solves the transport equations. SAGE combustion model can be used for modeling of different combustion regimes including ignition, premixed and mixing-controlled.

Different chemical mechanisms are available for the oxidation of Primary Reference Fuels (PRF), iso-octane and n-heptane, for gasoline and diesel, respectively. A detailed chemical mechanism for iso-octane and n-heptane including 1034 species and 4236 reactions from LLNL [35] has been developed. A reduced PRF mechanism based on the detailed LLNL PRF mechanism consisting of 45 species and 142 reactions has been developed by ERC for combustion CFD simulations [52]. In this study a reduced dual-fuel chemical mechanism 
for n-heptane and iso-octane including 43 species and 78 reversible reactions combining the mechanisms of Jia and Xie [53] for iso-octane and Patel [54] for n-heptane is used. To accelerate the solution of detailed chemical kinetics, the multi-zone approach from [55] is used to solve detailed chemistry (SAGE) in zones. In the multi-zone model, at each discrete time t, every cell in CONVERGE is at some thermodynamic state. Based on the thermodynamic state of the cells, the cells are grouped into zones. In a two-dimensional zoning strategy, the zoning is done based on two variables: the temperature and the equivalence ratio of the cells where cells with temperature and equivalence ratio differences less than $5 \mathrm{~K}$ and 0.05 are grouped in a same zone. For each zone, the average temperature and the composition are determined to specify the thermodynamic state of the mixture in that zone then the SAGE chemistry solver is used on each zone.

\subsubsection{Emission models}

Two sub models are used to simulate soot and $\mathrm{NO}_{\mathrm{x}}$ emissions. The production of soot mass $M_{S}$ within a computational cell can be determined from a single-step competition between

the soot mass formation rate $\dot{M}_{s f}$ and the soot mass oxidation rate $\dot{M}_{S o}$ so according to Hiroyasu and Kadota model [56]

$$
\frac{d M_{s}}{d t}=\dot{M}_{s f}-\dot{M}_{s o}
$$


where the formation rate is given by:

$$
\dot{M}_{s f}=S F M_{\text {form }}
$$

where $M_{\text {form }}$ is the mass of the soot formation (typically fuel vapor) in grams and

$$
S F=A_{s f} P^{0.5} \exp \left(\frac{-E_{s f}}{R_{u} T}\right)
$$

where $P$ is the cell pressure in bar, $R_{u}$ is the universal gas constant in cal/(K.gmol), T is the cell temperature, $E_{s f}$ is the activation energy, and $A_{s f}$ is the Arrhenius pre-exponential factor.

The extended Zel'dovich mechanism as described by Heywood [37] is used to predict $\mathrm{NO}_{\mathrm{x}}$ formation. This mechanism is given by the following set of reactions:

$$
\begin{aligned}
& \mathrm{O}+\mathrm{N}_{2} \rightleftharpoons \mathrm{NO}+\mathrm{N} \\
& \mathrm{N}+\mathrm{O}_{2} \rightleftharpoons \mathrm{NO}+\mathrm{O} \\
& \mathrm{N}+\mathrm{OH} \rightleftharpoons \mathrm{NO}+\mathrm{H}
\end{aligned}
$$




\subsubsection{Turbulence Model}

In this study the Reynolds-Averaged Navier-Stokes (RANS) based Re-Normalization Group (RNG) k- $\varepsilon$ model [57] is used to simulate turbulence in flow field in the combustion chamber. This turbulence model is computationally efficient than the other available turbulence models such as Large Eddy Simulation (LES) and Direct Numerical Simulation (DNS). In the RANS models the flow variables (e.g., velocity) are decomposed into an ensemble mean and a fluctuating term as follows:

$$
u_{i}=\overline{u_{i}}+u_{i}^{\prime}
$$

where $u_{i}$ is the instantaneous velocity, $\overline{u_{i}}$ is the ensemble velocity and $u_{i}^{\prime}$ is the fluctuating velocity. The turbulence intensity is obtained from the turbulent kinetic energy by the following equation [57]:

$$
K=\frac{3}{2} u_{i}^{2} I^{2}
$$

where $k$ is the turbulent kinetic energy and $I$ is the turbulence intensity. The turbulence intensity is usually set to a value between 0.01 and 0.10 . The turbulent dissipation is given 
by the following equation [57]:

$$
\varepsilon=\frac{c_{\mu}^{3 / 4} k^{3 / 2}}{l e}
$$

where $c_{\mu}$ is a model constant (in simulations, 0.0845), $k$ is the turbulent kinetic energy, and $l e$ is the turbulent length scale. The turbulent dissipation for wall boundary condition is given as follows:

$$
\varepsilon=\frac{c_{\mu}^{3 / 4} k^{3 / 2}}{\kappa y}
$$

where $\varepsilon$ is the turbulent dissipation in the center of the near wall cell (not at the wall surface), $\mathrm{y}$ is the distance from the wall to the middle of the cell, $c_{\mu}$ is a turbulence model constant, and $\kappa$ is Karmen's constant. In simulations Karmen's constant, turbulent kinetic energy and turbulent dissipation are selected $0.42,62 \mathrm{~m}^{2} / \mathrm{s}^{2}$ and $17183 \mathrm{~m}^{2} / \mathrm{s}^{3}$, respectively. These values were recommended at CONVERGE workshop for RCCI combustion simulations.

Conjugate heat transfer model is applied to solve the flow and heat transfer in both the solid and fluid regions. CFD calculations for both the solid and fluid phases are performed simultaneously in a conjugate heat transfer (CHT) simulation. In this study, O'Rourke and Amsden conjugate heat transfer model [58] is applied to consider heat loss through the cylinder wall as well as heat transfer between cells. This model is useful to capture fast 
transient heat flux between the combustion chamber and the solid wall.

\subsection{Model Validation}

After developing the CFD model in CONVERGE it is critical to validate the model against RCCI experimental data. Experimnetal data from [3] for the GM 1.9-liters RCCI engine (Table 2.1) is used to evaluate the CFD model's accuracy in predicting combustion phasing and emission.

This section presents the results for in-cylinder pressure, heat release rate, crank angle for 10 percent mass of fuel burned (CA10), crank angle for 50 percent mass of fuel burned (CA50), crank angle for 90 percent mass of fuel burned (CA90), BD (i.e, CA90-CA10) and emissions (i.e., $\mathrm{HC}, \mathrm{CO}$ and $\mathrm{NO}_{\mathrm{x}}$ ). The simulation results are compared with experimental data for the RCCI operating conditions previously listed in Table 2.3. Validations for in-cylinder pressure and heat release rate for three different cases are shown in Figures 3.4

to 3.9. Quantitative metrics for combustion phasing and emissions are presented in Tables 3.2 and 3.3. 


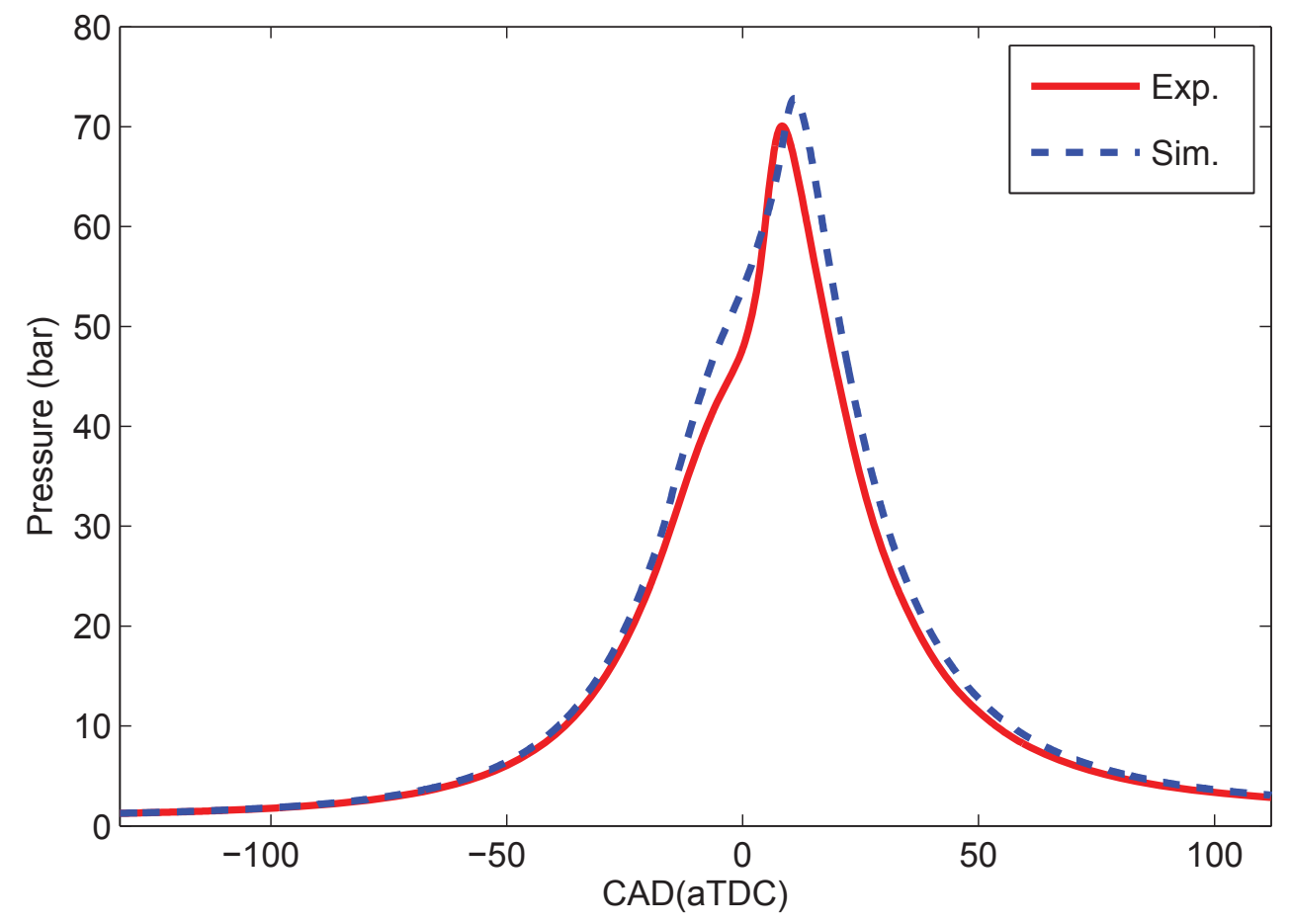

Figure 3.4: Pressure trace validation for the engine operating condition corresponding to case $a$ in Table 2.3

Validation results for in-cylinder pressure and heat release rate in Figures 3.4 and 3.5 for case (a) show that the RCCI model is capable of predicting the first phase of combustion, low temperature heat release (diesel auto-ignition) accurately. However predicted CA50 is delayed compared to the experimental CA50 due to slow combustion rate in simulation. The possible reason for this delay is using simplified chemical mechanism for gasoline and diesel which is not capable of predicting gasoline combustion precisely. 


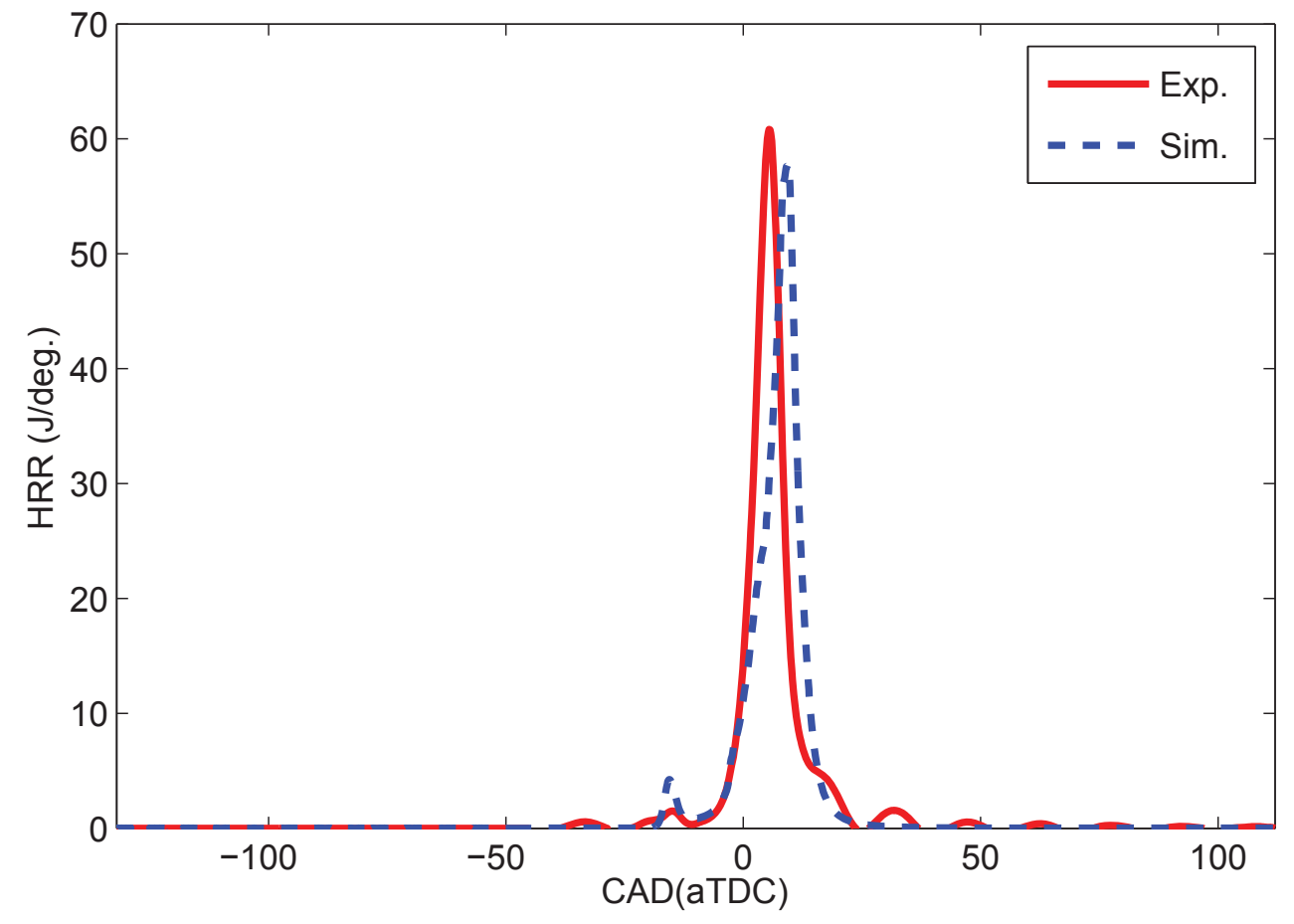

Figure 3.5: Heat Release Rate (HRR) validation for the engine operating condition corresponding to case a in Table 2.3

The $\mathrm{HC}$ and $\mathrm{CO}$ emissions are in good agreement with the experimental values. However as seen in Table 3.3 there is a considerable difference in predicting $\mathrm{NO}_{\mathrm{x}}$ emission. This is because the extended Zel'dovich mechanism [37] that is utilized for predicting $\mathrm{NO}_{\mathrm{x}}$ formation, is not able to estimate $\mathrm{NO}_{\mathrm{x}}$ formation at low temperature combustion regime. This model is mainly useful for predicting $\mathrm{NO}_{\mathrm{x}}$ for diesel engines with high combustion temperatures (typically more than $1800 \mathrm{~K}$ ) [59]. $\mathrm{NO}_{\mathrm{x}}$ emission predictions can be improved by using more accurate $\mathrm{NO}_{\mathrm{x}}$ models [31]. 


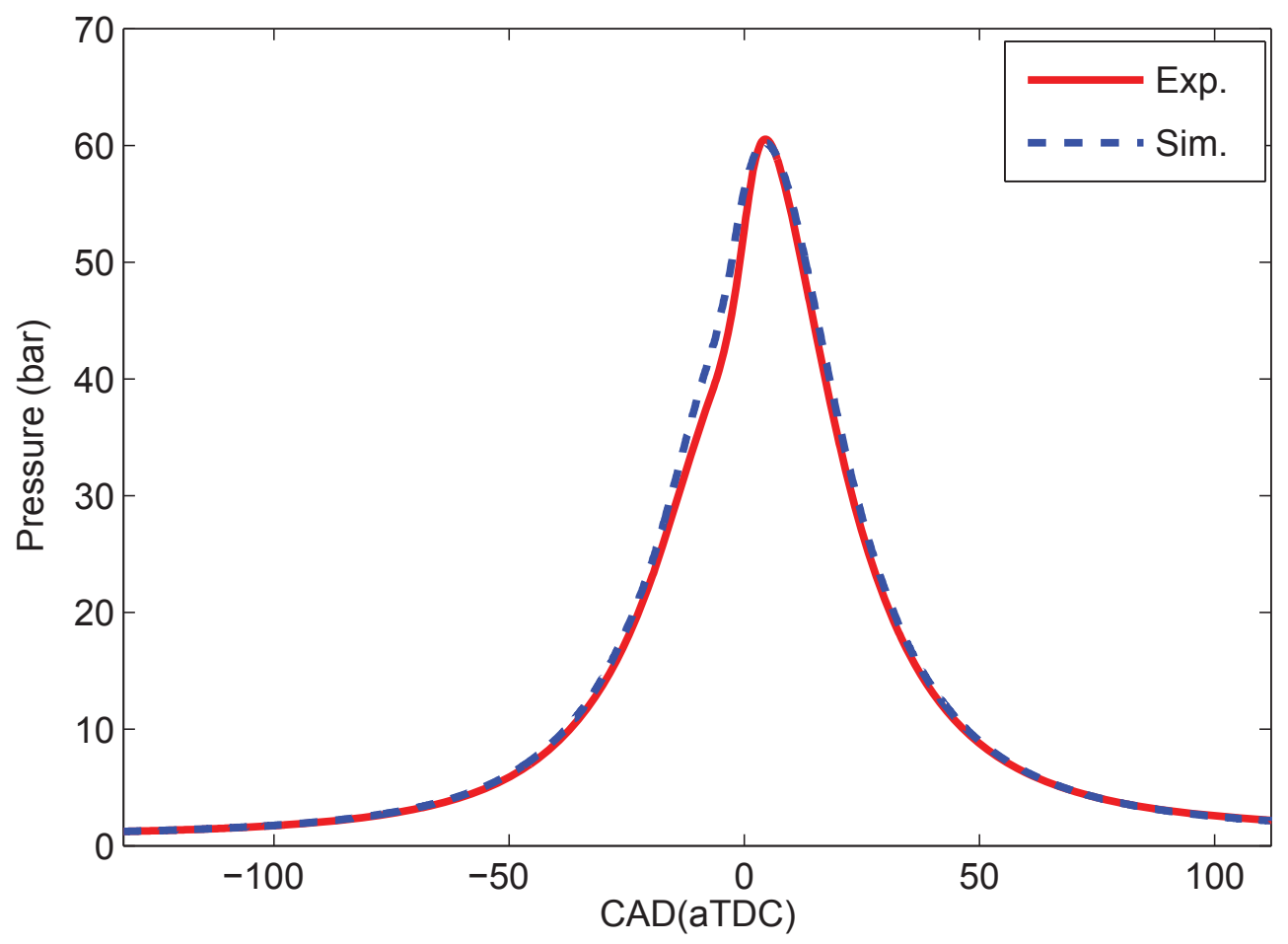

Figure 3.6: Pressure trace validation for the engine operating condition corresponding to case $b$ in Table 2.3

Validation results for case (b) show that the simulated and experimental in-cylinder pressure are in good agreement with average error less than $2 \mathrm{CAD}$ for combustion phasing. However the peak HRR in simulation is lower than peak HRR in the experiment. The same situation exists for case (c). These differences in peak HRR will be justified by showing that the values of $\mathrm{HC}$ and $\mathrm{CO}$ in Table 3.3 for cases (b) and (c) are significantly greater than the experimental values. Therefore it is expected to have lower peak HRR in simulations. The greater values of $\mathrm{HC}$ and $\mathrm{CO}$ in simulations in comparison to experiments for cases (b) and (c) is because of wall impingement of diesel fuel which consists of 42 and 
$57 \%$ of total amount of fuel for cases (b) and (c), respectively. Discrepancy between model and experiment can be reduced by using techniques of spray visualization and developing accurate spray model for the DI fuel injectors in this study. Soot validation is not included in Table 3.3 since experimental data was not available for soot emission.

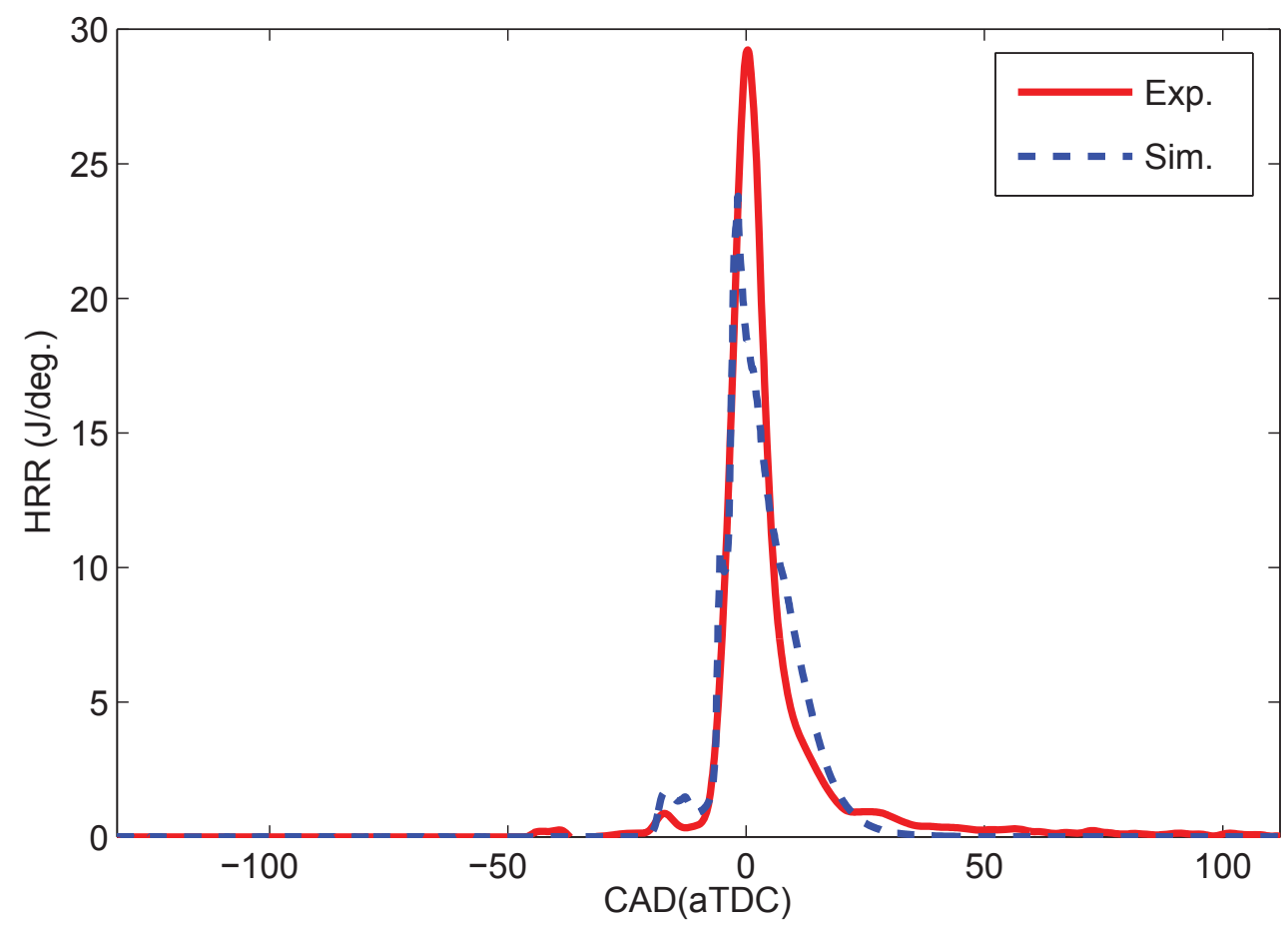

Figure 3.7: Heat Release Rate (HRR) validation for the engine operating condition corresponding to $\underline{\text { case } b}$ in Table 2.3

There is an average error of around 4 CAD for predicting CA90 for the three cases in Table 2.3. Therefore an uncertainty in the applied heat transfer model causes discrepancy between the model and the experiment particularly for the case (c). A new heat transfer model can be developed for RCCI combustion; thus, more accurate prediction of CA90 and $\mathrm{BD}$ can be achieved. 


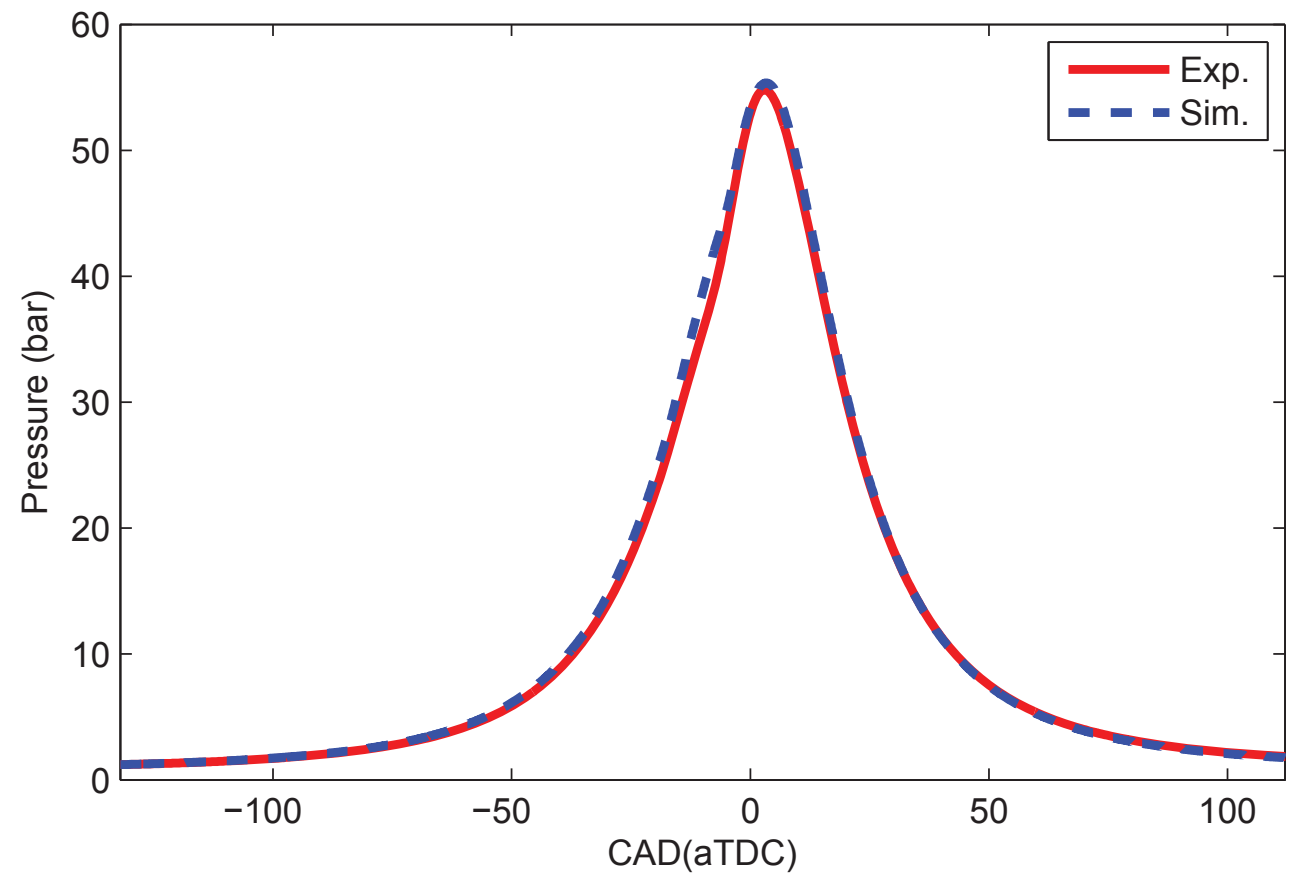

Figure 3.8: Pressure trace validation for the engine operating condition corresponding to $\underline{\text { case } c}$ in Table 2.3

Table 3.2

Comparison between experimental (Exp.) and simulated (Sim.) combustion phasing (CA10, CA50, CA90, BD)

\begin{tabular}{|c|c|c|c|c|c|c|c|c|}
\hline \multirow{2}{*}{ Case \# } & \multicolumn{2}{|c|}{$\begin{array}{c}\text { CA10 } \\
\left({ }^{\circ} \mathrm{aTDC}_{\mathrm{f}}\right)\end{array}$} & \multicolumn{2}{|c|}{$\begin{array}{c}\text { CA50 } \\
\left({ }^{\circ} \mathrm{aTDC}_{\mathrm{f}}\right)\end{array}$} & \multicolumn{2}{|c|}{$\begin{array}{c}\text { CA90 } \\
\left({ }^{\circ} \mathrm{aTDC}_{\mathrm{f}}\right)\end{array}$} & \multicolumn{2}{|c|}{$\begin{array}{c}\mathrm{BD} \\
(\mathrm{CAD})\end{array}$} \\
\hline & Exp. & Sim. & Exp. & Sim. & Exp. & Sim. & Exp. & Sim \\
\hline $\mathrm{a}$ & 0.3 & 0.0 & 5.8 & 7.8 & 12.3 & 12.5 & 12.0 & 12.5 \\
\hline b & -3.8 & -5.0 & 1.5 & 1.6 & 16.3 & 13.0 & 20.1 & 18.0 \\
\hline $\mathrm{c}$ & -6.5 & -5.9 & -0.3 & 0.2 & 17.1 & 9.0 & 23.6 & 14.9 \\
\hline
\end{tabular}




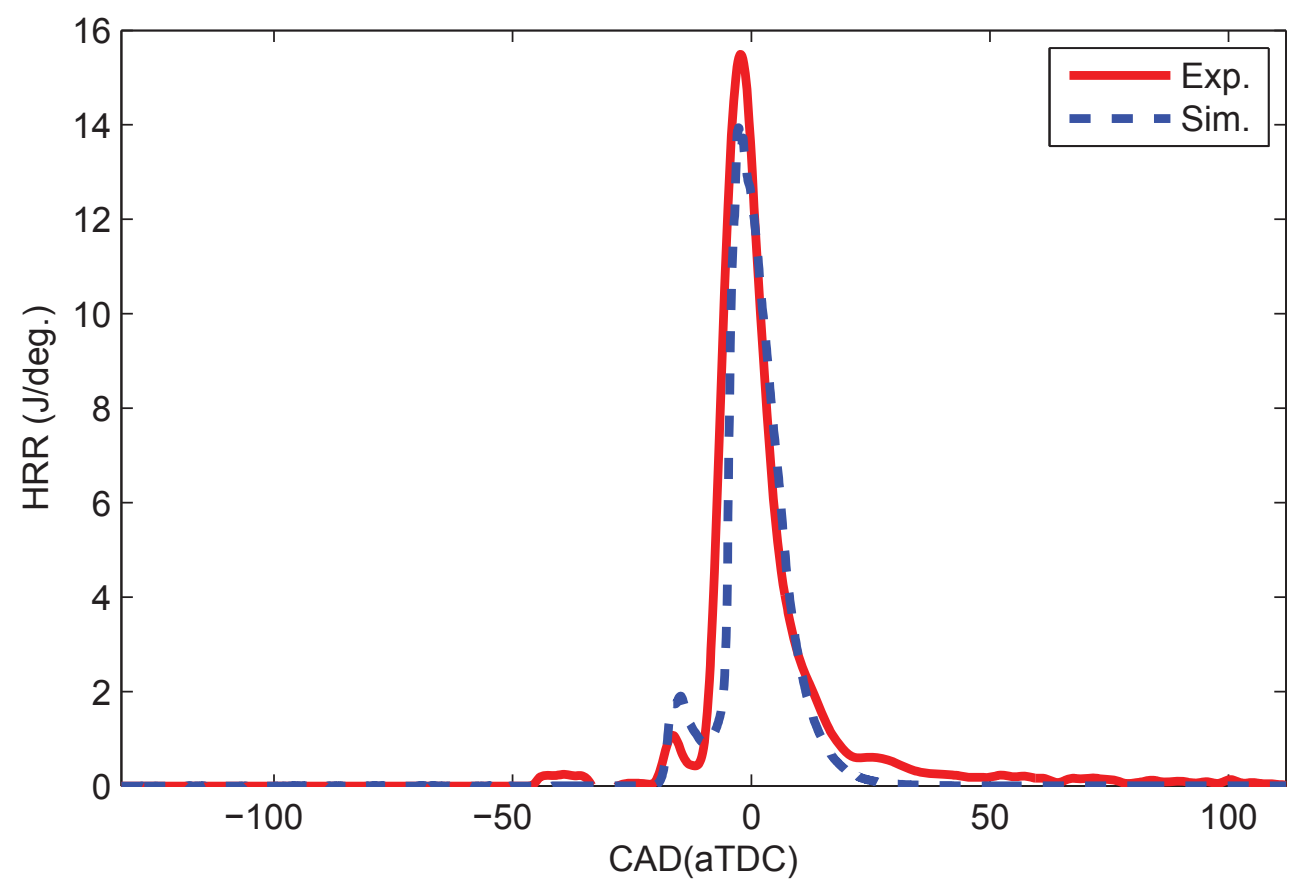

Figure 3.9: Heat Release Rate (HRR) validation for the engine operating condition corresponding to $\underline{\text { case } c}$ in Table 2.3

Table 3.3

Comparison between experimental (Exp.) and simulated (Sim.) engine-out emissions $\left(\mathrm{NO}_{\mathrm{x}}, \mathrm{HC}, \mathrm{CO}\right)$

\begin{tabular}{|c|c|c|c|c|c|c|}
\hline \multirow{2}{*}{ Case \# } & \multicolumn{2}{|c|}{$\mathrm{NO}_{\mathrm{x}}$} & \multicolumn{2}{c|}{$\mathrm{HC}$} & \multicolumn{2}{c|}{$\mathrm{CO}$} \\
\cline { 2 - 7 }$(\mathrm{g} / \mathrm{kg}$-fuel $)$ & \multicolumn{2}{c|}{$(\mathrm{g} / \mathrm{kg}$-fuel $)$} & \multicolumn{2}{c|}{ (g/kg-fuel) } \\
\hline & Exp. & Sim. & Exp. & Sim. & Exp. & Sim. \\
\hline $\mathrm{a}$ & 0.61 & 0.04 & 63.74 & 53.86 & 64.59 & 41.84 \\
\hline $\mathrm{b}$ & 0.34 & 0.20 & 48.31 & 116.30 & 105.94 & 244.20 \\
\hline $\mathrm{c}$ & 0.43 & 0.06 & 65.05 & 159.06 & 262.26 & 395.61 \\
\hline
\end{tabular}





\section{Chapter 4}

\section{Combustion and Performance Analysis-}

\section{Effects of Fuel Injection Parameters}

In this chapter the effects of fuel injection parameters including Premixed Ratio (PR), injection pressure, SOI timing and spray angle on combustion and performance of the RCCI engine are discussed. Case (a) in Table 2.3 is considered as a base point for further parametric study. The specifications of the light-duty diesel engine is the same as those in chapters 2 and 3. 


\subsection{Premixed Ratio (PR)}

In this section the effects of PR on RCCI engine combustion and performance parameters are discussed. PR is the ratio of gasoline fuel to the total amount of fuel combining gasoline and diesel fuels. In this study, gasoline serves as a low reactive fuel injected through the PFI system and diesel serves as a high reactive fuel injected through the DI system.

$$
\mathrm{PR}=\frac{\mathrm{m}_{\text {gasoline }}}{\mathrm{m}_{\text {gasoline }}+\mathrm{m}_{\text {diesel }}}
$$

Figures 4.1 and 4.2 show the cylinder pressure and heat release rates by changing the PR. It can be seen that, by increasing PR, peak cylinder pressure and heat release rate decrease and combustion phasing is retarded. This is because by increasing gasoline fuel, reactivity of the mixture decreases. On the other hand diesel fuel serves as a high reactive fuel which is the source of auto-ignition. Diesel injection is responsible for initiation of combustion and therefore causes gasoline fuel to burn $[60,61]$. As a result, by increasing PR (i.e., decreasing diesel fuel portion), the mixture ignites with more difficulty in comparison to case with more diesel fuel [62]. In the case with less diesel fuel it is expected less amount of gasoline fuel burns. Since number of auto-ignition points will be less than the case with more diesel fuel. That is why peak heat release rate decreases by increasing PR. Combustion phasing is easily controlled by changing the premixed gasoline percentage. Figure 4.2 also shows increasing gasoline fuel does not change the location and amount of 
peak Low Temperature Heat Release (LTHR) significantly.

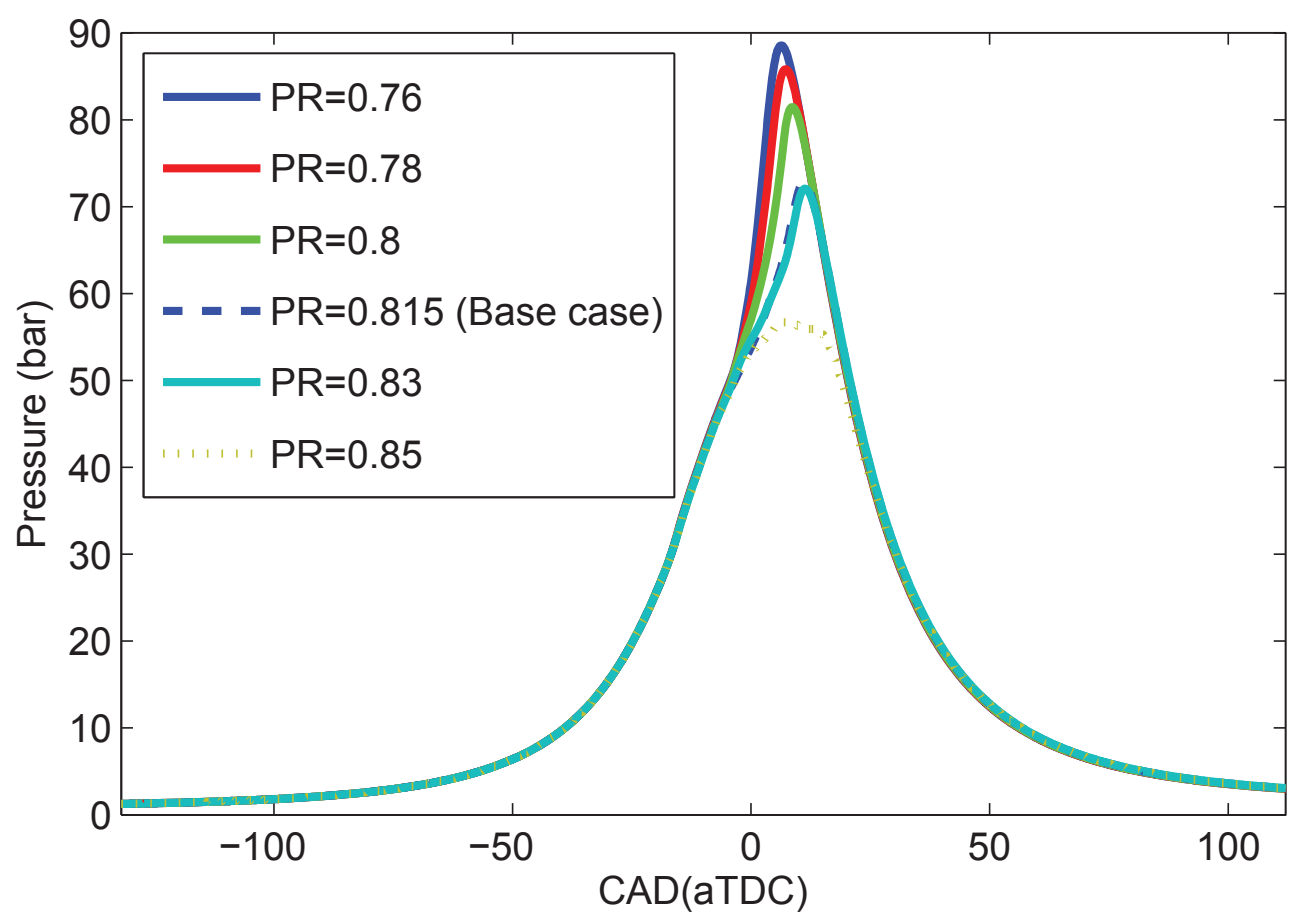

Figure 4.1: Effects of Premixed Ratio (PR) on in-cylinder pressure for engine operating condition corresponding to case a in Table 2.3 


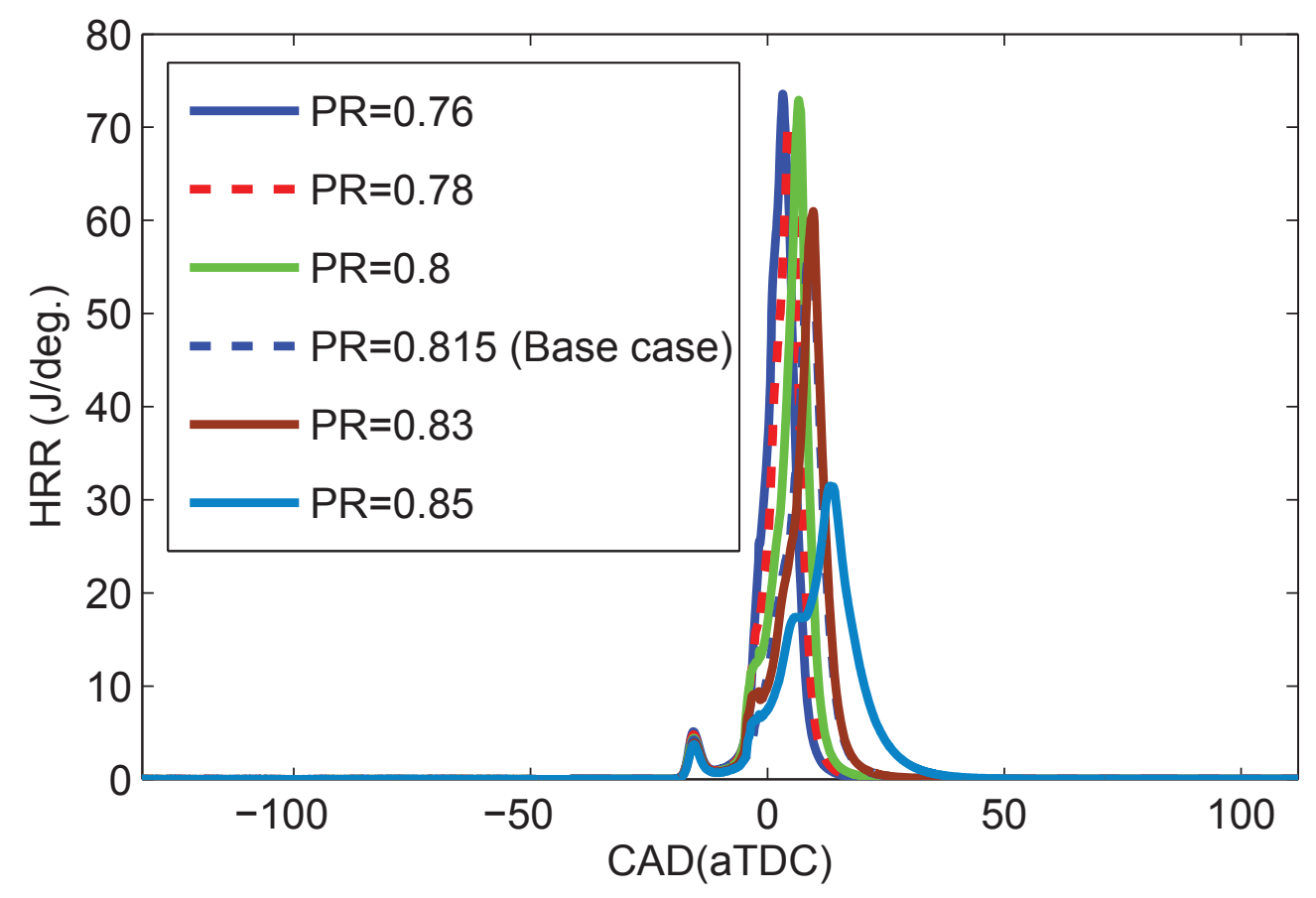

Figure 4.2: Effects of Premixed Ratio (PR) on Heat Release Rate (HRR) for engine operating condition corresponding to $\underline{\text { case } a}$ in Table 2.3

As shown in Figure 4.3, increasing PR from 0.76 to 0.85 results in retarding CA10, CA50 and CA90 with more than 2, 5 and $10 \mathrm{CAD}$, respectively. In addition, BD is prolonged more than $10 \mathrm{CAD}$. It is seen that dependence of CA10 on amount of gasoline fuel is less than CA50 and CA90. This is because diesel fuel as a high reactive fuel will control the initiation of combustion therefore it is expected that changing gasoline fuel does not affect CA10 considerably.

The dependence of combustion phasing on the PR has several implications for the practical application of the RCCI combustion concept. First, an engine operating in the RCCI 
combustion mode must have accurate control over the fuel quantity delivered from each of the two fuel injection systems. Second, RCCI combustion process benefits from the existence of direct diesel fuel injection which is the control knob of the combustion phasing that is lost with traditional HCCI or early injection PCCI combustion [60].

(a)

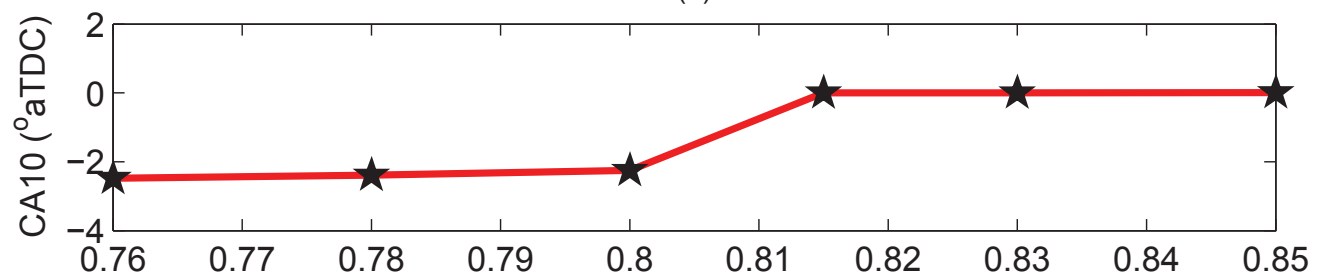

(b)

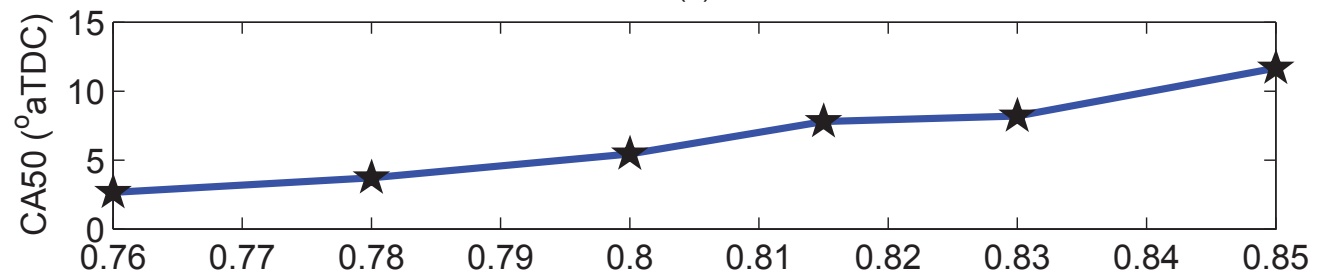

(c)

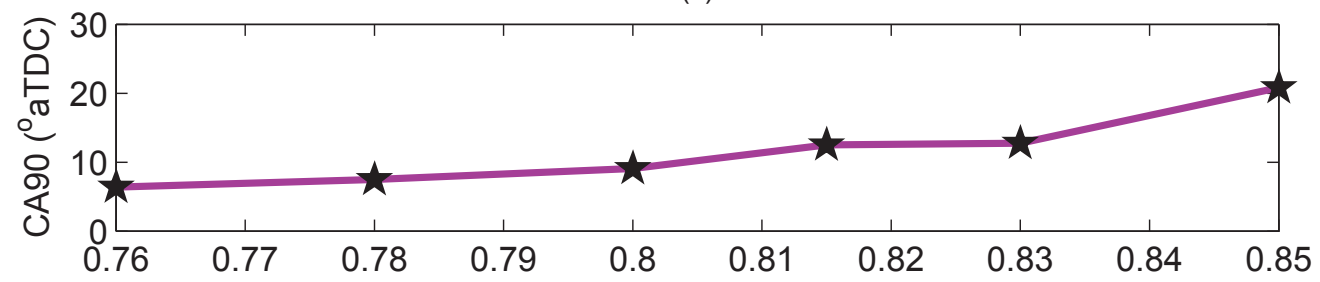

(d)

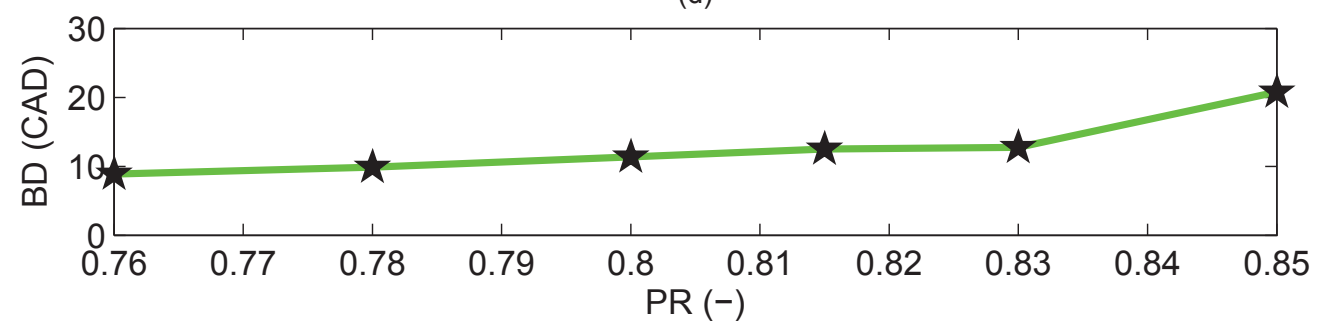

Figure 4.3: Effects of Premixed Ratio (PR) on combustion phasing (CA10, CA50, CA90, BD) for engine operating condition corresponding to case a in Table 2.3 
Figure 4.4 shows emissions results for different gasoline mass percentage. The general trend shows that increasing gasoline fuel percentage causes $\mathrm{HC}, \mathrm{CO}$ and soot to increase. However $\mathrm{NO}_{\mathrm{x}}$ decreases. This is due to decrease in cylinder temperature by increasing gasoline fuel percentage as seen in Figure 4.5. Increasing PR causes peak pressure to decrease and combustion phasing to retard therefore cylinder temperature decreases [63]. Due to running lean mixture and having maximum in-cylinder gas temperature below 1800 $\mathrm{K}$ for all cases with different gasoline mass percentage, $\mathrm{NO}_{\mathrm{x}}$ and soot are out of concern.
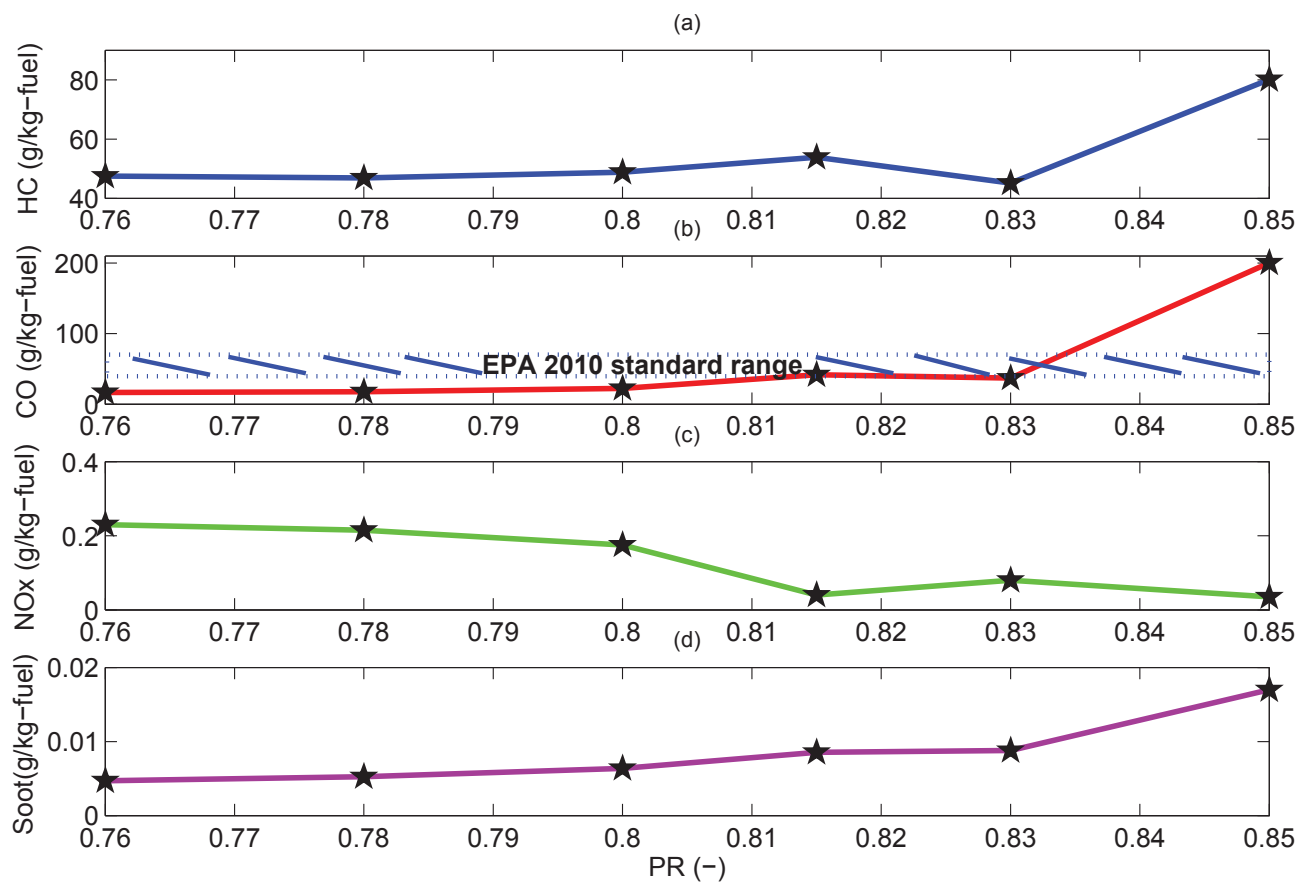

Figure 4.4: Effects of Premixed Ratio (PR) on engine-out emissions including $\mathrm{HC}, \mathrm{CO}, \mathrm{NO}_{\mathrm{x}}$ and soot for engine operating condition corresponding to $\underline{\text { case } a}$ in Table 2.3 


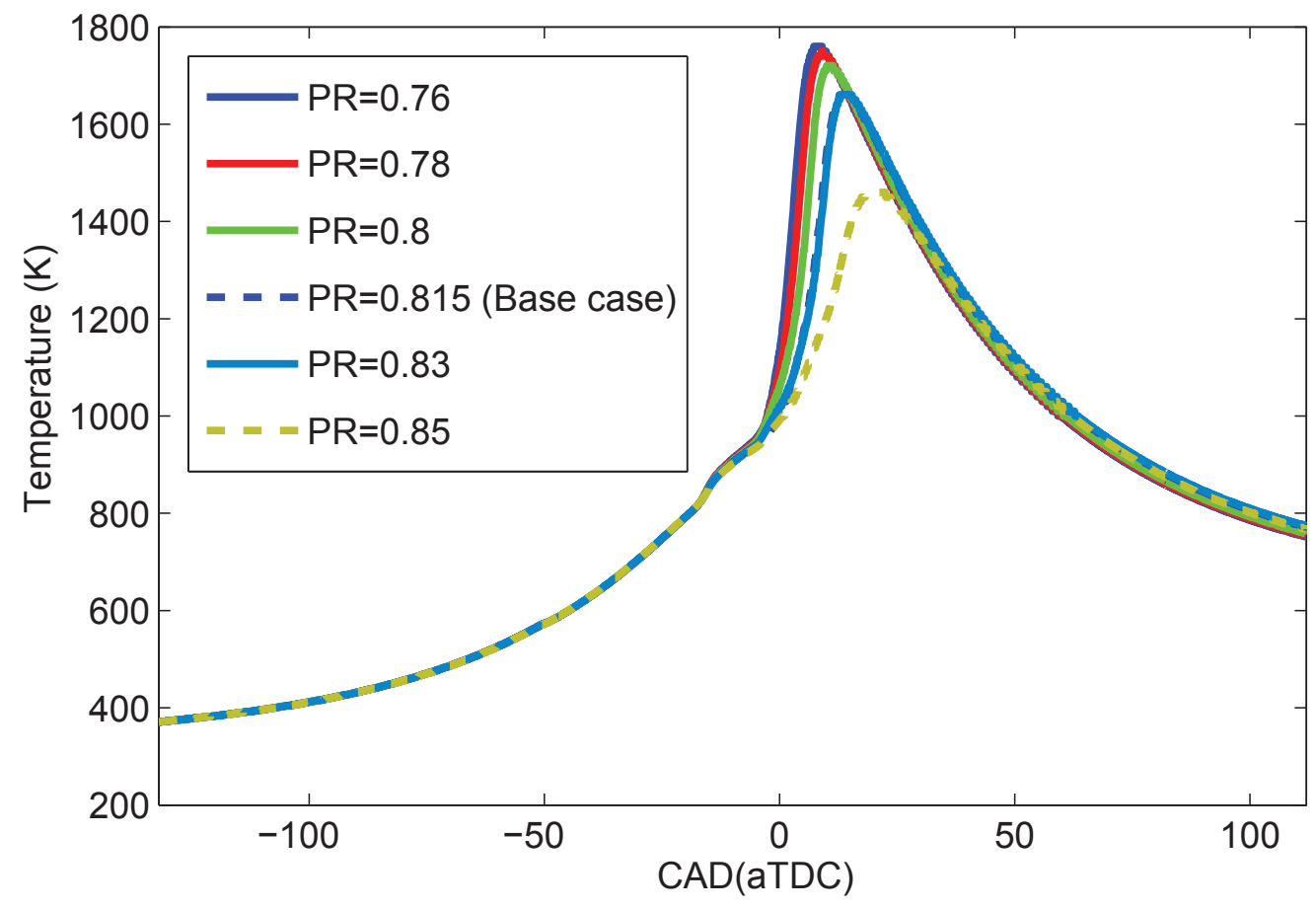

Figure 4.5: Effects of Premixed Ratio (PR) on mean in-cylinder temperature for engine operating condition corresponding to case a in Table 2.3

The maximum temperature of $1760 \mathrm{~K}$ occurs at case with $\mathrm{PR}=0.76$ while the minimum cylinder temperature of $1460 \mathrm{~K}$ occurs at $\mathrm{PR}=0.85$ which leads to a substantial increase in $\mathrm{HC}$ and $\mathrm{CO}$ emissions. As shown in Figure 4.4 the amounts of $\mathrm{NO}_{\mathrm{x}}$ and soot for all operating cases are well below United States (US) 2010 Environmental Protection Agency (EPA) regulations for Light-duty vehicles (LDV) for $\mathrm{NO}_{\mathrm{x}}$ and soot emissions [64] (i.e., $1 \mathrm{~g} / \mathrm{kg}$-fuel and $0.25 \mathrm{~g} / \mathrm{kg}$-fuel for NOx and soot, respectively). However due to low combustion temperature and low exhaust gas temperature higher $\mathrm{HC}$ and $\mathrm{CO}$ would be expected which necessitates using aftertreatment systems such as Diesel Oxidation Catalyst 
(DOC) to reduce $\mathrm{HC}$ and $\mathrm{CO}$ emissions [63]. The standard ranges of $\mathrm{HC}$ and $\mathrm{CO}$ emissions based on EPA 2010 emissions regulations for LDV are presented in Appendix D. It is important to note that since wall and crevice temperatures are low, the diesel fuel parcels, which impinge cylinder wall, remain unburned and form HC. In addition, the fuel parcels, which do not have enough time to oxidize, lead to soot emission inside the cylinder [65].

Figure 4.6 shows combustion efficiency as well as gross and net IMEP as a function of PR. Combustion efficiency is calculated from the following equation [66]:

$$
\eta_{c}=\sum\left(R H R / Q_{\text {in }}\right) * 100
$$

where $\sum R H R$ is integrated value of heat release rate and $Q_{i n}$ is the total energy amount of input fuel. In all cases, both gasoline and diesel are considered therefore $Q_{\text {in }}$ is calculated by the following equation:

$$
Q_{\text {in }}=m_{\text {gasoline }} * L H V_{\text {gasoline }}+m_{\text {diesel }} * L H V_{\text {diesel }}
$$

where Lower Heating Value (LHV) for gasoline and diesel are 42.87 and $41.28 \mathrm{MJ} / \mathrm{kg}$, respectively.

As shown in Figure 4.6 combustion efficiency decreases by increasing gasoline mass percentage and this is consistent with Figure 4.4 where increasing PR causes $\mathrm{HC}$ and $\mathrm{CO}$ to increase and as a result combustion efficiency decreases. $\mathrm{CO}$ cannot be converted to $\mathrm{CO}_{2}$ 
due to low combustion temperature and lack of $O$ radicals [67].

$\mathrm{IMEP}_{\mathrm{g}}$ is calculated by the following equation [37] which considers the work delivered during compression and expansion strokes.

$$
I M E P_{g}=\left(\int_{-180}^{180} p d V\right) / V_{d}
$$

where $V_{d}$ is the displaced volume. In calculations for all engine performance parameters, pressure trace in the cylinder is considered. Since closed engine cycle starting from IVC upto EVO is simulated, the required data for rest of the cycle is approximated with experimental data for calculating both gross and net IMEP [33]. The procedure to calculate gross and net IMEP from simulation data is explained in Appendix A.

$\operatorname{IMEP}_{\mathrm{n}}$ is calculated by the following equation [37] which considers the whole cycle including intake, compression, expansion and exhaust strokes.

$$
I M E P_{n}=\left(\int_{-360}^{360} p d V\right) / V_{d}
$$

It is shown in Figure 4.6 that $\mathrm{IMEP}_{\mathrm{g}}$ and $\mathrm{IMEP}_{\mathrm{n}}$ decrease dramatically when PR exceeds 0.83. This is because pressure curve for $\mathrm{PR}=0.85$ in Figure 4.1 decreases after TDC as it is approaching misfire/partial burn condition and therefore the area under the pressure-volume diagram would be less in comparison to other PRs. This observation also implies that 
increasing PR to more than 0.83 would result in misfire/partial burn since the amount of diesel fuel is not enough to initiate the combustion. By increasing PR from 0.76 to 0.83 a slight decrease in $\mathrm{IMEP}_{\mathrm{g}}$ and $\mathrm{IMEP}_{\mathrm{n}}$ is observed.

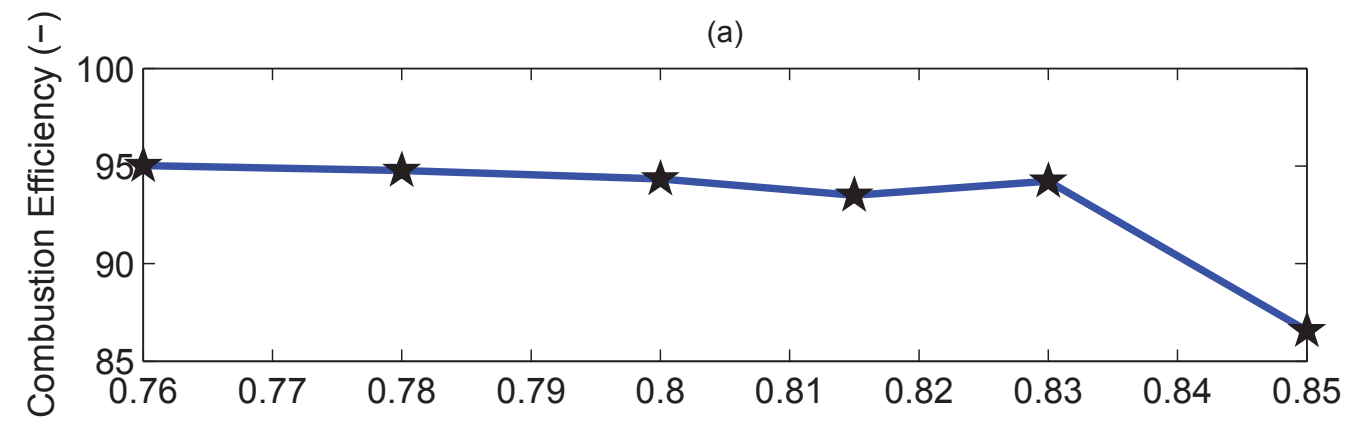

(b)

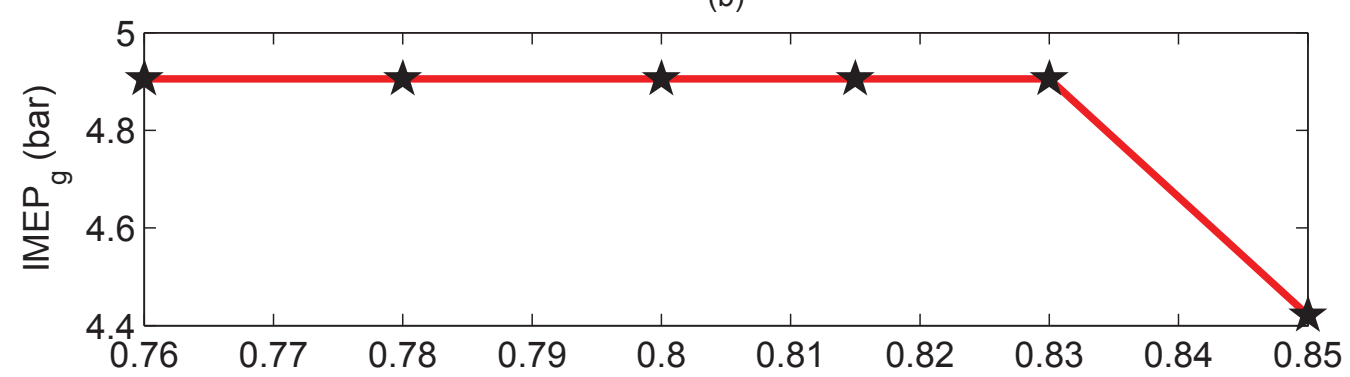

(c)

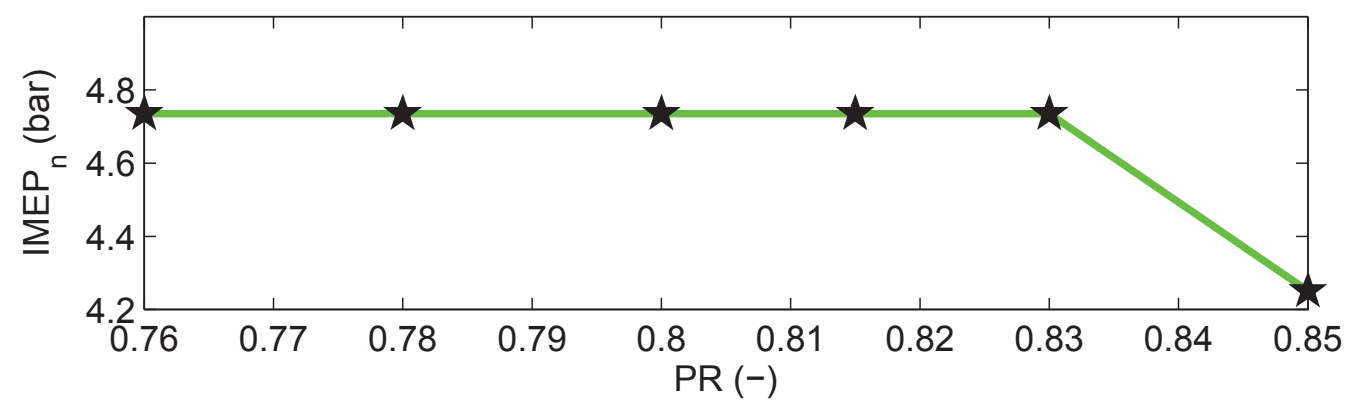

Figure 4.6: Effects of Premixed Ratio (PR) on combustion efficiency, $\mathrm{IMEP}_{\mathrm{g}}$ and $\mathrm{IMEP}_{\mathrm{n}}$ for engine operating condition corresponding to case a in Table 2.3

The similar observation is seen in Figure 4.7 for gross and net indicated efficiencies which 
shows that exceeding PR from 0.83 yields rapid decrease in $\eta_{i n d .-g}$ and $\eta_{\text {ind.- } n}$. In addition a slight decrease in gross and net indicated efficiencies can be observed when PR increases from 0.76 to 0.83 .

Gross and net indicated efficiencies are calculated by the following equations [37]:

$$
\eta_{\text {ind. }-g}=\left(\int_{-180}^{180} p d V\right) / Q_{\text {in }}
$$

$$
\eta_{\text {ind. }-n}=\left(\int_{-360}^{360} p d V\right) / Q_{\text {in }}
$$

Gross and net thermal efficiencies are calculated by the following equations [37]:

$$
\eta_{t h-g}=\eta_{\text {ind. }-g} / \eta_{c}
$$

$$
\eta_{t h-n}=\eta_{\text {ind. }-n} / \eta_{c}
$$


(a)

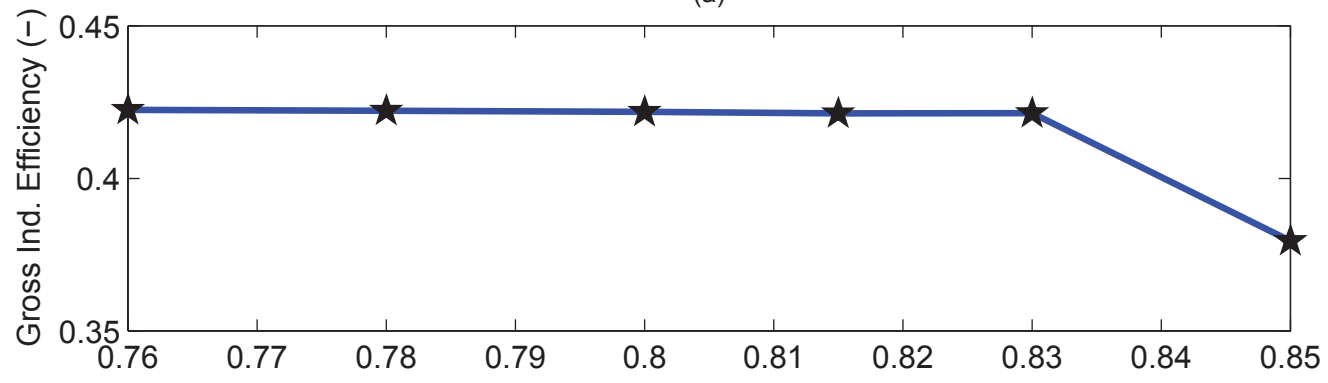

(b)

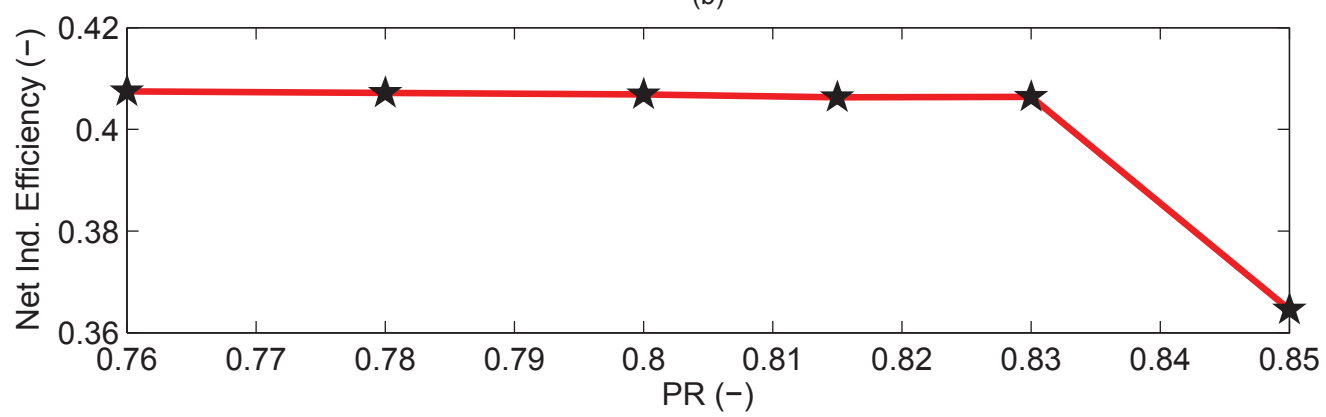

Figure 4.7: Effects of Premixed Ratio (PR) on $\eta_{\text {ind.-g }}$ and $\eta_{\text {ind. }-n}$ for engine operating condition corresponding to case a in Table 2.3

Figure 4.8 shows Peak Pressure Rise Rate (PPRR) and ringing intensity as a function of PR.

Ringing intensity is calculated by the following equation [33]:

$$
R I\left(\frac{M W}{m^{2}}\right)=\frac{1}{2 \gamma} \frac{\left(0.05(d P / d t)_{\max }\right)^{2}}{p_{\max }} \sqrt{\gamma R T_{\max }}
$$

where $\gamma$ is the ratio of specific heats considered the average value during the closed cycle, $(d P / d t)_{\max }$ is the maximum pressure rise rate, $p_{\max }$ is the maximum cylinder pressure, $T_{\text {max }}$ is the maximum cylinder temperature and $\mathrm{R}$ is the gas constant which is the average 
value over the entire closed cycle calculated by the following equation:

$$
R(J / k g . K)=C_{p} \text { ave. }-C_{v} \text {,ave. }
$$

where $C_{p}$,ave. and $C_{v}$,ave. are the average values for the entire closed cycle. $C_{p}$,ave. and $C_{v}$,ave. are calculated for all species which exist at crank angle interval from IVC up to EVO.

PPRR decreases as PR increases. In addition, by increasing PR maximum cylinder pressure and temperature decrease. These observations are consistent with cylinder pressure traces in Figure 4.1. Therefore it is expected to have higher ringing intensity at lower PR that is seen in Figure 4.8. It is found by Dec, et. al [68] that ringing intensities below 5 $\mathrm{MW} / \mathrm{m}^{2}$ resulted in acceptable combustion noise and knock free operation; thus, in this work $5 \mathrm{MW} / \mathrm{m}^{2}$ is used as an upper limit for acceptable combustion noise. It is observed that ringing intensities for all different PRs are well below the upper limit for acceptable combustion noise and knock. 
(a)

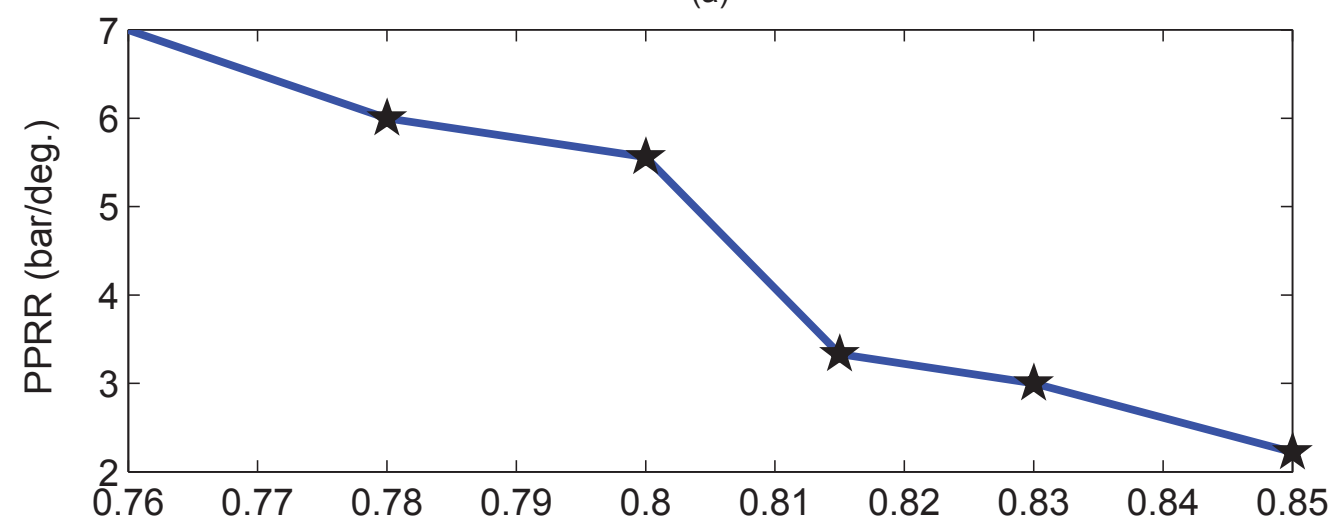

(b)

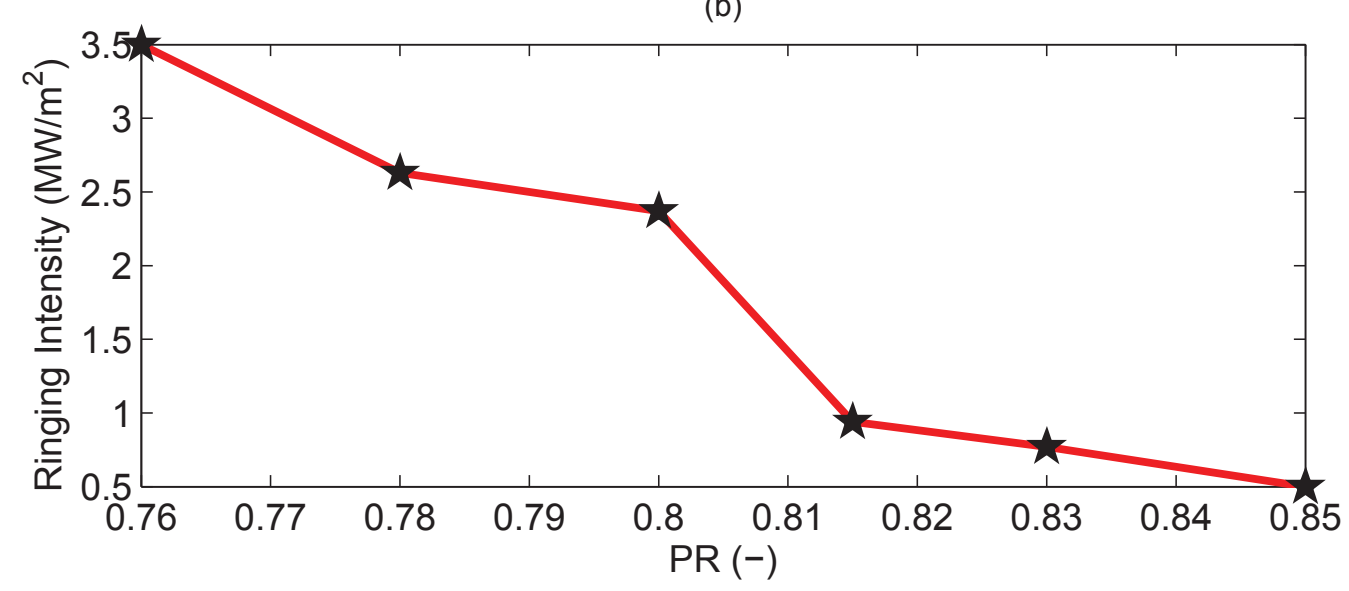

Figure 4.8: Effects of Premixed Ratio (PR) on PPRR and ringing intensity for engine operating condition corresponding to case a in Table 2.3

\subsection{Injection Pressure}

In this section the effects of DI fuel injection pressure on combustion and performance of the RCCI engine will be discussed. Injection pressure is one of the most important parameter which affects atomization, vaporization and dispersion of the liquid fuel [69]. 
Higher injection pressure causes diesel fuel to vaporize rapidly therefore mixing process will be rapid and mixture will be more homogeneous $[69,70,71]$. On the other hand by increasing fuel injection pressure, fuel particle diameter decreases. Therefore their inertia will decrease and they cannot penetrate into the combustion chamber (penetration length will be reduced) [69] and flame spreads around the chamber by slow propagation; while lower injection pressure with greater particle diameter yields greater flexibility for fuel distribution throughout the combustion chamber.

To investigate the effects of injection pressure on RCCI combustion, case (a) in Table 2.3 is considered as a base point. Since for this specific operating point the amount of diesel fuel consists $18.5 \%$ of total amount of fuel, fuel particle size and distribution play a significant role on combustion and performance of engine.

As shown in Figure 4.9 increasing injection pressure from 380 bar to 580 bar causes peak pressure to decrease from near 80 bar to 70 bar. This is because by increasing injection pressure, fuel parcels' diameter decreases and these parcels with smaller diameter can hardly accumulate near the bowl where temperature is high. Therefore ineffective auto-ignition will occur which cannot propagate through the whole combustion chamber and provide enough energy for gasoline to burn rapidly. Figure 4.10 and 4.11 support this justification and show that for injection pressure 380 bar, diesel fuel parcels accumulate around the bowl. As a result, strong auto-ignition points occur near the bowl and squish region at crank angle $6^{\circ}$ aTDC that results in higher peak cylinder pressure. However, by 
increasing injection pressure to 580 bar it is clearly seen that at crank angle $6^{\circ}$ aTDC the auto-ignition point near the bowl deteriorates and therefore yields inefficient combustion and lower peak pressure. In addition, at higher injection pressures, wall film level increases near the wall and crevices due to diesel fuel wall impingement. This limits the fuel combustion [63].

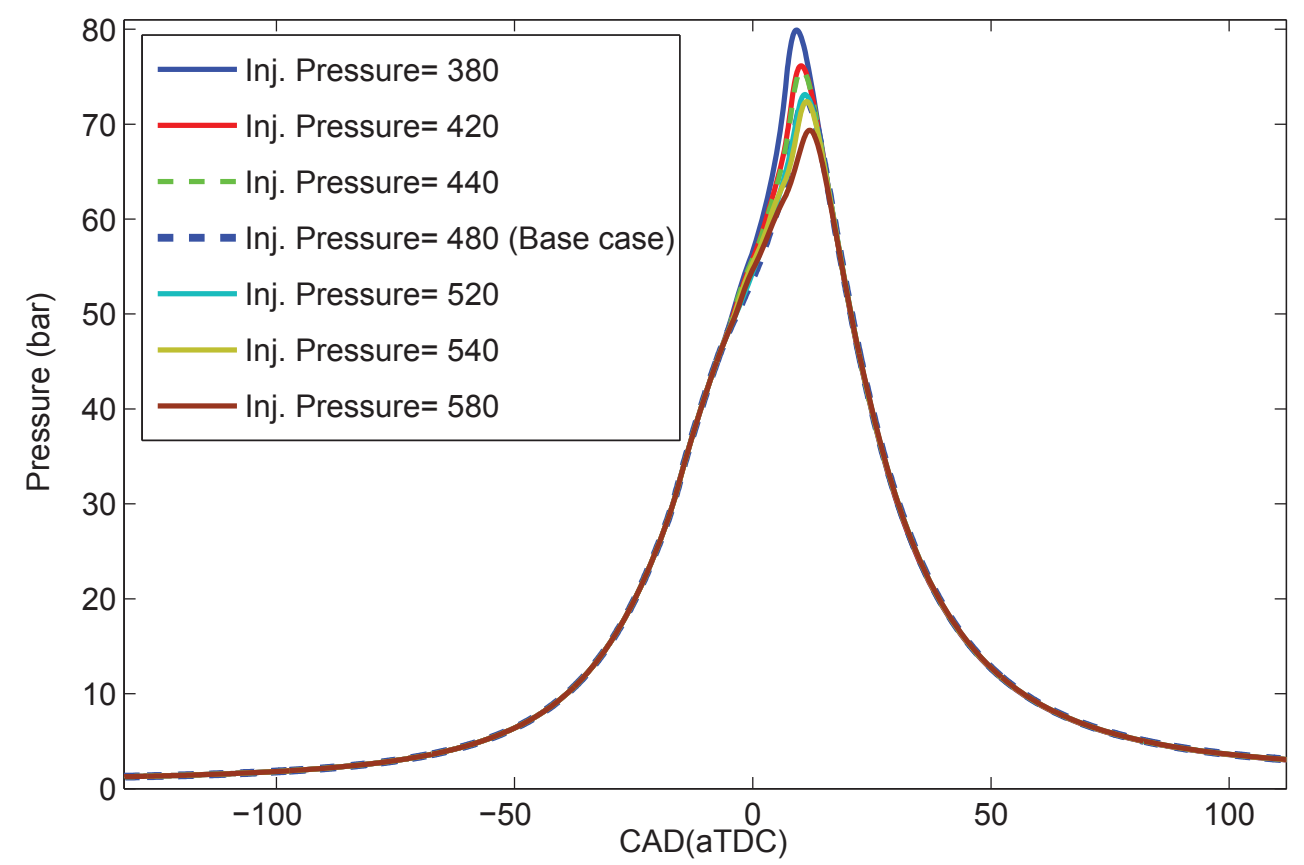

Figure 4.9: Effects of injection pressure on in-cylinder pressure for engine operating condition corresponding to case a in Table 2.3 

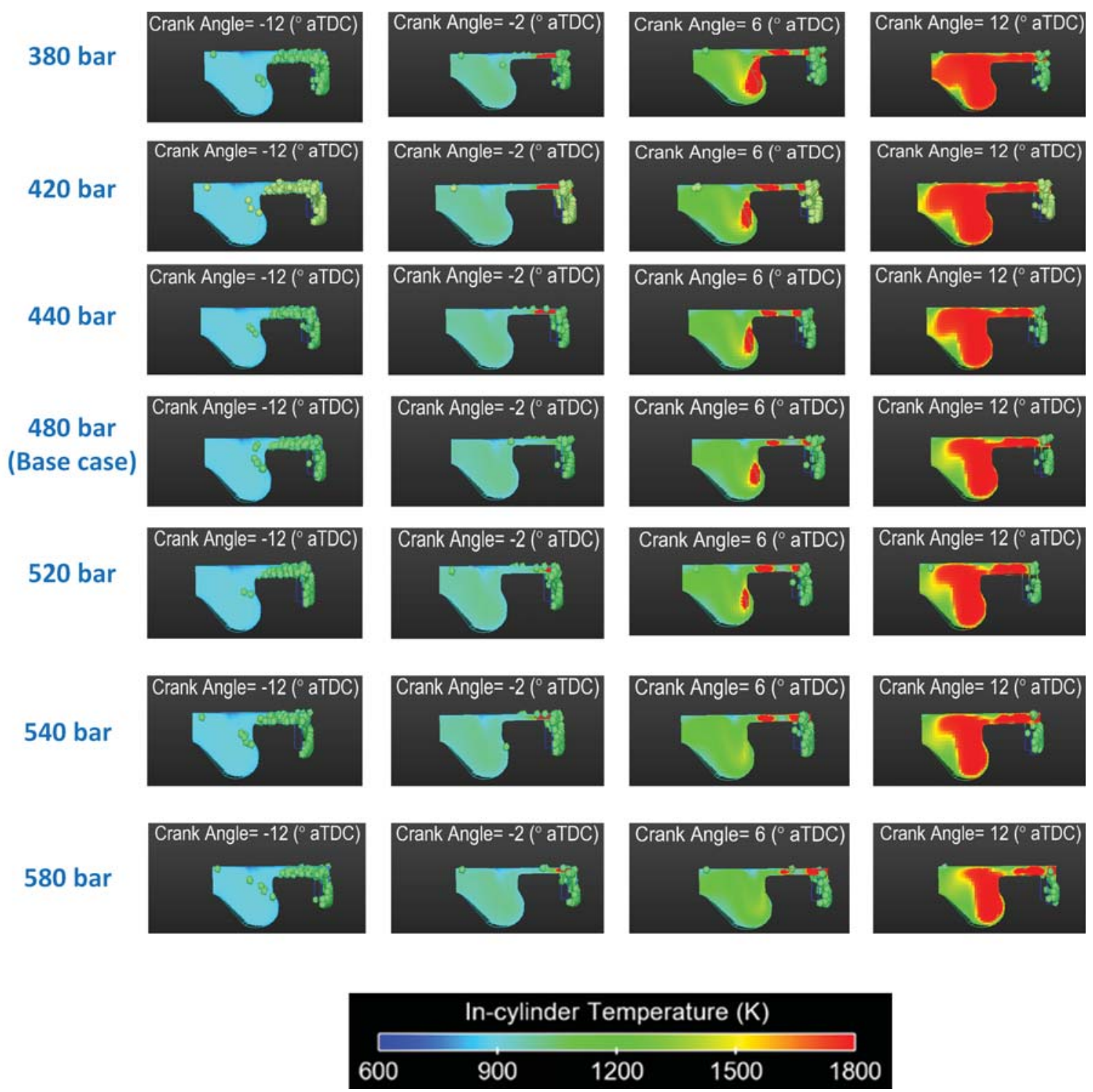

Figure 4.10: Cylinder temperature cut planes at 4 crank angles for each of the injection pressure for engine operating condition corresponding to case $a$ in Table 2.3. Fuel parcels are shown by green color pentagons. 


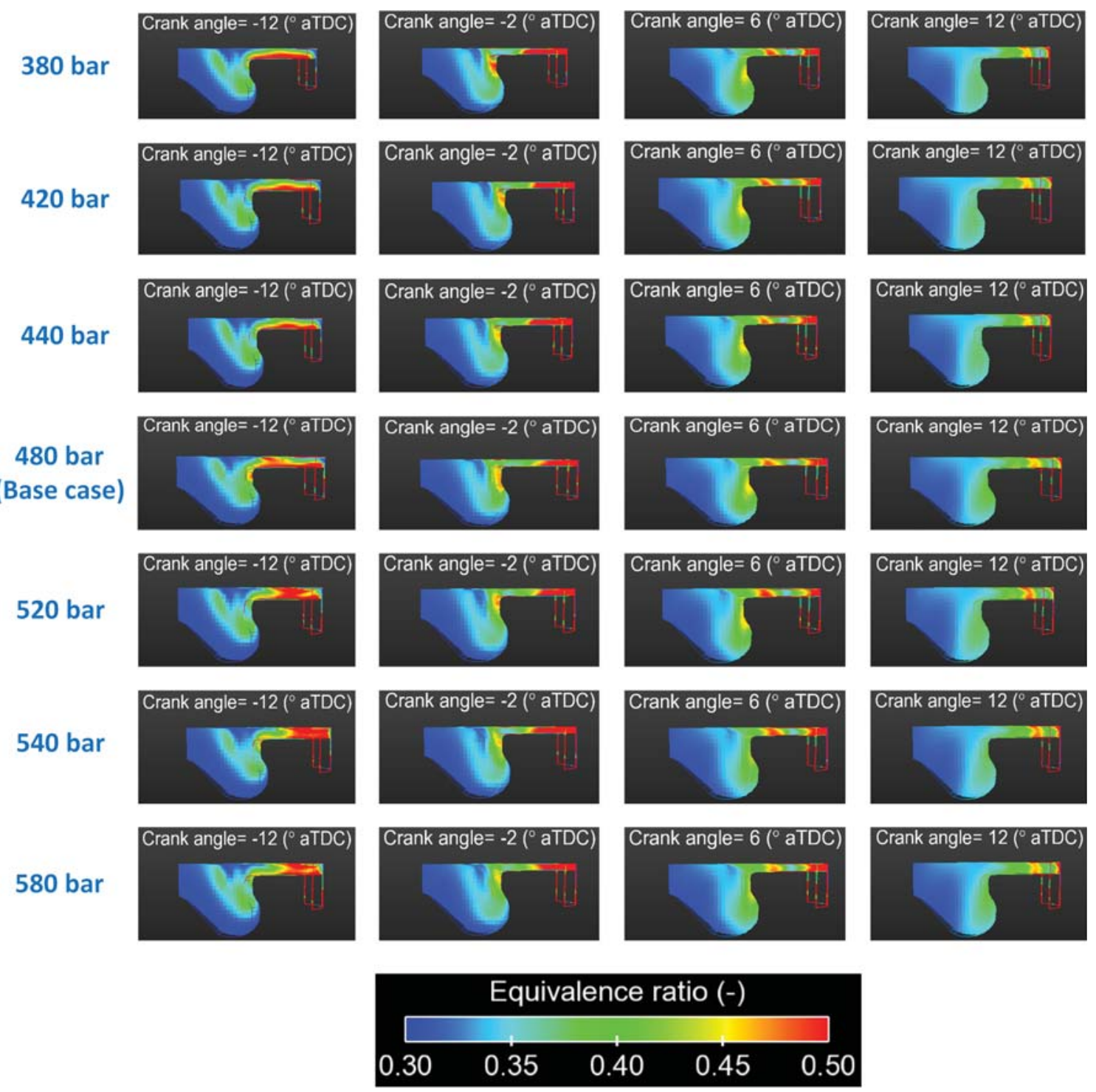

Figure 4.11: Equivalence ratio cut planes at 4 crank angles for each of the injection pressure for engine operating condition corresponding to case a in Table 2.3.

Figures 4.12 and 4.13 show the HRR and combustion phasing as a function of injection pressure. Similar to cylinder pressure curve it is seen that by increasing injection pressure the peak HRR decreases and combustion phasing (CA50) is retarded. By increasing 
injection pressure weak auto-ignition occurs near the piston bowl, less gasoline fuel will burn in comparison to low injection pressure and therefore peak HRR decreases. In addition, due to slow flame propagation as a result of weak auto-ignition points at higher injection pressure, combustion phasing (CA50) is delayed. The variation in CA10 is mainly dependent on diesel fuel parcels distribution and where and how those parcels reach auto-ignition condition. Therefore a specific trend is not observed in CA10 by changing the injection pressure.

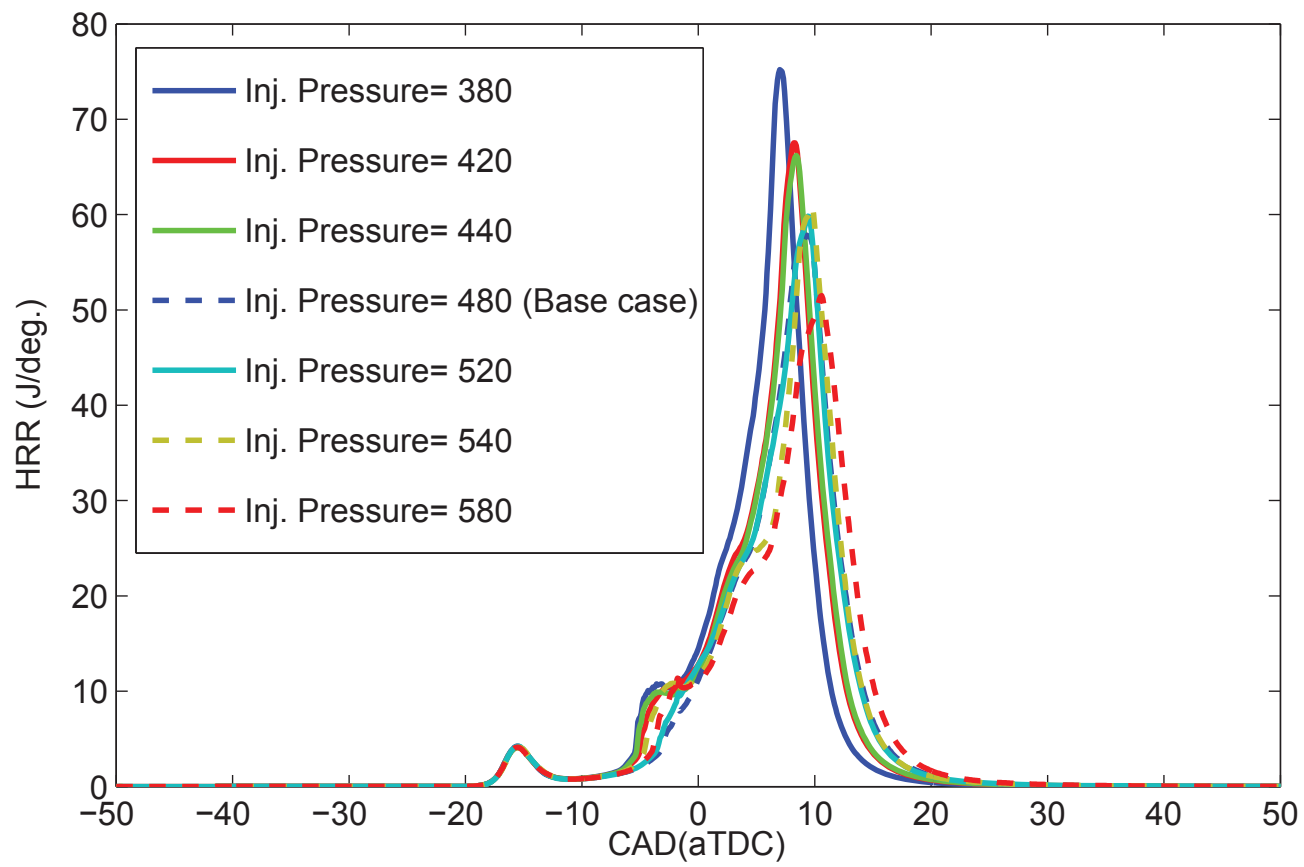

Figure 4.12: Effects of injection pressure on Heat Release Rate (HRR) for engine operating condition corresponding to case $a$ in Table 2.3

For this specific case, increasing injection pressure by 200 bar causes combustion phasing (CA10, CA50, CA90 and BD) variation of around 2 CAD. Overall, a small sensitivity is 
observed in combustion phasing for changes in diesel injection pressure, however, higher sensitivity is observed for changes in peak in-cylinder gas pressure and HRR as shown in Figures 4.9 and 4.12 .

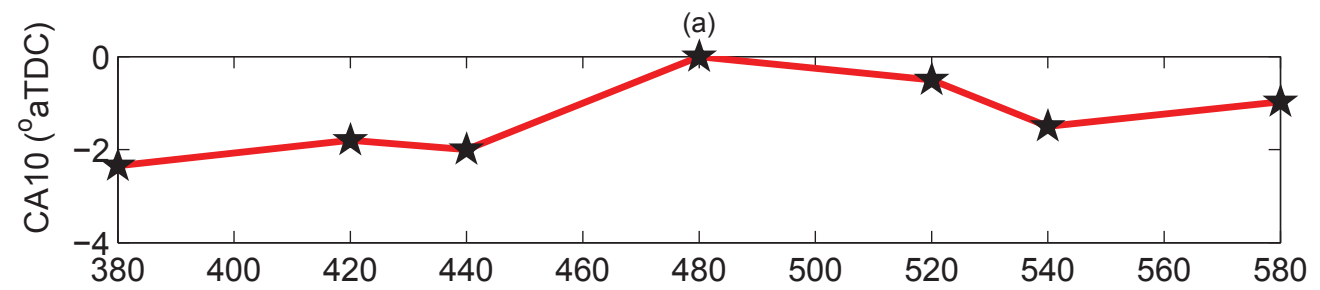

(b)
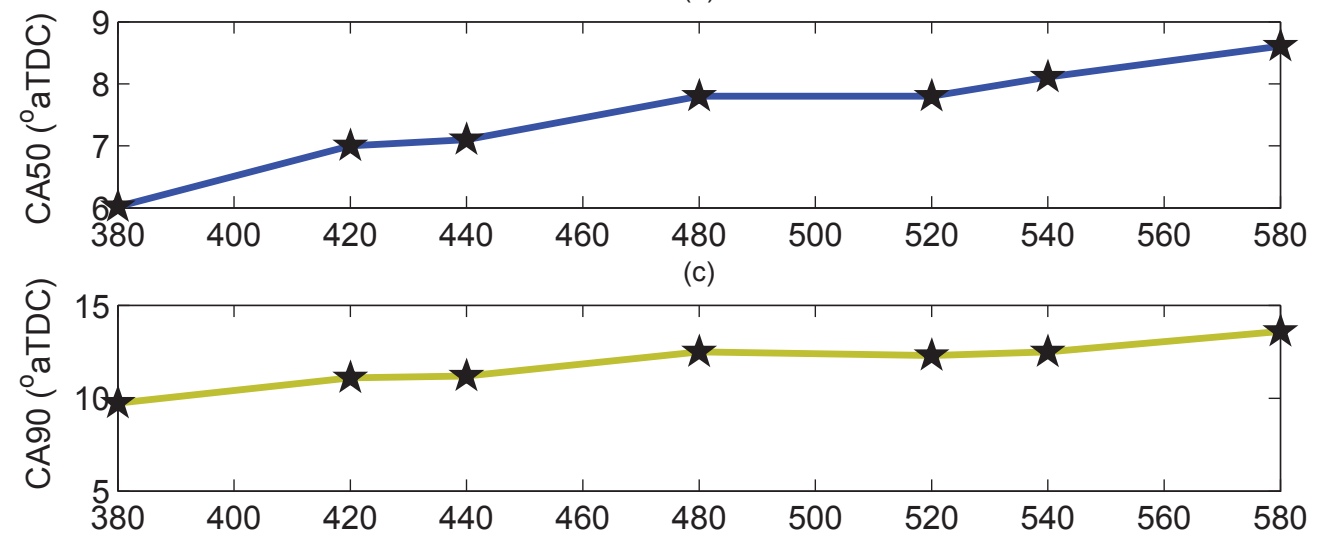

(d)

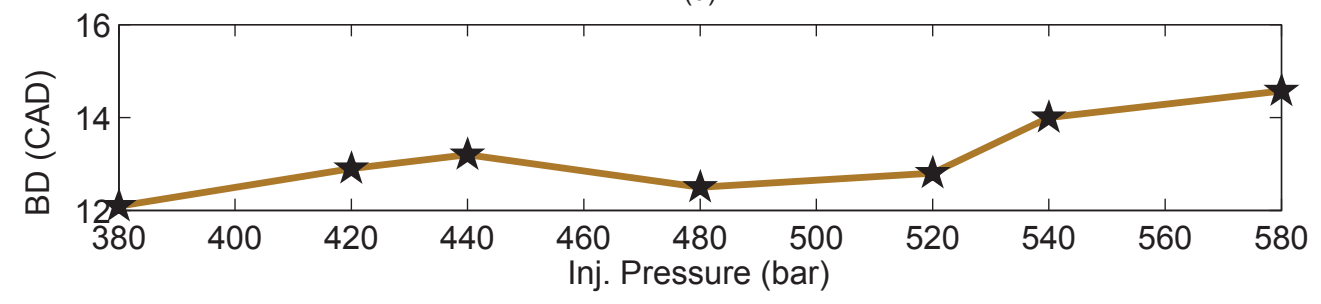

Figure 4.13: Effects of injection pressure on combustion phasing (CA10, CA50, CA90, BD) for engine operating condition corresponding to case a in Table 2.3

Figure 4.14 shows engine-out emissions $\left(\mathrm{HC}, \mathrm{CO}, \mathrm{NO}_{\mathrm{x}}\right.$ and soot) results as a function of injection pressures. Higher $\mathrm{HC}, \mathrm{CO}$ and soot values are observed at higher injection 
pressures due to lower cylinder gas temperatures while $\mathrm{NO}_{\mathrm{x}}$ emission decreases due to the same reason. The main reason of increase in $\mathrm{HC}$ and $\mathrm{CO}$ at higher injection pressures is the impingement of diesel fuel at high injection pressure with cylinder wall and entering more fuel to the crevice region. Injected diesel fuel, which enters the cylinder at high injection pressure, produces rich zone near the wall and crevices for this engine with the utilized injection strategy. The standard ranges of $\mathrm{HC}$ and $\mathrm{CO}$ emissions based on EPA 2010 emissions regulations for LDV are presented in Appendix D.

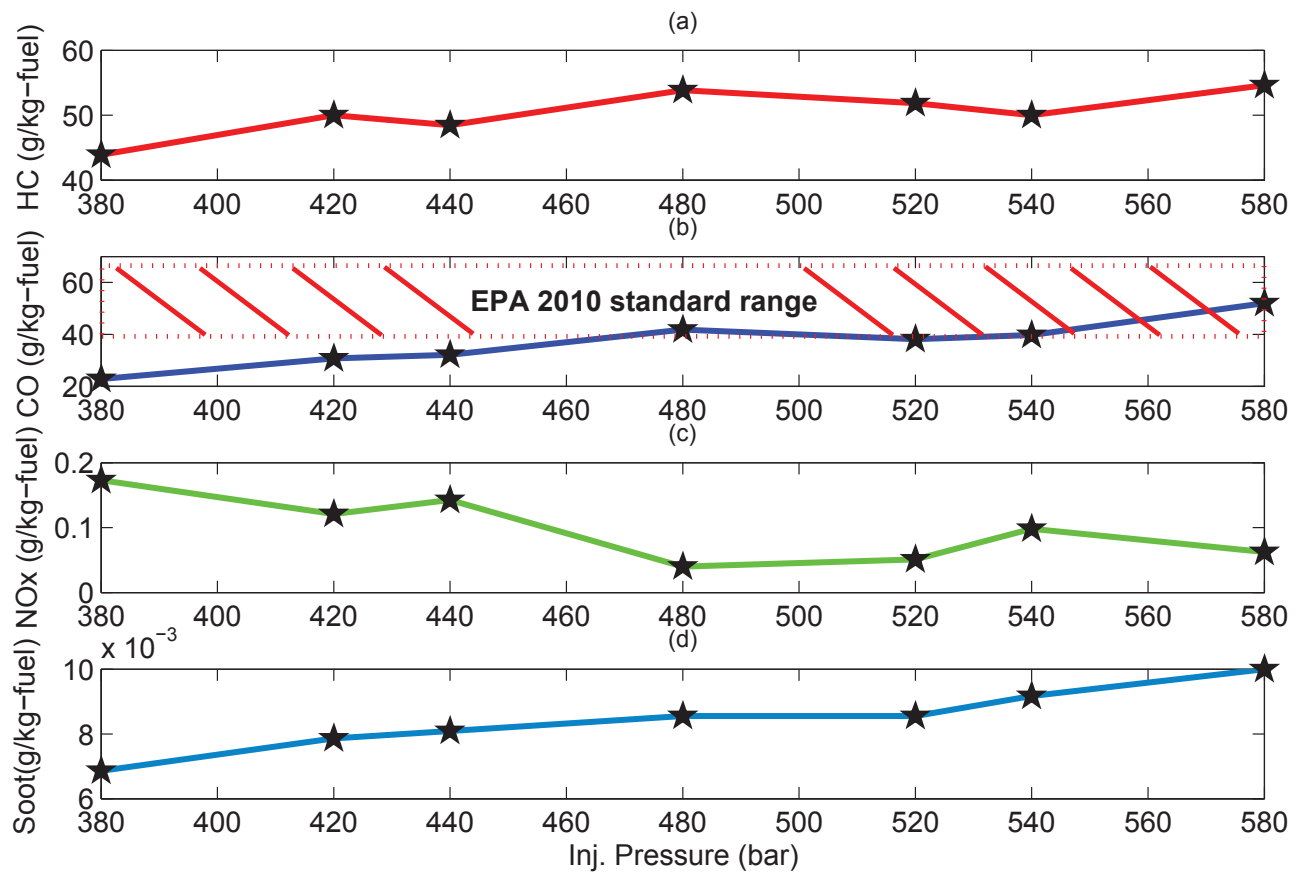

Figure 4.14: Effects of injection pressure on engine-out emissions including $\mathrm{HC}, \mathrm{CO}, \mathrm{NO}_{\mathrm{x}}$ and soot for engine operating condition corresponding to case $a$ in Table 2.3

Combustion efficiency, $\mathrm{IMEP}_{\mathrm{g}}$ and $\mathrm{IMEP}_{\mathrm{n}}$ are shown in Figure 4.15. Due to higher HC and $\mathrm{CO}$ values at higher injection pressures combustion efficiency decreases as the injection 
pressure increases. The whole change in IMEP is less than 0.1 bar for changes in injection pressure. This indicates that changing injection pressure does not affect IMEP significantly.

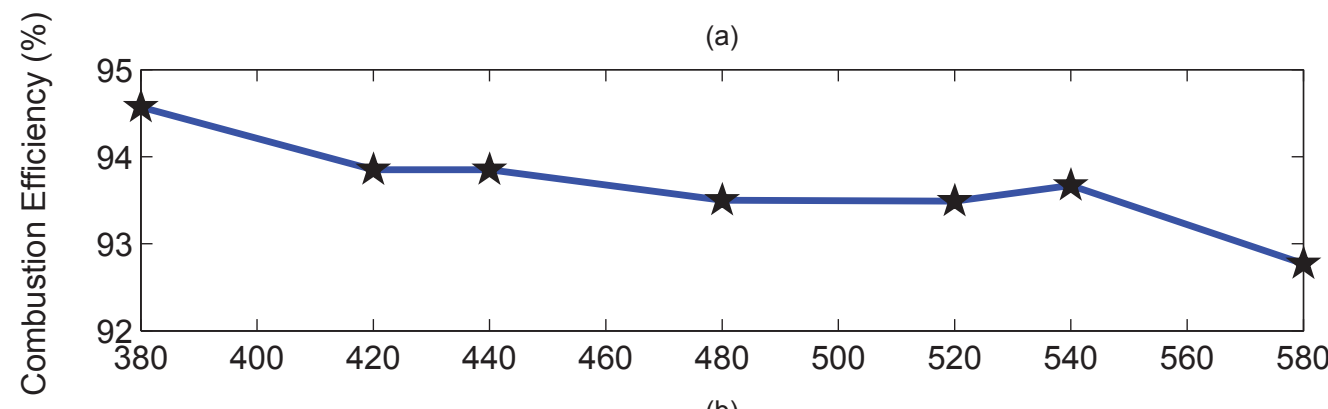

(b)

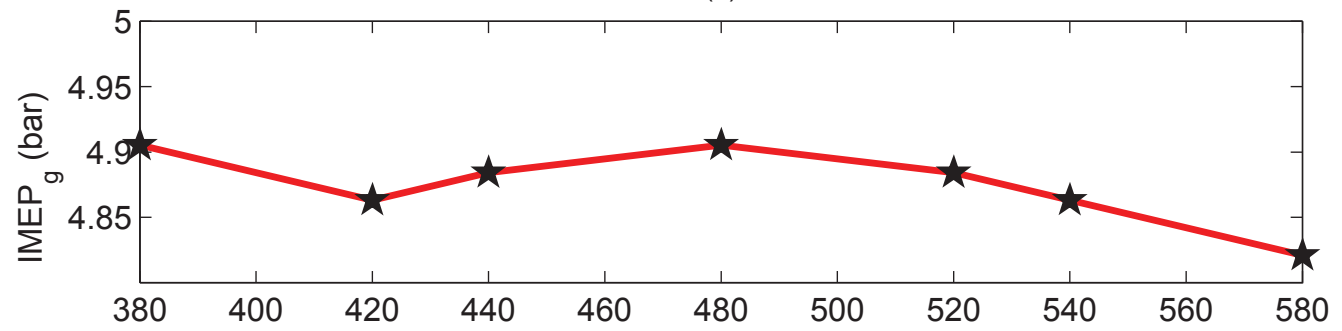

(c)

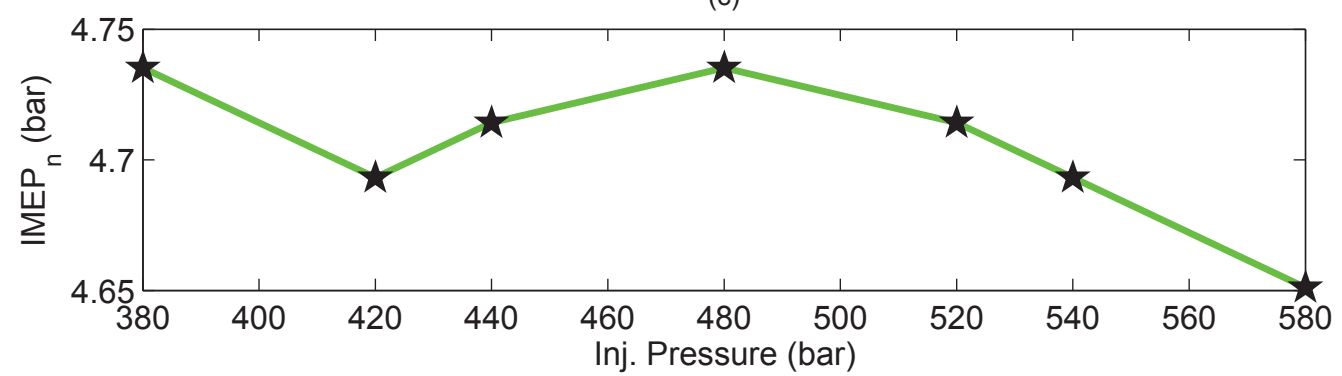

Figure 4.15: Effects of injection pressure on combustion efficiency, $\mathrm{IMEP}_{\mathrm{g}}$ and $\mathrm{IMEP}_{\mathrm{n}}$ for engine operating condition corresponding to $\underline{\text { case } a}$ in Table 2.3

The similar behavior is seen in Figure 4.16 for gross and net thermal efficiency. Although the maximum gross and net thermal efficiecy occur at 380 and 480 bar injection pressures; however it is seen that the maximum variation over the 200 bar injection pressure sweep 
is less than 1 percent. The maximum efficiency at 480 bar injection pressure is due to spreading the parcels back into the piston bowl after wall impingement.

(a)

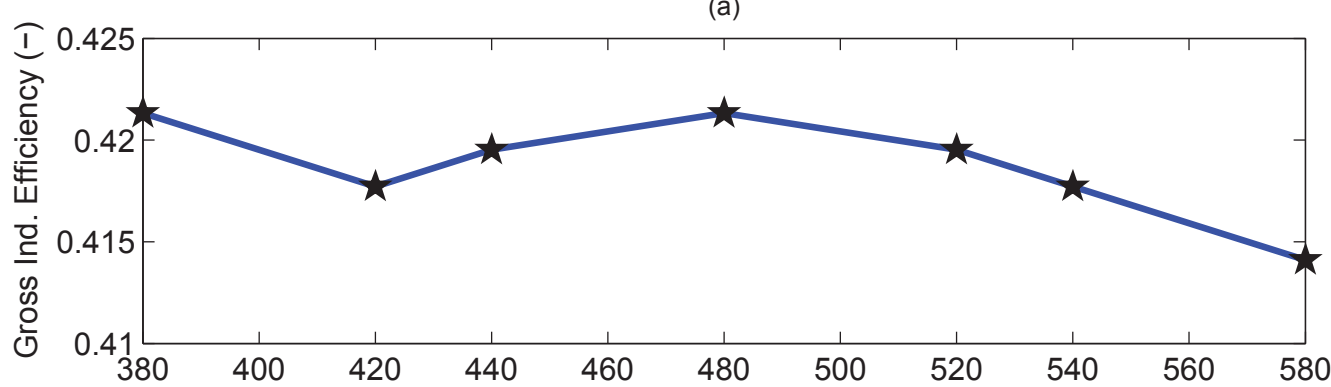

(b)

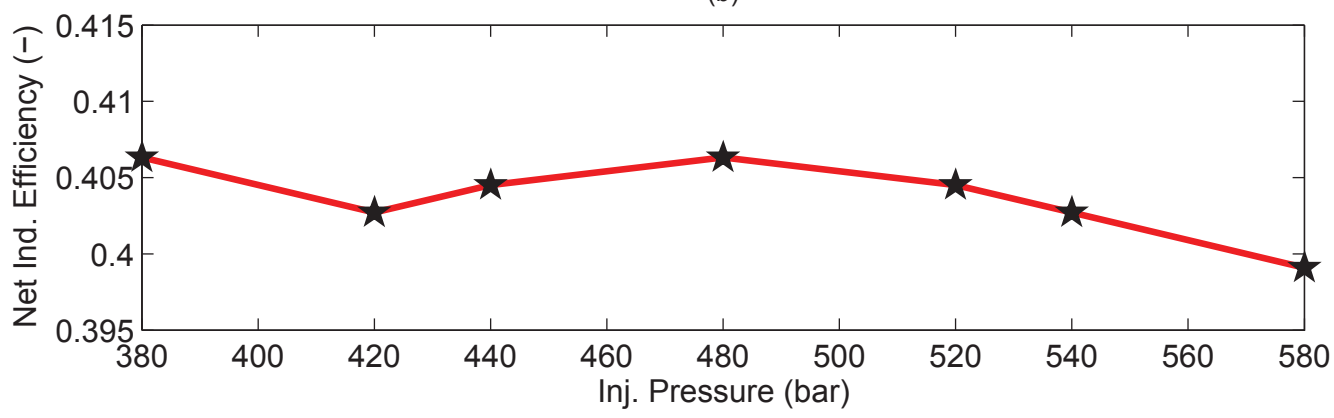

Figure 4.16: Effects of injection pressure on $\eta_{\text {ind.-g }}$ and $\eta_{\text {ind.- } n}$ for engine operating condition corresponding to case a in Table 2.3

Figure 4.17 shows the PPRR and ringing intensity as a function of injection pressure. It is observed that by increasing injection pressure PPRR decreases significantly. Ringing intensity represents combustion noise and knocking tendency [68]. It is seen that as injection pressure increases ringing intensity decreases. For all injection pressures, the values of ringing intensities are less than the standard value of free combustion noise and knock (i.e., $\mathrm{RI}=5 \mathrm{MW} / \mathrm{m}^{2}$ ) [68]. 
(a)

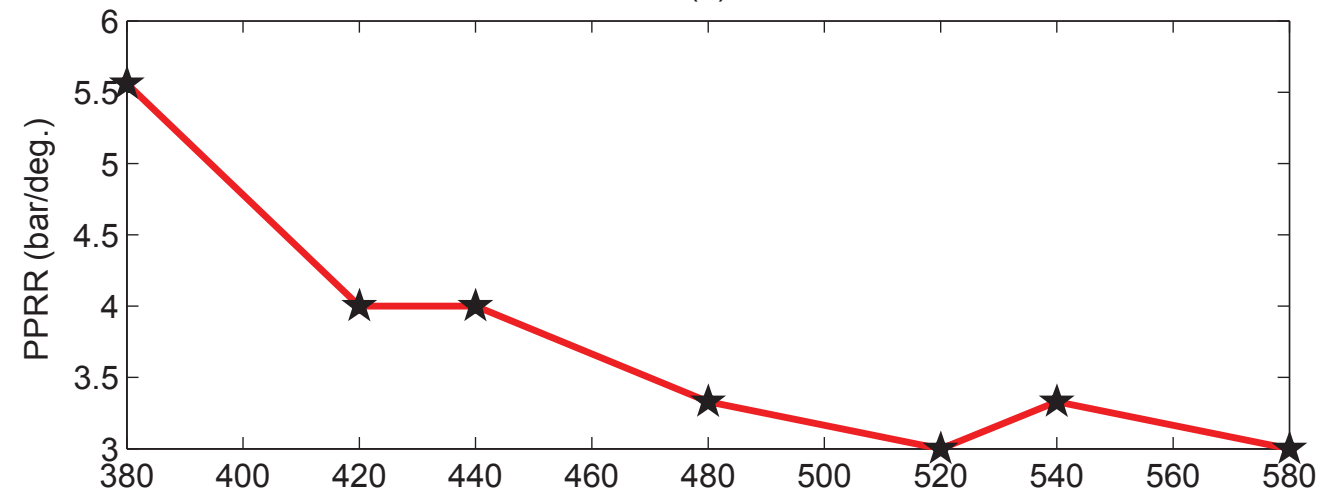

(b)

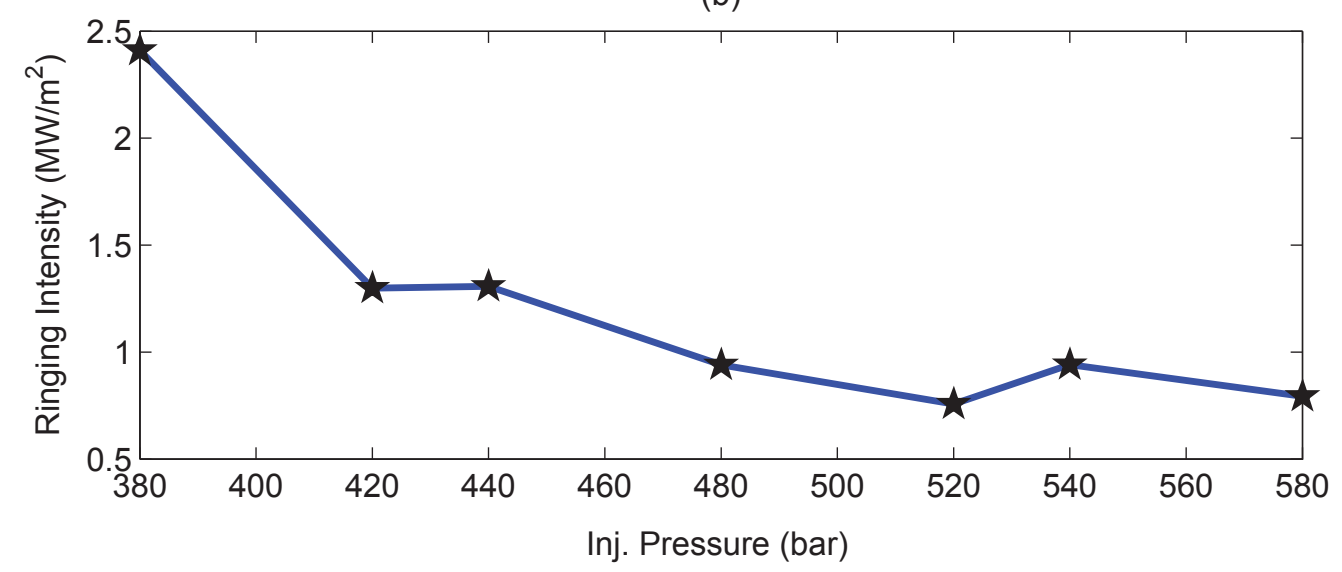

Figure 4.17: Effects of injection pressure on PPRR and ringing intensity for engine operating condition corresponding to $\underline{\text { case } a}$ in Table 2.3

\subsection{Start of Injection Timing}

In this section, the effects of Start of Injection (SOI) timings sweep on the performance and combustion of the RCCI engine is studied. 
By advancing injection of diesel fuel in the compression stroke, the mixing time is increased, creating a partially premixed mixture of gasoline, diesel and air. By increasing time for the diesel fuel to mix with the premixed gasoline-air mixture, local equivalence ratio values become lower which increases the level of homogeneity of the mixture in the combustion chamber. Therefore it is expected to have overally less reactive mixture due to the longer mixing time $[34,72]$. If diesel SOI is too early, combustion can become unstable as the mixture reactivity gradient decreases. For delayed SOI, the time available for mixing decreases; thus, fuel rich regions are formed which results in an increase in $\mathrm{NO}_{\mathrm{x}}$ and soot emissions [34].

Figure 4.18 shows the cylinder pressure for different SOI timings sweep. It is seen that $\mathrm{SOI}=-58^{\circ}$ aTDC has the highest peak pressure while $\mathrm{SOI}=-63^{\circ}$ aTDC has the lowest one. This is because by advancing SOI, the time available for mixing diesel with gasoline and air mixture increases and it is expected to have HCCI like combustion with higher peak cylinder pressure and temperature which can be observed in case with $\mathrm{SOI}=-58^{\circ}$ aTDC. However furhter advancing SOI timing causes combustion to become unstable as the mixture becomes too premixed (i.e., having low local reactivity gradients) as seen in $\mathrm{SOI}=-63^{\circ}$ aTDC in Figure 4.19. Retarding SOI timings do not affect the cylinder peak pressure considerably. The effects of retarding SOI timings can be seen more on emission results later. 


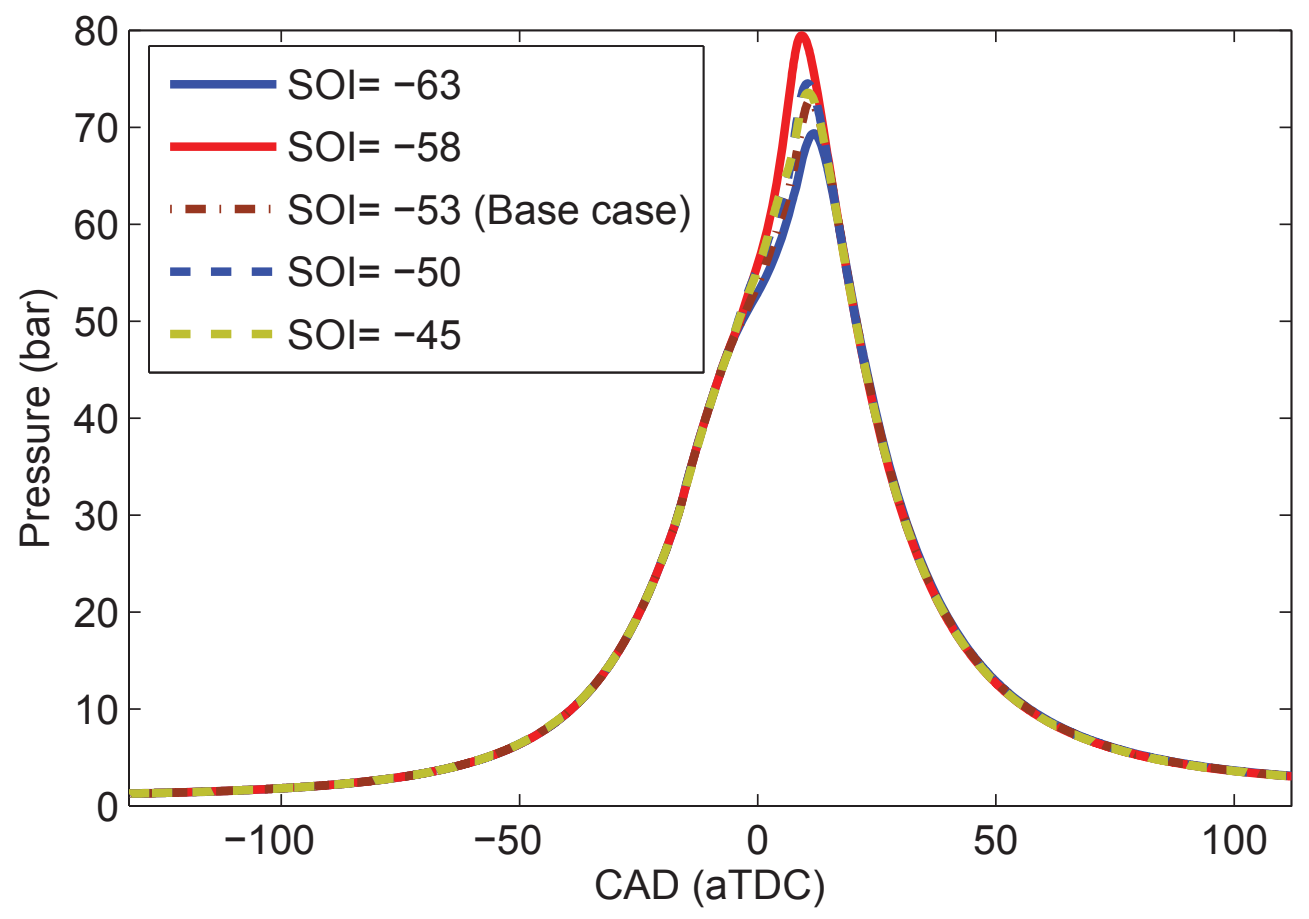

Figure 4.18: Effects of SOI timing sweep on in-cylinder pressure for engine operating condition corresponding to case a in Table 2.3 


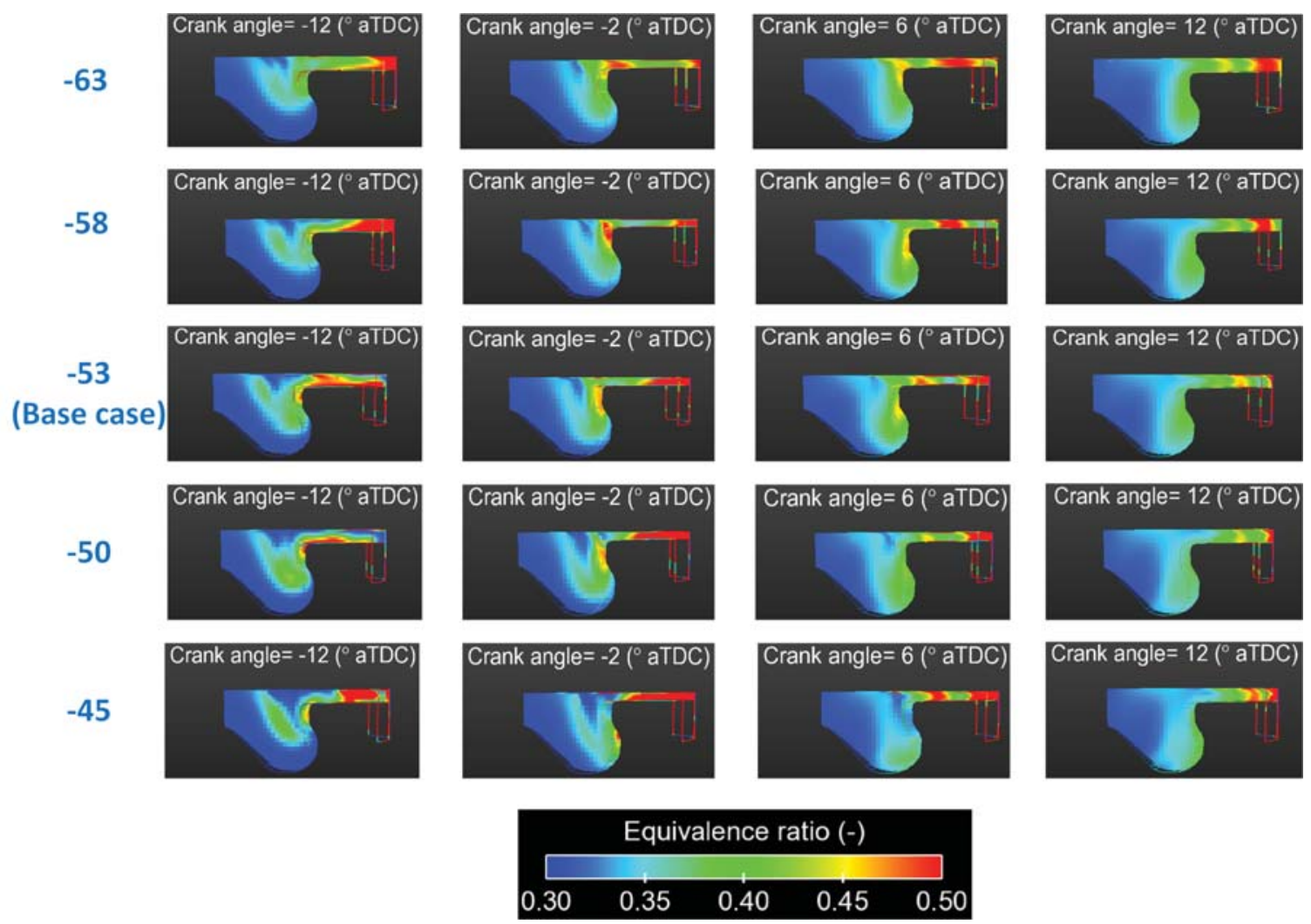

Figure 4.19: Equivalence ratio cut planes at 4 crank angles for each of the SOI timings (deg. aTDC) for engine operating condition corresponding to case $a$ in Table 2.3

Figure 4.20 shows the HRR for different SOI timings. Similar to cylinder pressure curve, the case with $\mathrm{SOI}=-58^{\circ}$ aTDC has the maximum peak HRR and the case with $\mathrm{SOI}=-63^{\circ}$ aTDC has the lowest peak HRR. This can be inferred to this point that in-cylinder gas temperature for $\mathrm{SOI}=-58^{\circ}$ aTDC is the highest and ignition centers, originating from diesel fuel ignition, can ignite more gasoline fuel in comparison to other SOI timings. As shown in Figure 4.21 the highest in-cylinder gas temperature occurs for $\mathrm{SOI}=-58^{\circ}$ aTDC with $1710 \mathrm{~K}$ while $\mathrm{SOI}=-63^{\circ}$ aTDC has the lowest in-cylinder gas temperature with $1640 \mathrm{~K}$. It 
should be noted that the diesel fuel parcels distribution throughout the combustion chamber plays an important role on cylinder pressure, HRR and combustion phasing. This means that accumulation of diesel parcels locally in the chamber serves as a strong ignition center to ignite the gasoline fuel in the chamber.

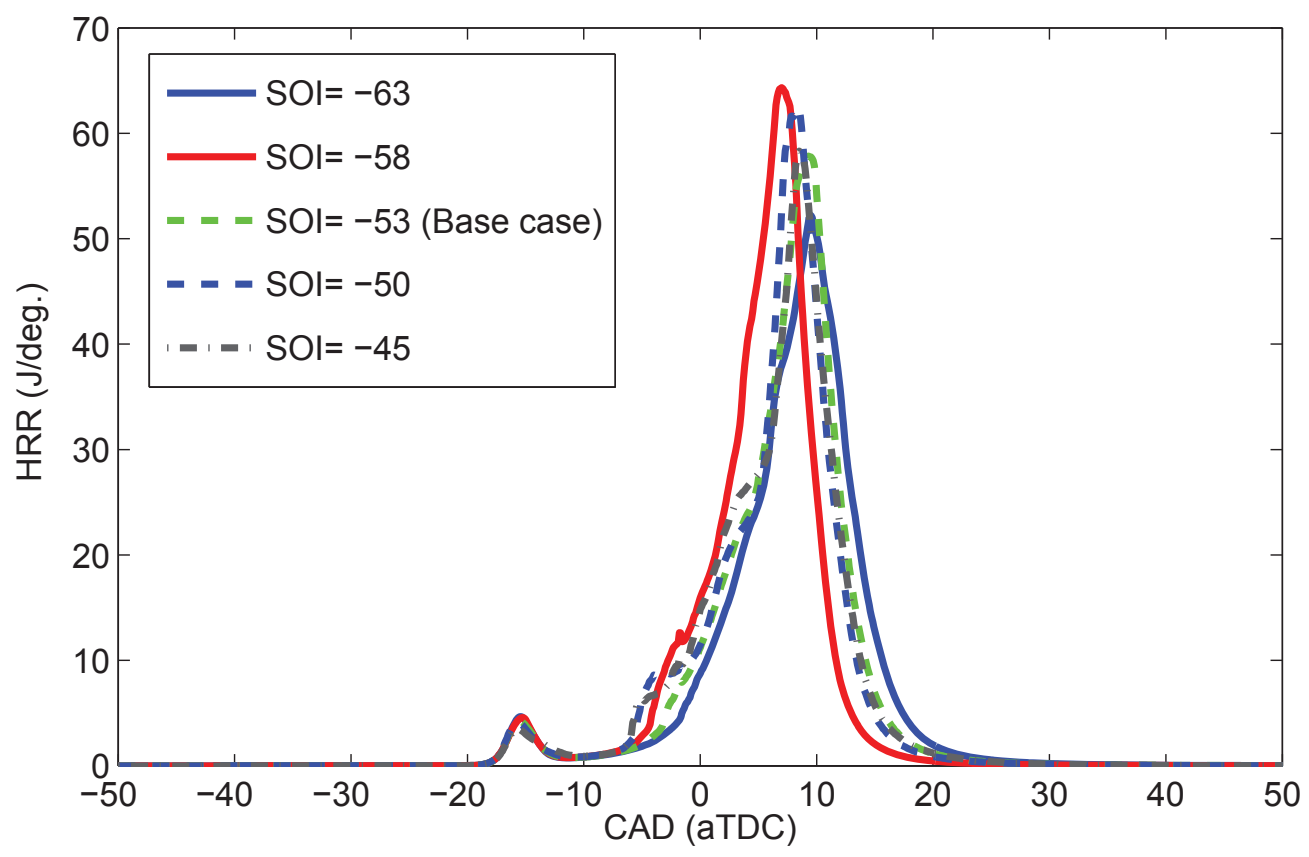

Figure 4.20: Effects of SOI timing sweep on Heat Release Rate (HRR) for engine operating condition corresponding to $\underline{\text { case } a}$ in Table 2.3 


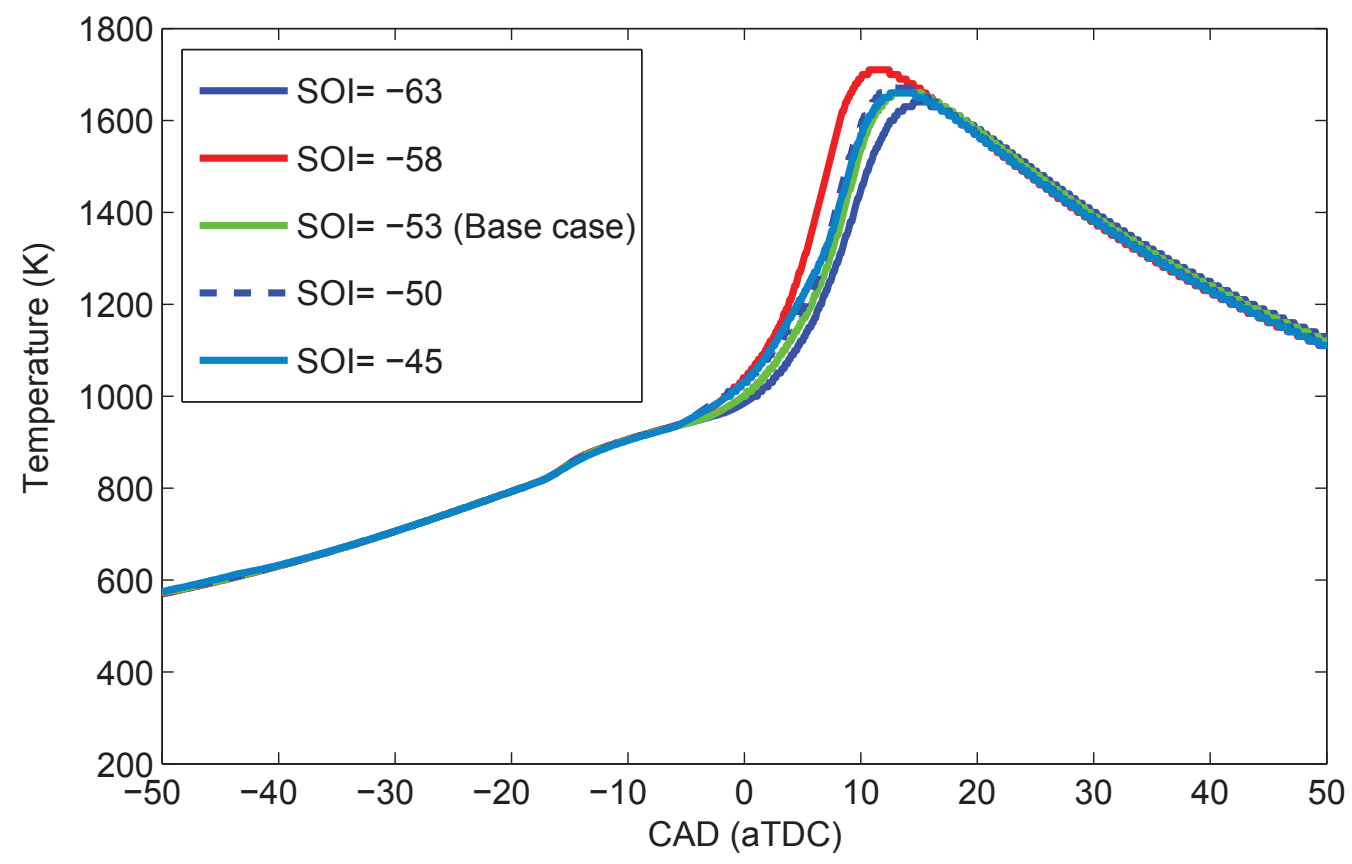

Figure 4.21: Effects of SOI timing sweep on mean in-cylinder gas temperature for engine operating condition corresponding to case $a$ in Table 2.3

As seen in Figure 4.22 at crank angle $6^{\circ}$ aTDC there exists a strong ignition point (red color) near the bowl for the case with $\mathrm{SOI}=-58^{\circ}$ aTDC which consequently propagates throughout the whole combustion chamber as seen in crank angle of $12^{\circ}$ aTDC. 


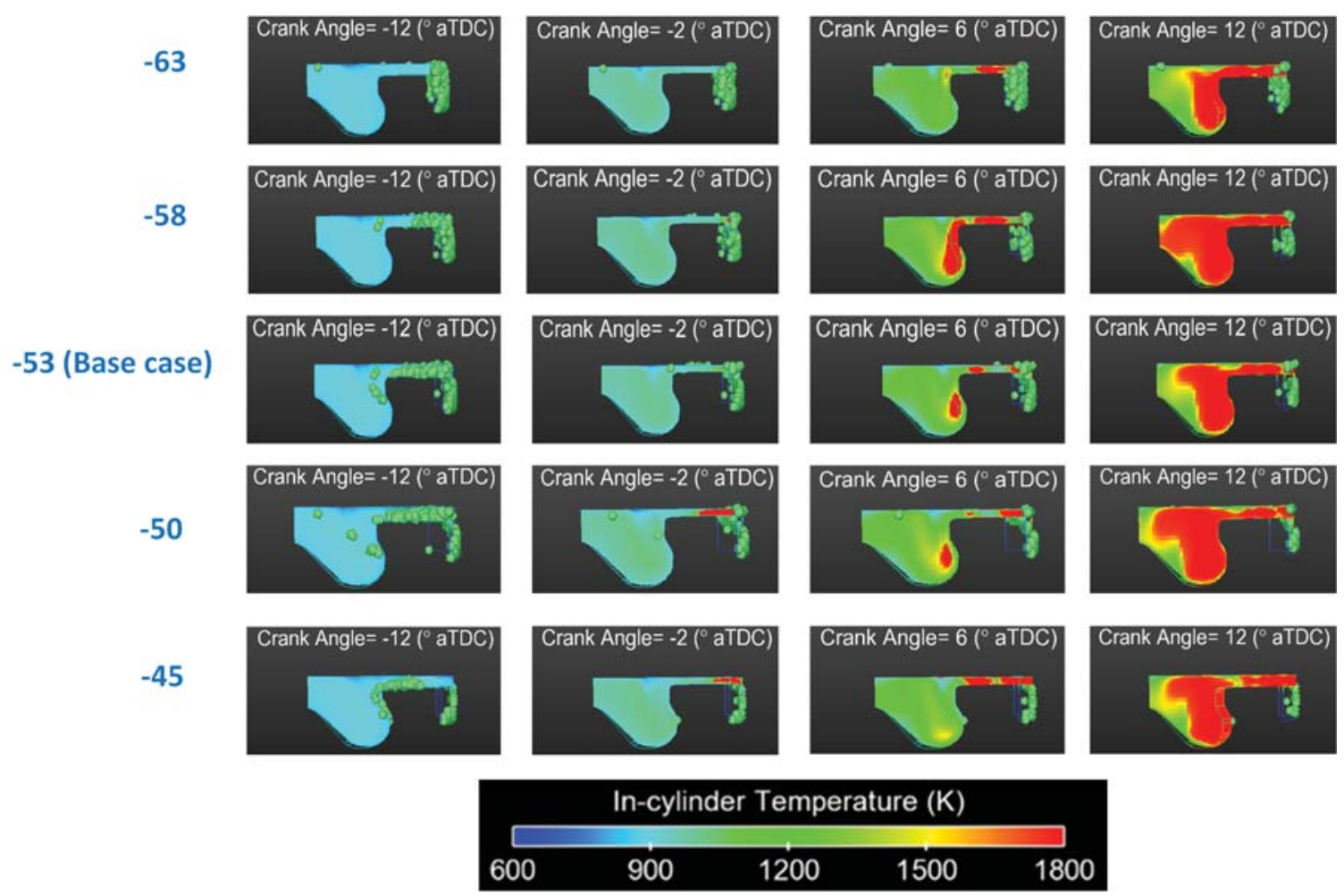

Figure 4.22: Cylinder temperature cut planes at 4 crank angles for each of the SOI timings (deg. aTDC) for engine operating condition corresponding to case $a$ in Table 2.3. Fuel parcels are shown by green color pentagons.

Therefore it is expected that the case with $\mathrm{SOI}=-58^{\circ}$ aTDC has the highest peak cylinder pressure, temperature and HRR. While for the case with $\mathrm{SOI}=-63^{\circ}$ aTDC it is seen that there is no ignition point near the bowl at crank angle $6^{\circ}$ aTDC and a small ignition point near the cylinder liner is seen which is difficult to propagate through the combustion chamber and ignite the gasoline fuel. Therefore the case with SOI $=-63^{\circ}$ aTDC has the weakest combustion. 
(a)

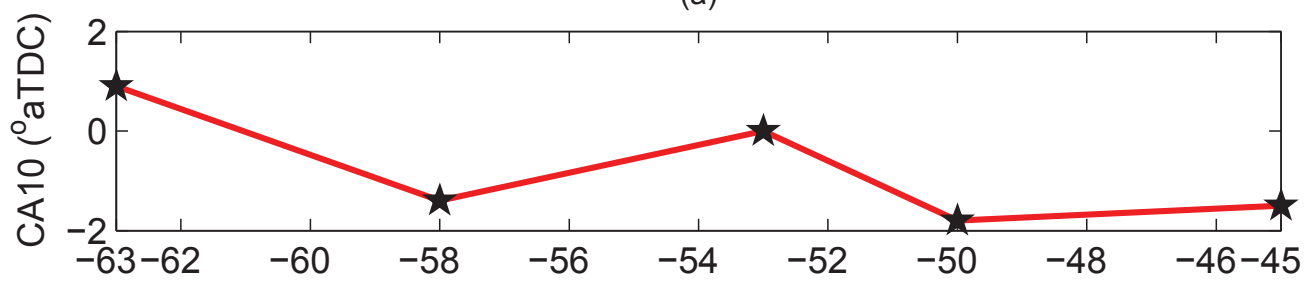

(b)

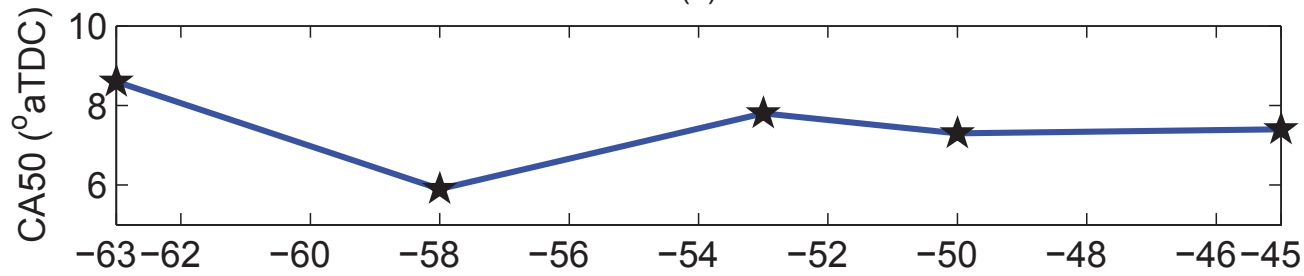

(c)

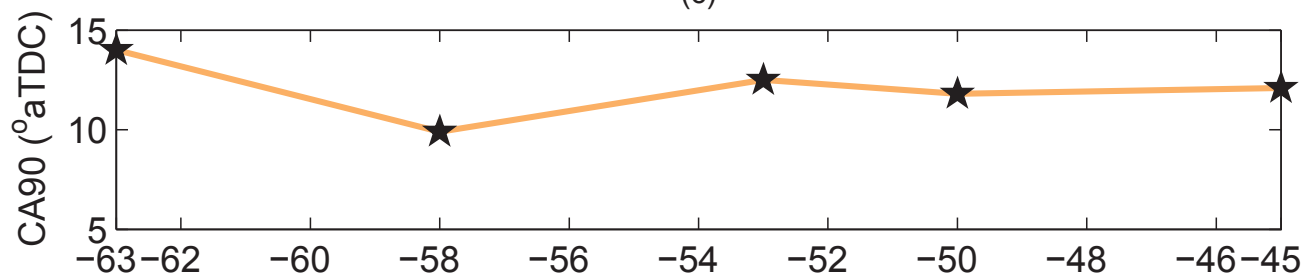

(d)

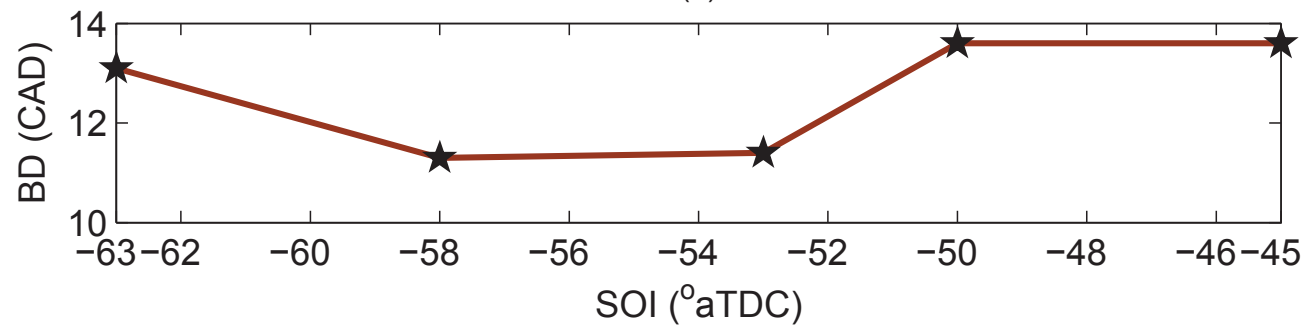

Figure 4.23: Effects of SOI timing sweep on combustion phasing (CA10, CA50, CA90, BD) for engine operating condition corresponding to case a in Table 2.3

Figure 4.23 shows combustion phasing (CA10, CA50, CA90 and BD) as a function of SOI timings. It is seen that by advancing SOI timing from the base case (SOI $=-53^{\circ}$ aTDC) to $\mathrm{SOI}=-58^{\circ}$ aTDC, CA10, CA50 and CA90 are advanced. By further advancing SOI timing to $-63^{\circ}$ aTDC combustion phasing delayed due to weak and unstable combustion 
(approaching partial burn condition). By retarding SOI timings CA50 and CA90 do not change significantly while CA10 is advanced by around 2 CAD. The maximum BD occurs at $\mathrm{SOI}=-50^{\circ}$ aTDC (due to more advanced $\mathrm{SOC}$ ) while $\mathrm{SOI}=-58^{\circ}$ aTDC has the lowest $\mathrm{BD}$ and fastest combustion rate.

Figure 4.24 shows emission values as a function of SOI timings. Advancing SOI timing from the base case to $\mathrm{SOI}=-58^{\circ}$ aTDC causes $\mathrm{HC}, \mathrm{CO}$ and soot to decrease and $\mathrm{NO}_{\mathrm{x}}$ to increase. Advanced combustion phasing and increased cylinder peak pressure result in cylinder temperature increase and therefore it is expected to have less $\mathrm{HC}, \mathrm{CO}$ and soot but higher level of $\mathrm{NO}_{\mathrm{x}}$ in comparison to the base point. Advancing SOI timings to $-63^{\circ}$ aTDC causes $\mathrm{HC}, \mathrm{CO}$ and soot to increase and $\mathrm{NO}_{\mathrm{x}}$ to decrease. This is because of a decrease in cylinder gas pressure and retarded combustion phasing that leads to a decrease in cylinder gas temperature. Retarding SOI timing decreases the available time for diesel to mix with gasoline-air mixture. Therefore due to existence of locally rich mixtures, local cylinder gas temperature increases as shown in Figure 4.25 which results in an increase in $\mathrm{NO}_{\mathrm{x}}$ and soot emissions, while causes a decrease in $\mathrm{HC}$ and $\mathrm{CO}$ emissions. The standard ranges of HC and CO emissions based on EPA 2010 emissions regulations for LDV are presented in Appendix D. 

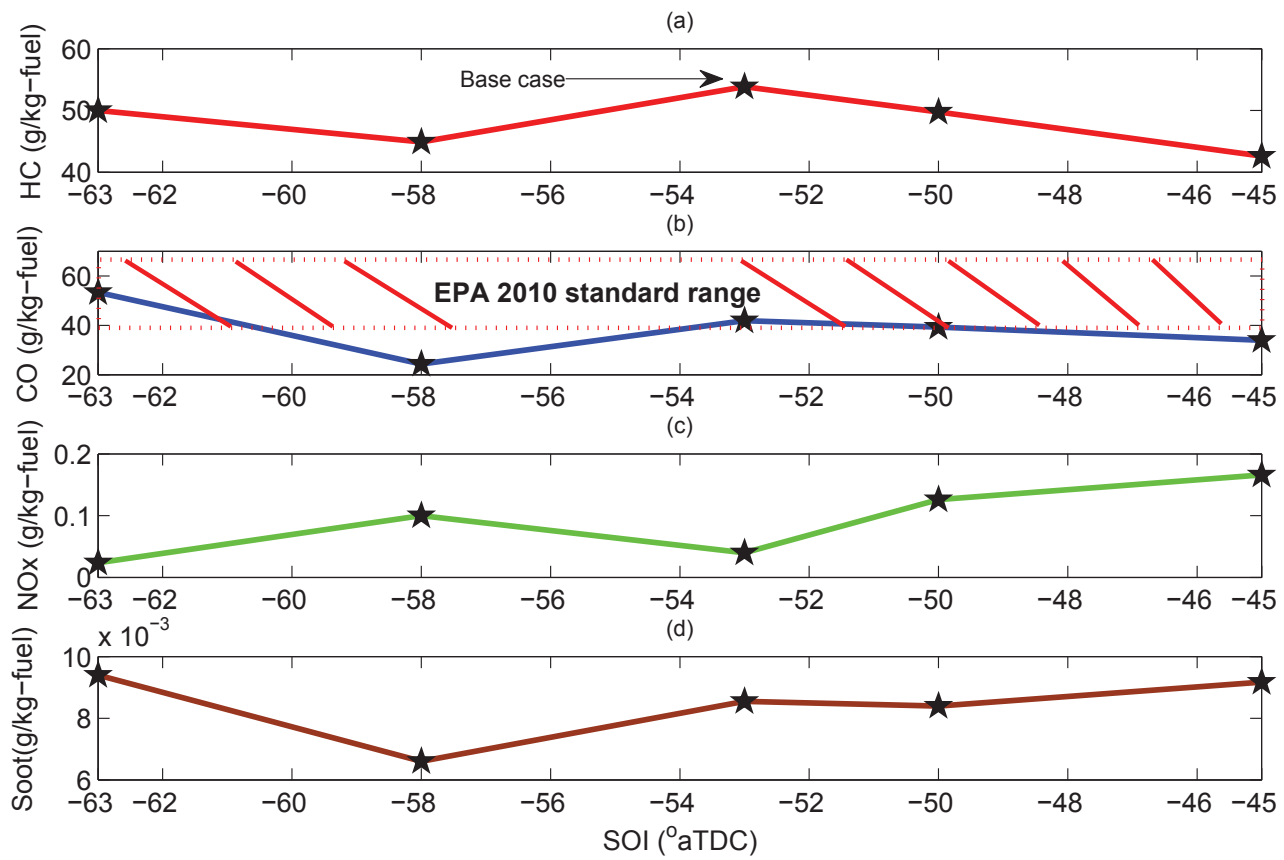

Figure 4.24: Effects of SOI timing sweep on engine-out emissions including $\mathrm{HC}, \mathrm{CO}, \mathrm{NO}_{\mathrm{x}}$ and soot for engine operating condition corresponding to case $a$ in Table 2.3 


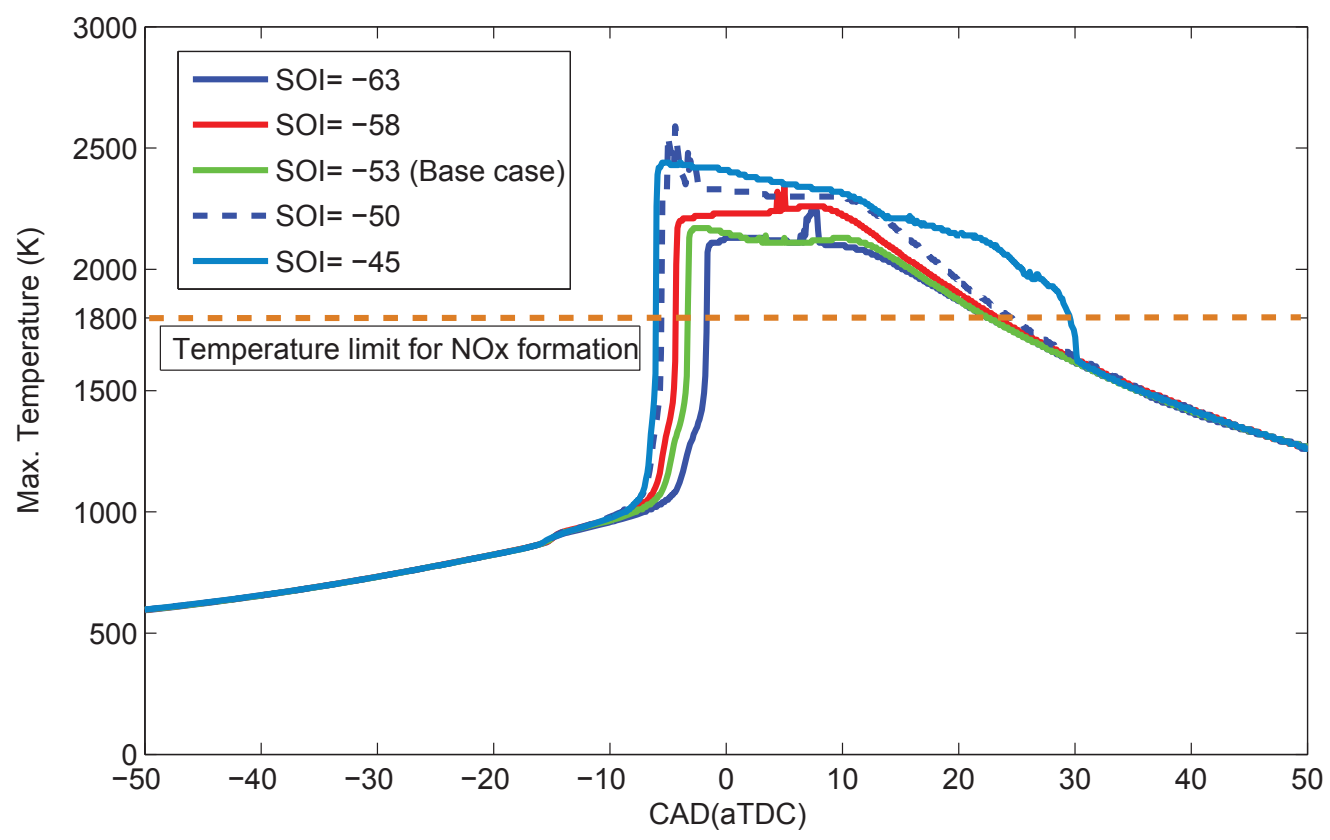

Figure 4.25: Effects of SOI timing sweep on max. in-cylinder gas temperature for engine operating condition corresponding to $\underline{\text { case } a}$ in Table 2.3

Figure 4.26 shows combustion efficiency, gross and net IMEP. As shown in Figure 4.24 SOI timings of $-58^{\circ}$ and $-45^{\circ}$ aTDC have the lowest $\mathrm{HC}$ and $\mathrm{CO}$ emissions. Therefore these SOI timings have the highest combustion efficiencies as seen in Figure 4.26. In general HC and $\mathrm{CO}$ emissions are inversely proportional to combustion efficiency. Higher $\mathrm{HC}$ and $\mathrm{CO}$ emissions yield lower combustion efficiency.

$\mathrm{SOI}=-58^{\circ}$ aTDC has the highest gross and net IMEP while the most early SOI timing has the lowest gross and net IMEP. As mentioned before the area under pressure-volume diagram is directly proportional to gross and net IMEP as well as gross and net indicated 
efficiency.

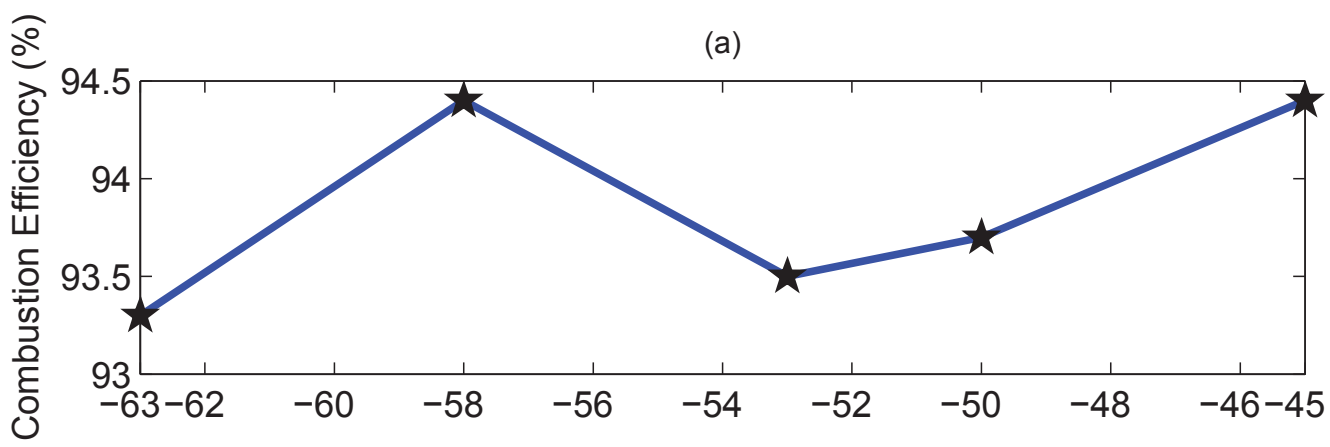

(b)

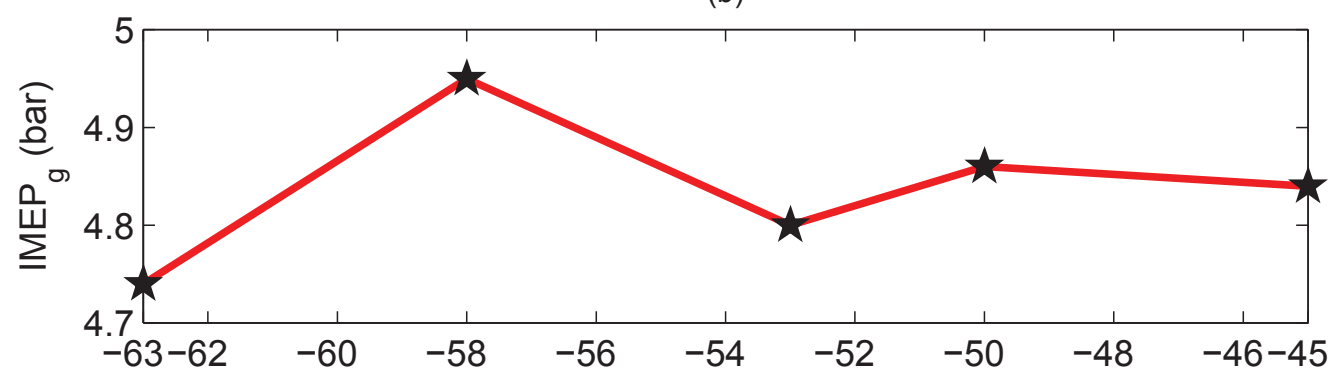

(c)

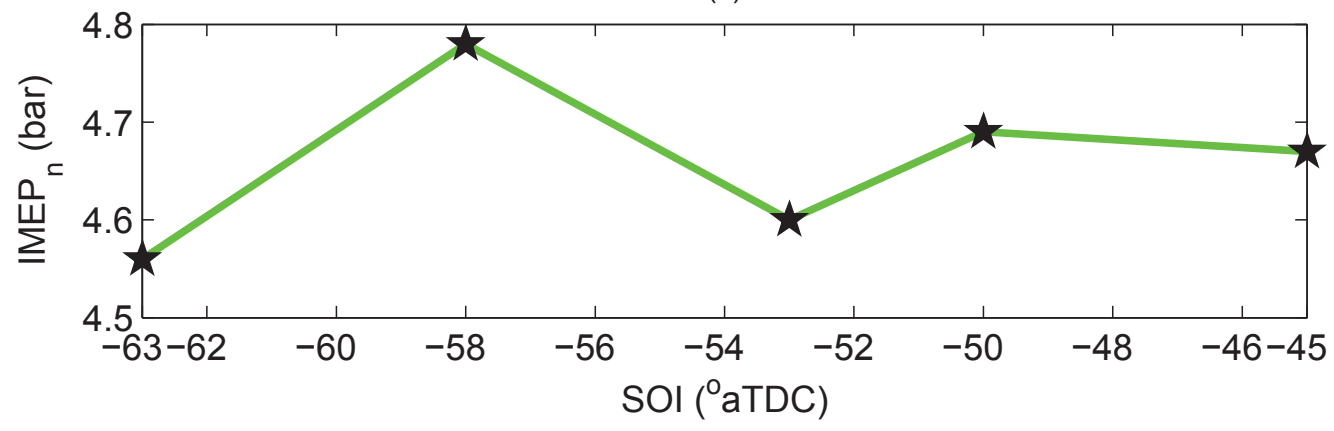

Figure 4.26: Effects of SOI timing sweep on combustion efficiency, $\mathrm{IMEP}_{\mathrm{g}}$ and IMEP $_{\mathrm{n}}$ for engine operating condition corresponding to $\underline{\text { case } a}$ in Table 2.3

Similar trend is seen in Figure 4.27 where the highest gross and net indicated efficiency is achieved at $\mathrm{SOI}=-58^{\circ}$ aTDC while $\mathrm{SOI}=-63^{\circ}$ aTDC has the lowest gross and net efficiency. The maximum variation of gross and net efficincy for different SOI timing sweep is around 
2 percent.

(a)

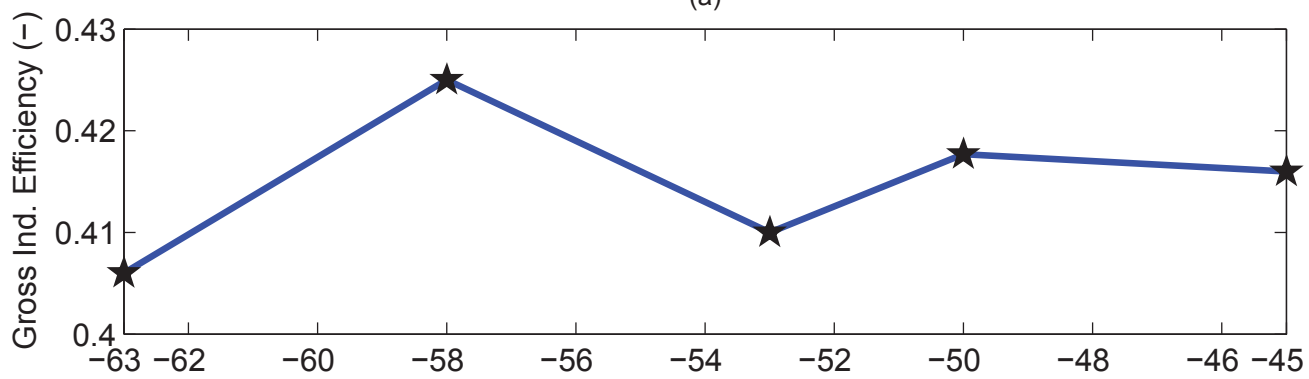

(b)

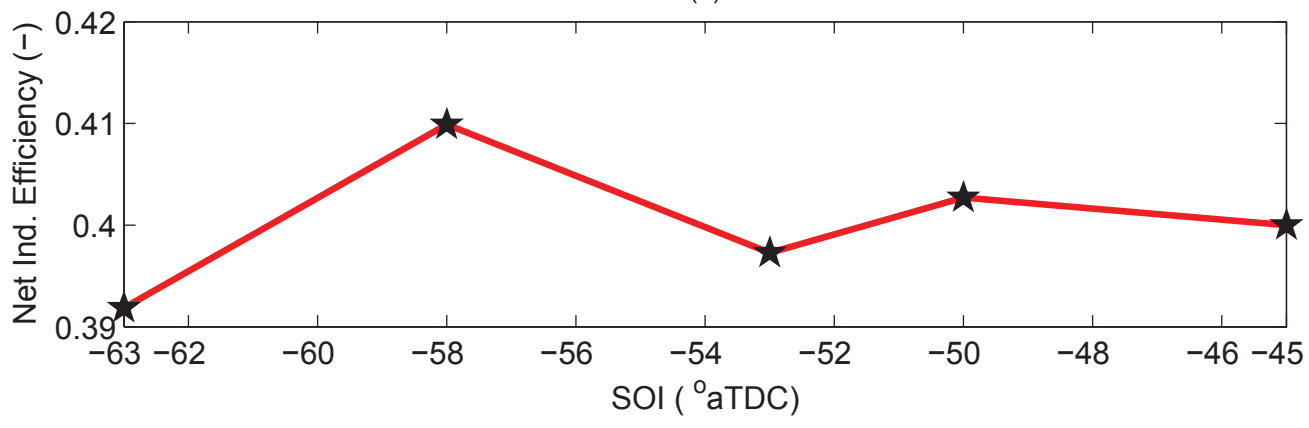

Figure 4.27: Effects of SOI timing sweep on $\eta_{\text {ind.- }}$ and $\eta_{\text {ind } .-n}$ for engine operating condition corresponding to $\underline{\text { case } a}$ in Table 2.3

Figure 4.28 shows the PPRR and ringing intensity as a function of SOI timing. It is observed that the maximum PPRR (around $4.5 \mathrm{bar} / \mathrm{deg}$.) occurs for SOI timings of $-58^{\circ}$ and $-50^{\circ}$ aTDC and $\mathrm{SOI}=-63^{\circ}$ aTDC has the lowest PPRR due to weak combustion. It is seen that $\mathrm{SOI}=-50^{\circ}$ aTDC has the highest ringing intensity. For all SOI timings, the values of ringing intensity are less than the standard value (i.e., $5 \mathrm{MW} / \mathrm{m}^{2}$ ) of combustion free of noise and knock. 
(a)

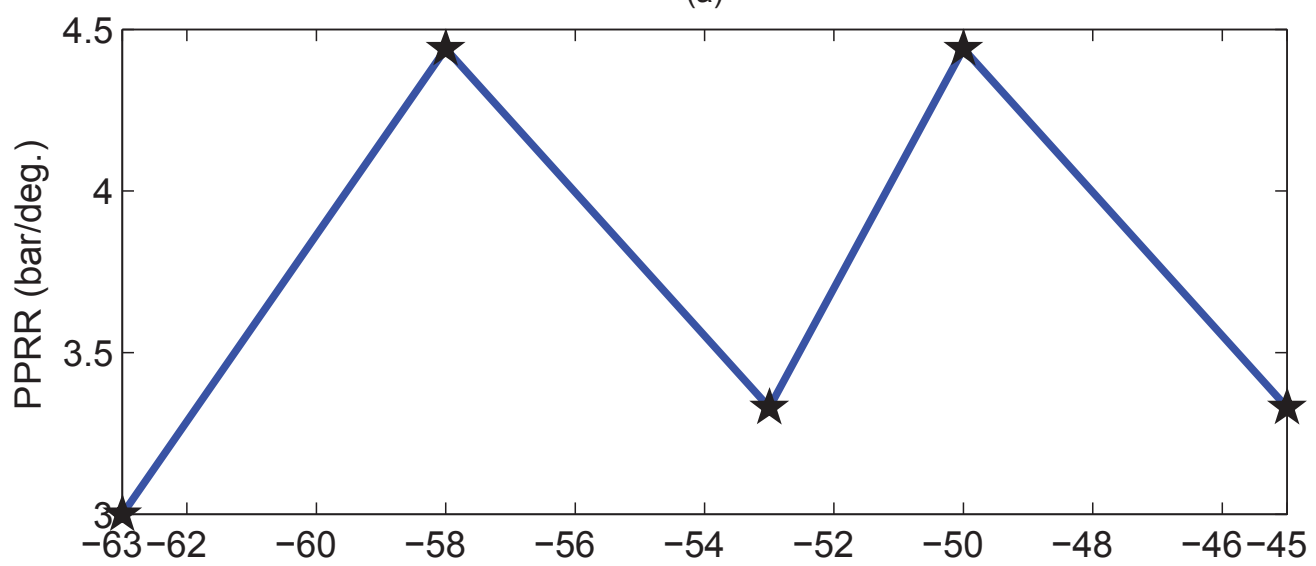

(b)

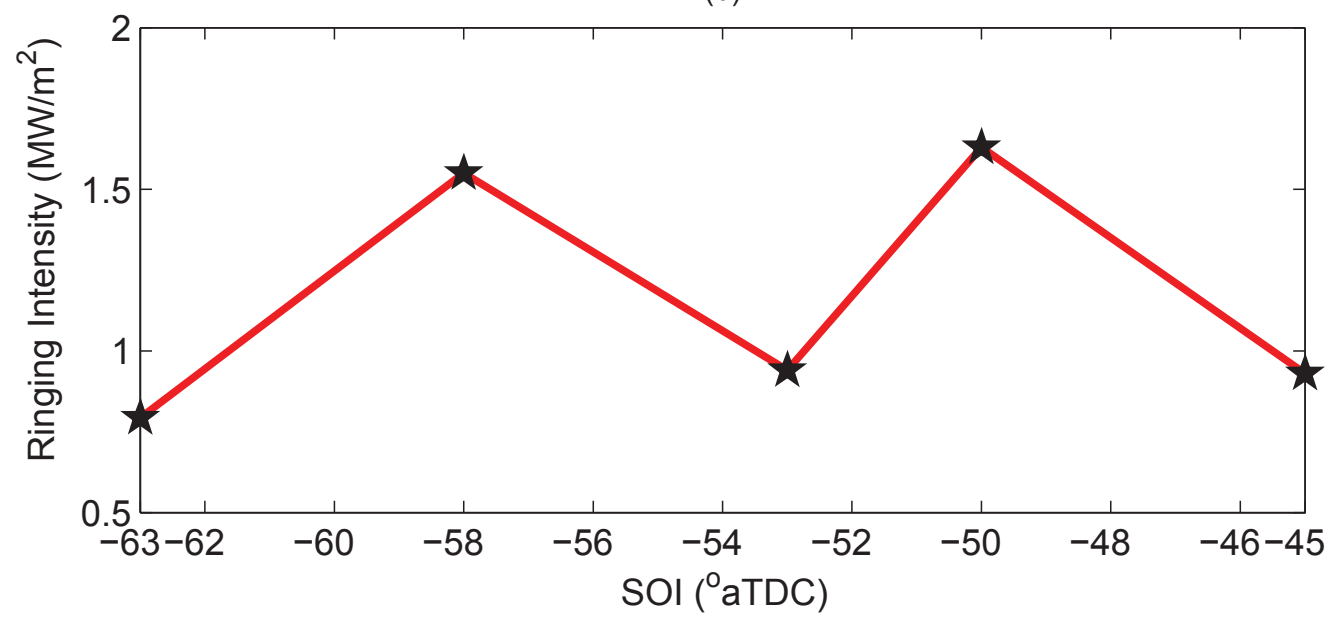

Figure 4.28: Effects of SOI timing sweep on PPRR and ringing intensity for engine operating condition corresponding to case $a$ in Table 2.3 


\subsection{Spray Angle}

In this section the effects of spray angle on the combustion and performance of the RCCI engine is discussed. Spray angle is one of the important parameters that specifies the location of impingement of diesel fuel parcels in the combustion chamber. Therefore choosing an appropriate spray angle can specify how diesel fuel parcels distribute throughout the combustion chamber and as a result have a considerable effect on the combustion and emission characteristics of an RCCI engine.

Figure 4.29 shows injection of diesel fuel parcels from the engine's seven-hole injector at injection pressure of 480 bar. 


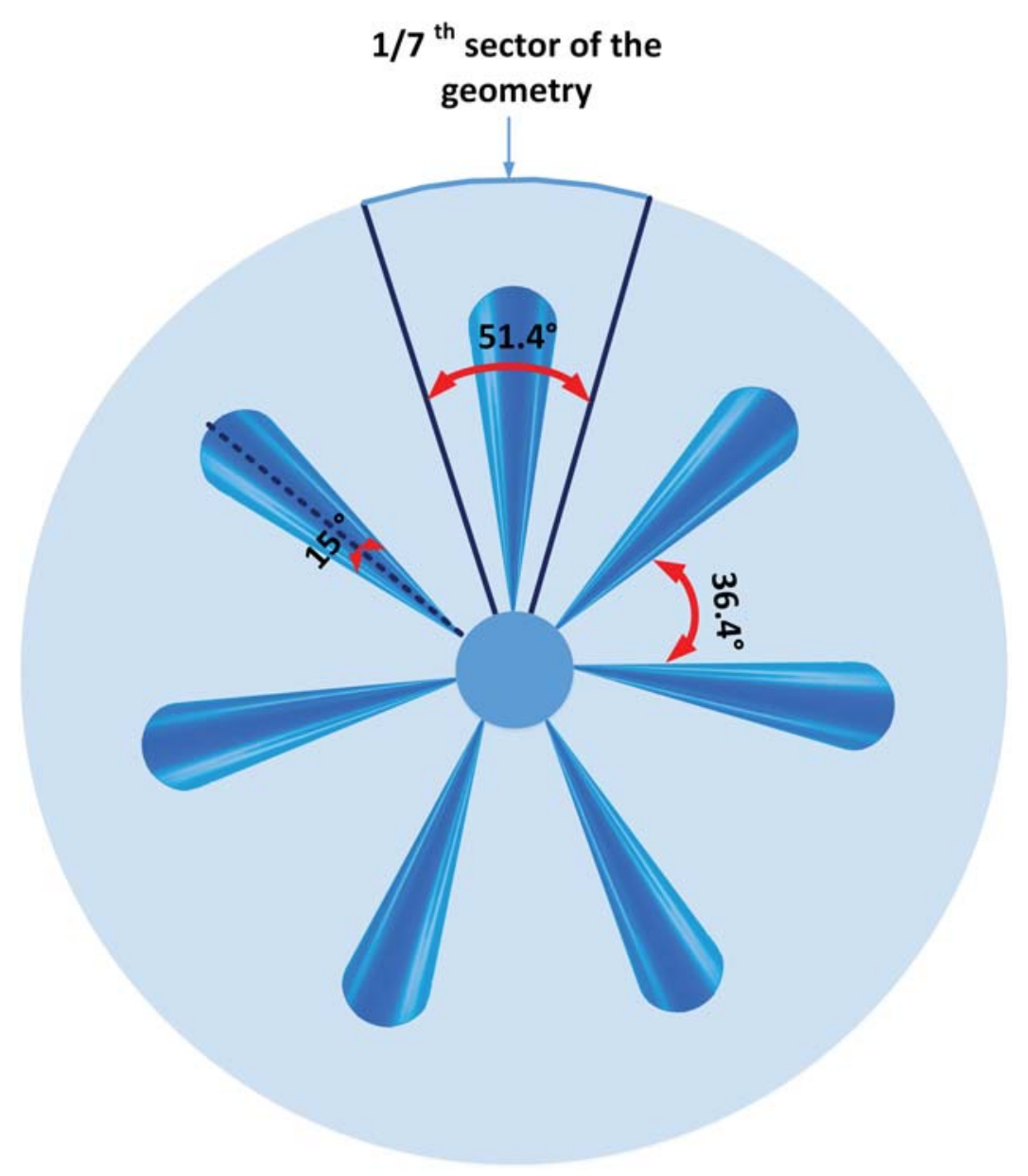

Figure 4.29: Fuel parcels spray from the engine's seven-hole injector at injection pressure of 480 bar.

Figure 4.30 shows different spray angles for the engine sector considered in this study. Spray angle is defined by the angle between the cone axis of diesel fuel parcels with the $\mathrm{Z}$ axis of the cylinder. As will be discussed later the variation in spray angle directly affects how much injected diesel fuel is ended up at squish region or piston bowl. 
a) $\alpha=25$ deg.

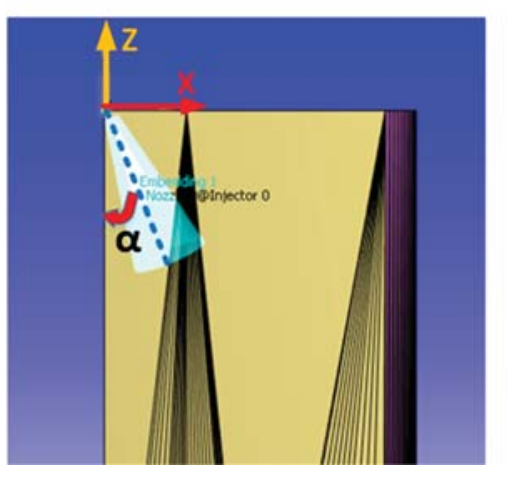

b) $\alpha=45$ deg.

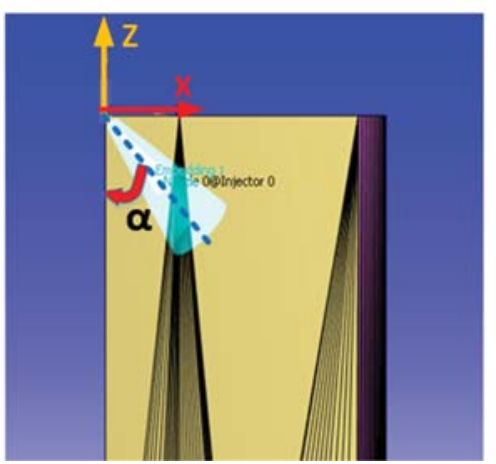

c) $\alpha=65$ deg.

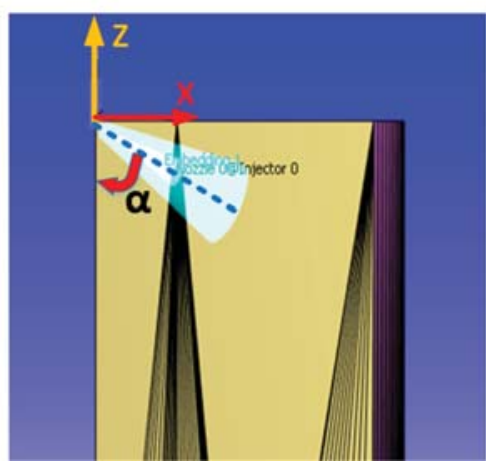

Figure 4.30: Different spray angles for the engine sector studied in this thesis

Figure 4.31 shows variation in cylinder pressure as a function of spray angle. It is observed that decreasing spray angle causes cylinder peak pressure to increase. This is because by decreasing spray angle, diesel fuel targets piston bowl where the surface temperature is high in comparison to the squish region, therefore peak cylinder pressure increases. The base point spray angle $\left(74^{\circ}\right)$ has the lowest peak cylinder pressure. Variations in spray angle have significant effect on cylinder pressure. Decreasing spray angle by around $50^{\circ}$ leads to 20 bar change in peak cylinder pressures. 


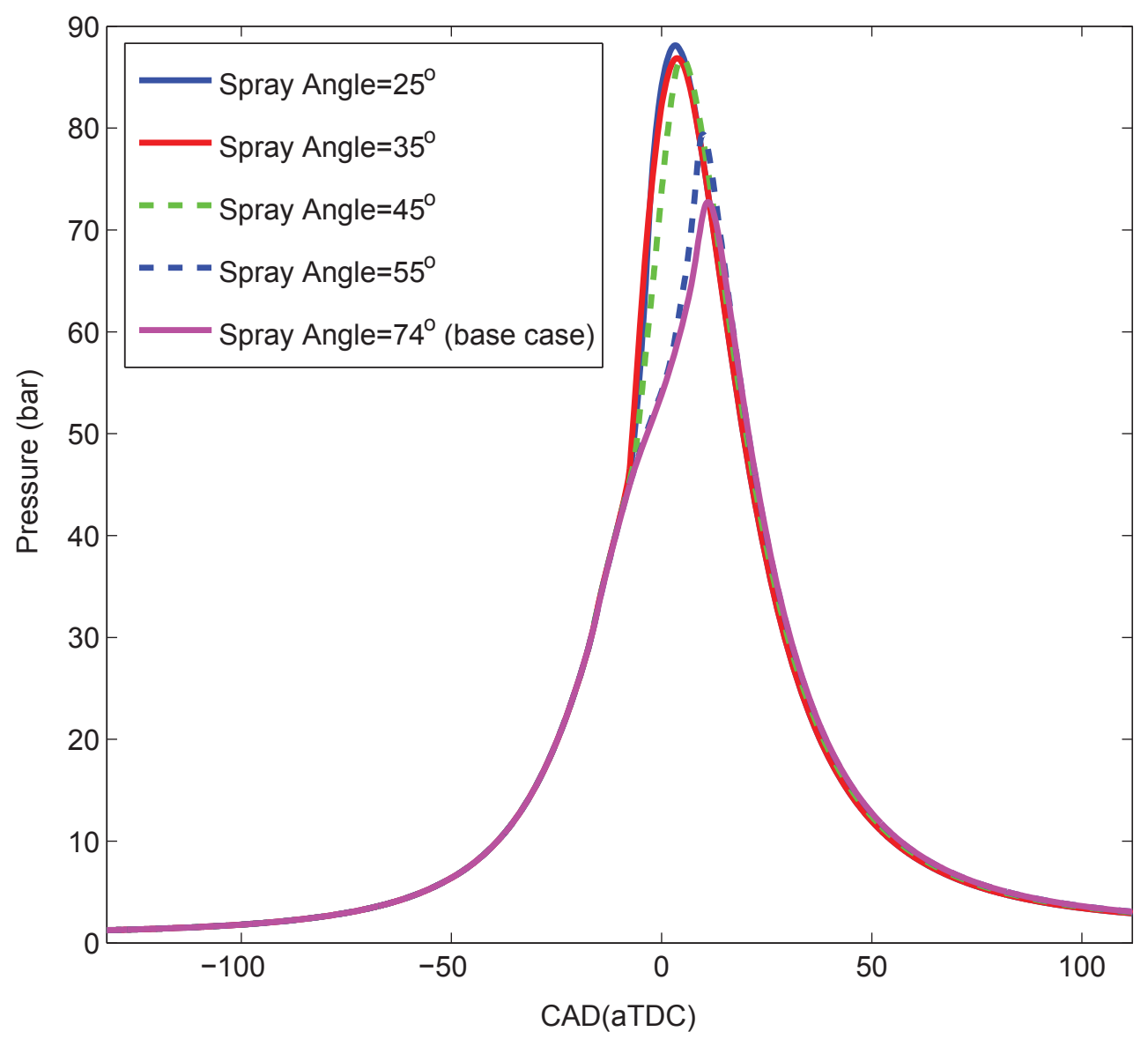

Figure 4.31: Effects of spray angle on in-cylinder pressure for engine operating condition corresponding to case a in Table 2.3

Figure 4.32 shows HRR for different spray angles. It is seen that at spray angle of $55^{\circ}$ the highest peak HRR is achieved. The variation of peak HRR for different spray angles can be explained by diesel fuel parcels distribution and mixing with gasoline-air mixture. Although piston bowl impingement is more desired than piston top impingement or cylinder liner impingement due to higher temperature of piston bowl, in the cases with 
smaller spray angles, it is possible that some droplets are attached to the piston surface due to the spray impingement as seen in Figure 4.33 for spray angles $25^{\circ}, 35^{\circ}$ and $45^{\circ}$ at crank angle $=-12^{\circ}$ aTDC. This happens when the incident angle of the impinging droplets is perpendicular to the piston bowl surface $[73,74]$. Therefore under this condition diesel parcels cannot mix with gasoline-air mixture perfectly and results in lower peak HRR as seen in Figure 4.32 for spray angles $25^{\circ}$ and $35^{\circ}$.

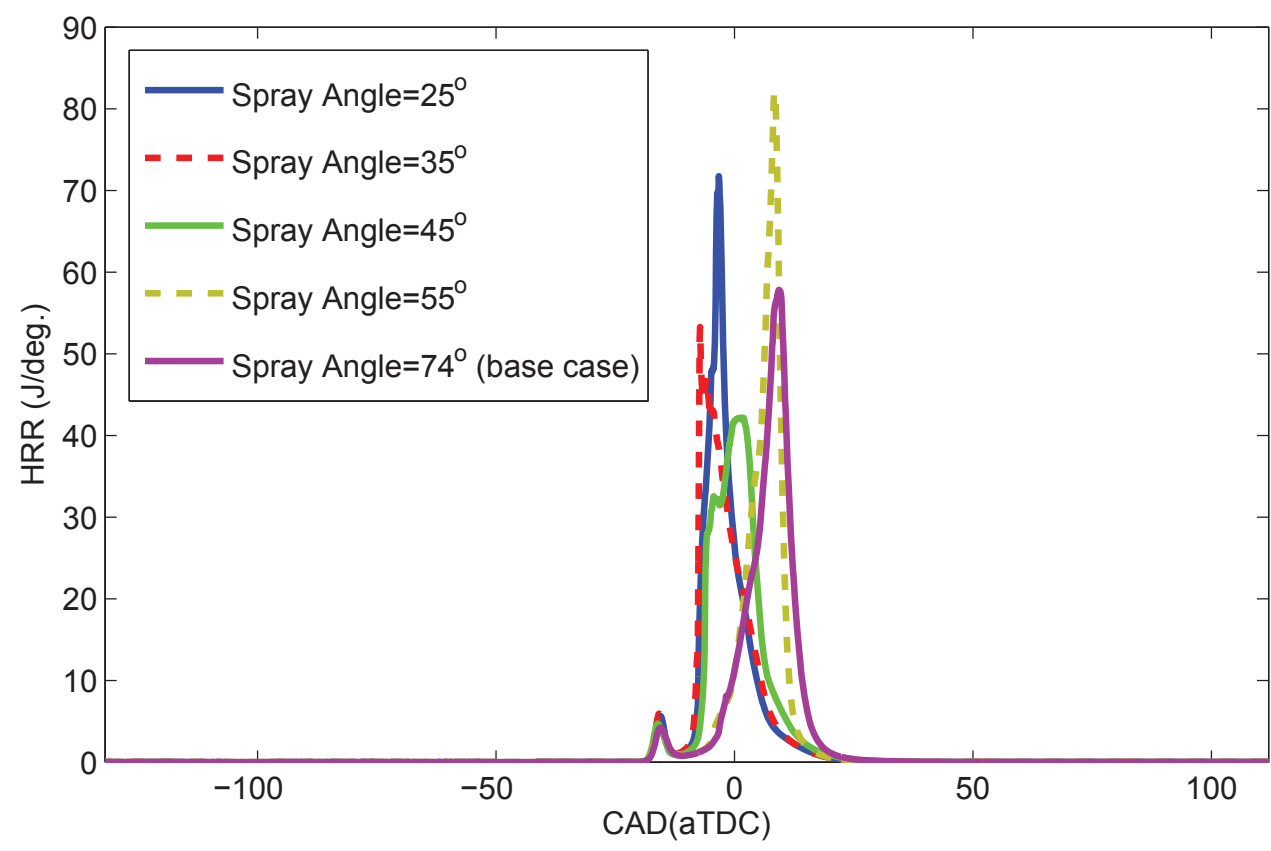

Figure 4.32: Effects of spray angle on Heat Release Rate (HRR) for engine operating condition corresponding to case a in Table 2.3 

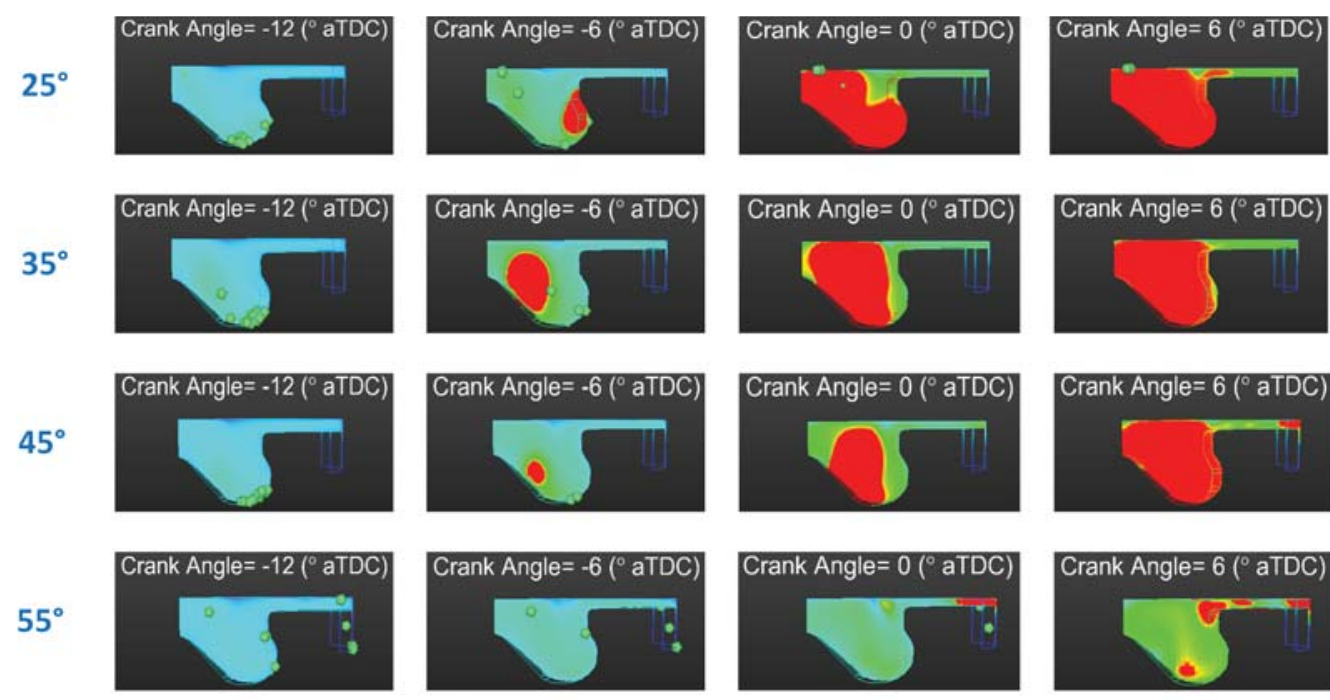

$74^{\circ}$ (Base case)
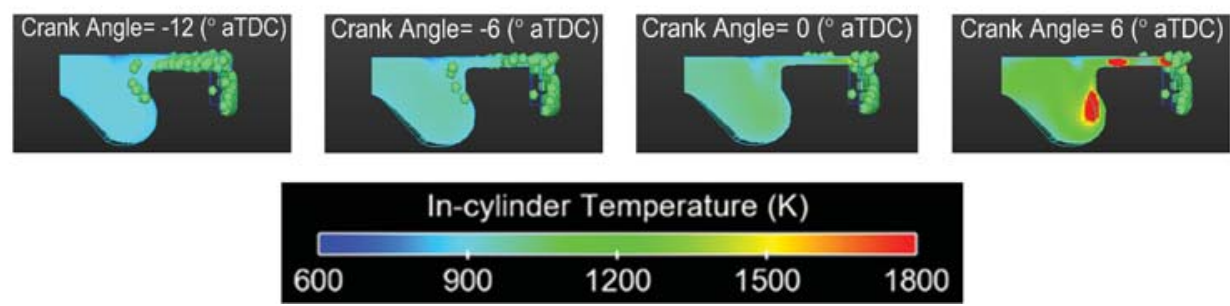

Figure 4.33: Cylinder temperature cut planes at 4 crank angles for each of the studied spray angles for engine operating condition corresponding to case $a$ in Table 2.3. Fuel parcels are shown by green color pentagons.

Combustion phasing for different spray angles is shown in Figure 4.34. In general, it is seen that using wider spray angles result in delayed combustion phasing (CA10, CA50 and CA90). It is observed that $50^{\circ}$ change in spray angle can result in variation of CA10, CA50, CA90 and BD by around 7, 10, 7.5 and 3 CAD, respectively. Therefore spray angle can be considered as a major injector design parameter to affect combustion phasing and rate of heat release. 
(a)

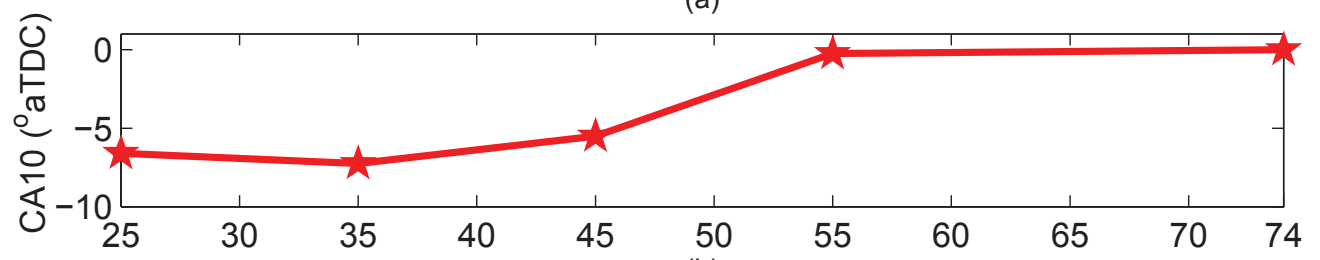

(b)

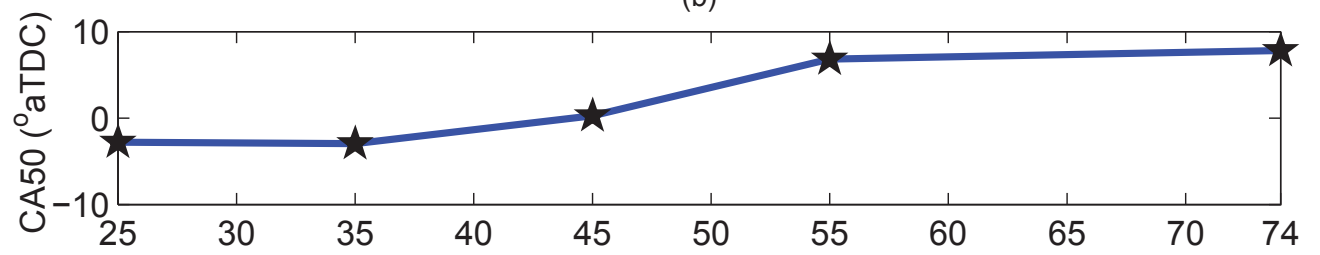

(c)

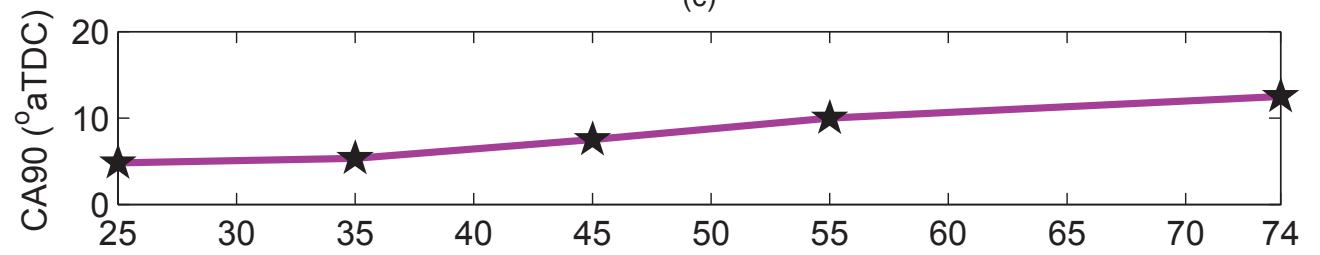

(d)

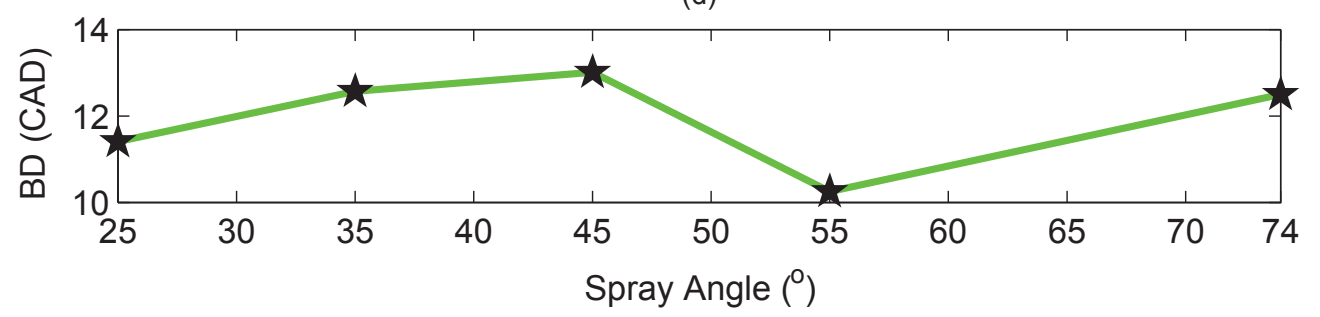

Figure 4.34: Effects of spray angle on combustion phasing (CA10, CA50, CA90, BD) for engine operating condition corresponding to case $a$ in Table 2.3

Figure 4.35 shows variation of engine-out emissions $\left(\mathrm{HC}, \mathrm{CO}, \mathrm{NO}_{\mathrm{x}}\right.$ and soot) for different spray angles. It is observed that narrower spray angles (i.e. $25^{\circ}, 35^{\circ}$ ) have higher values of $\mathrm{HC}$ and $\mathrm{CO}$ emissions. The reason is that for wider spray angles (i.e. $55^{\circ}$ and $74^{\circ}$ ) the diesel fuel targets the squish region; thus, the auto-ignition points will initiate and propagate in the squish region and near the cylinder liner. This causes complete consumption of the fuel 
in the squish region. While narrower spray angles cause the hydrocarbons to be consumed near the cylinder centerline. However by choosing this spray angle hydrocarbons cannot be burned or partially burned near the liner. This is because the diesel fuel with high reactivity targeting the piston bowl and not targeting the squish region as seen in Figure 4.33. Having $\mathrm{HC}$ near the cylinder liner resulted in greater $\mathrm{HC}$ emissions, because the liner is at the greatest cylinder radius, and therefore occupies a greater total volume when revolved about the cylinder axis [33]. The standard ranges of $\mathrm{HC}$ and $\mathrm{CO}$ emissions based on EPA 2010 emissions regulations for LDV are presented in Appendix D.

Figure 4.35 also shows that narrower spray angles yield greater $\mathrm{NO}_{\mathrm{x}}$ emissions due to higher cylinder gas temperatures. Figure 4.36 shows maximum cylinder gas temperature among all cells at each crank angle for different spray angles. It is observed that maximum cylinder gas temperature at spray angle $=35^{\circ}$ is the highest while for case with spray angle $=$ $74^{\circ}$ is the lowest. Cases with narrower spray angles (i.e. $25^{\circ}, 35^{\circ}, 45^{\circ}$ ) are not able to meet $\mathrm{NO}_{\mathrm{x}}$ emission regulation ( $1 \mathrm{~g} / \mathrm{kg}$-fuel) while for all different spray angles soot emission is well below the regulated soot emission limit of $0.25 \mathrm{~g} / \mathrm{kg}$-fuel. 
(a)
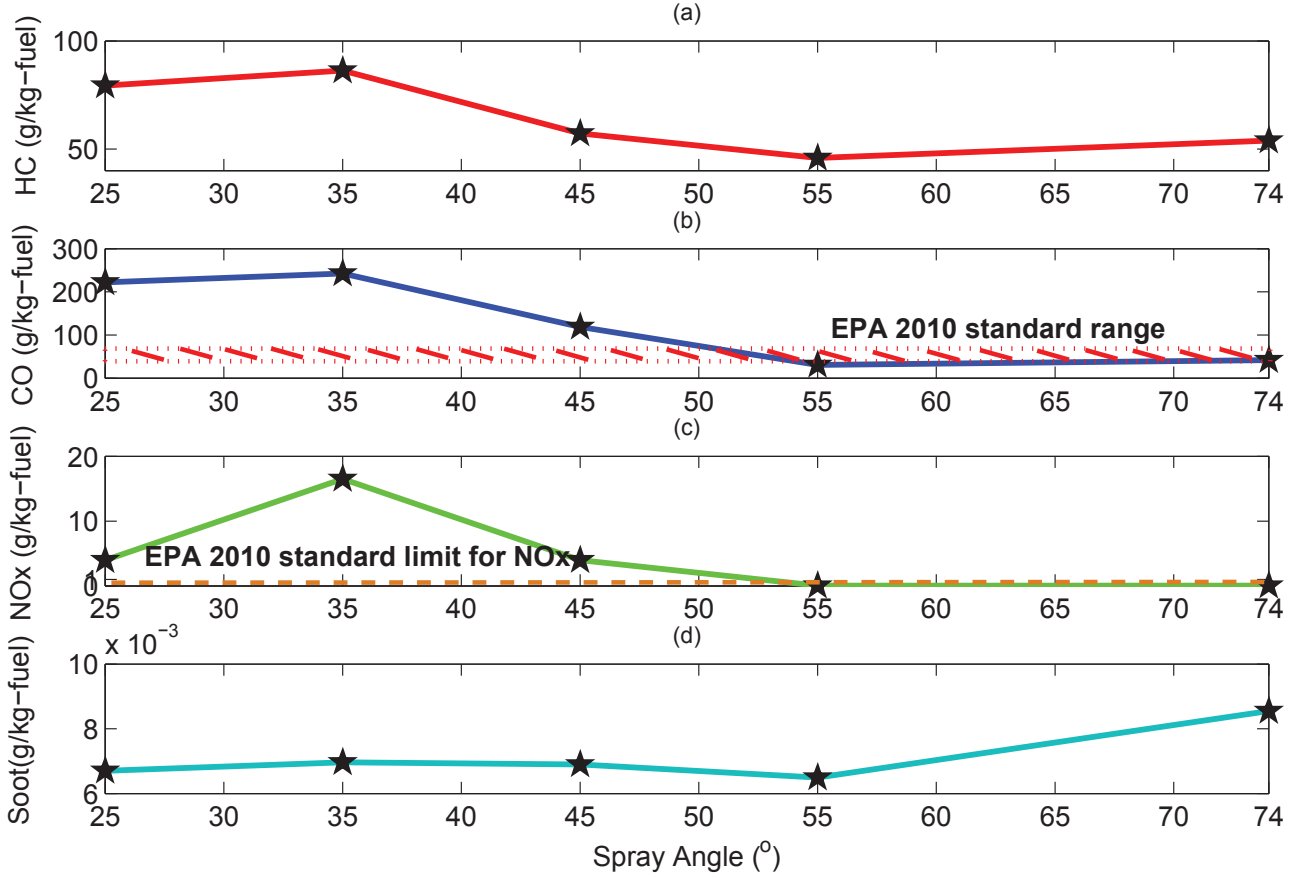

Figure 4.35: Effects of spray angle on engine-out emissions including $\mathrm{HC}$, $\mathrm{CO}, \mathrm{NO}_{\mathrm{x}}$ and soot for engine operating condition corresponding to case a in Table 2.3 


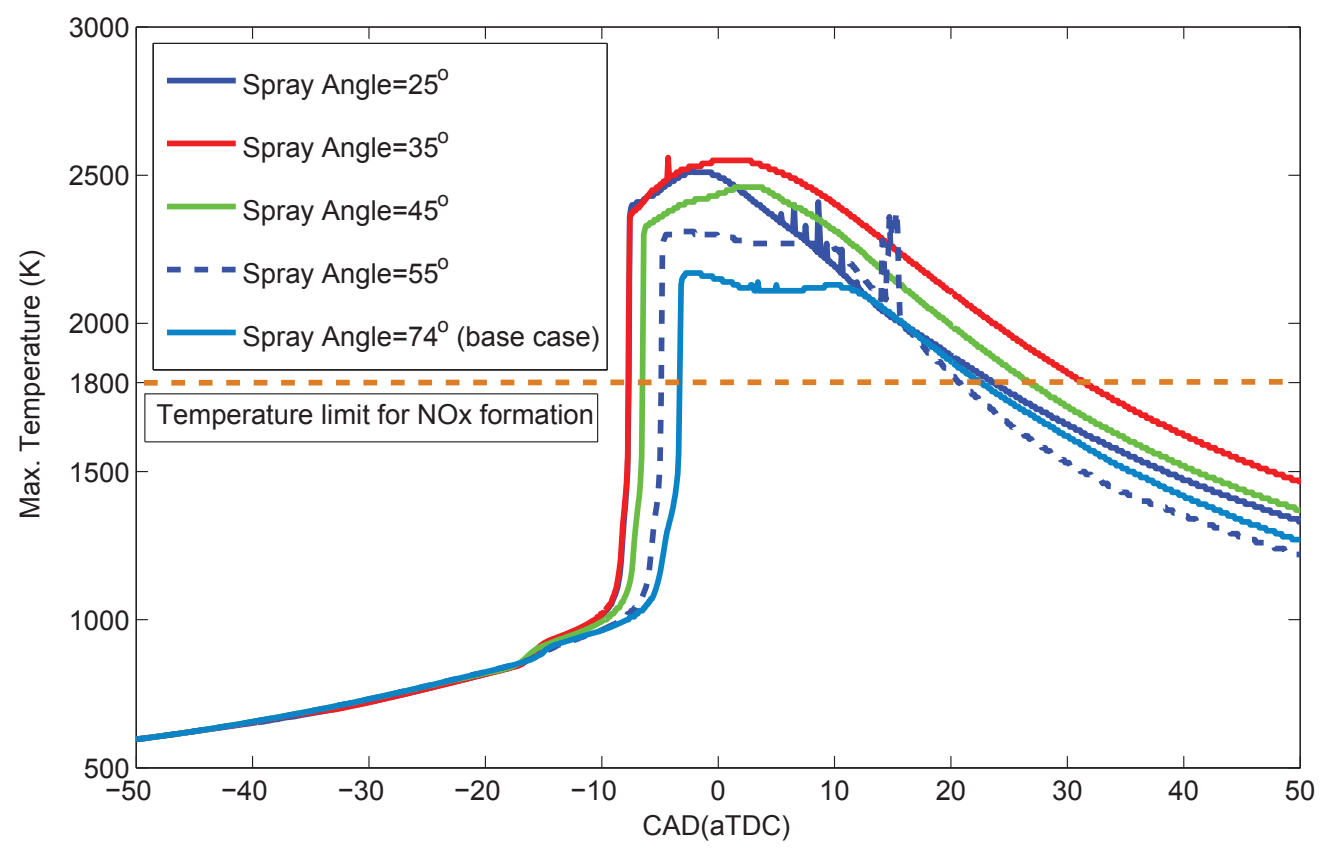

Figure 4.36: Effects of spray angle on max. in-cylinder gas temperature for engine operating condition corresponding to case a in Table 2.3

Combustion efficiency, gross and net IMEP are shown in Figure 4.37. It is seen that at operating point with spray angle of $55^{\circ}$ the highest combustion efficiency (near 95\%) is achieved. This is consistent with Figure 4.35 where the case with spray angle of $55^{\circ}$ has the lowest values of $\mathrm{HC}$ and $\mathrm{CO}$ emissions. As expected the case with spray angle of $35^{\circ}$ has the lowest combustion efficiency due to the highest values of $\mathrm{HC}$ and $\mathrm{CO}$ emissions.

The area under the pressure-volume diagram for the case with spray angle of $55^{\circ}$ is the highest and for spray angle of $35^{\circ}$ is the lowest. Therefore it is expected to have the highest and lowest gross and net IMEP at spray angles of $55^{\circ}$ and $35^{\circ}$, respectively. Strong 
auto-ignition occurs at spray angles $=25^{\circ}$ and $35^{\circ}$. However, combustion phasing for these cases are too early which results in negative work; thus gross and net IMEP are lowest.
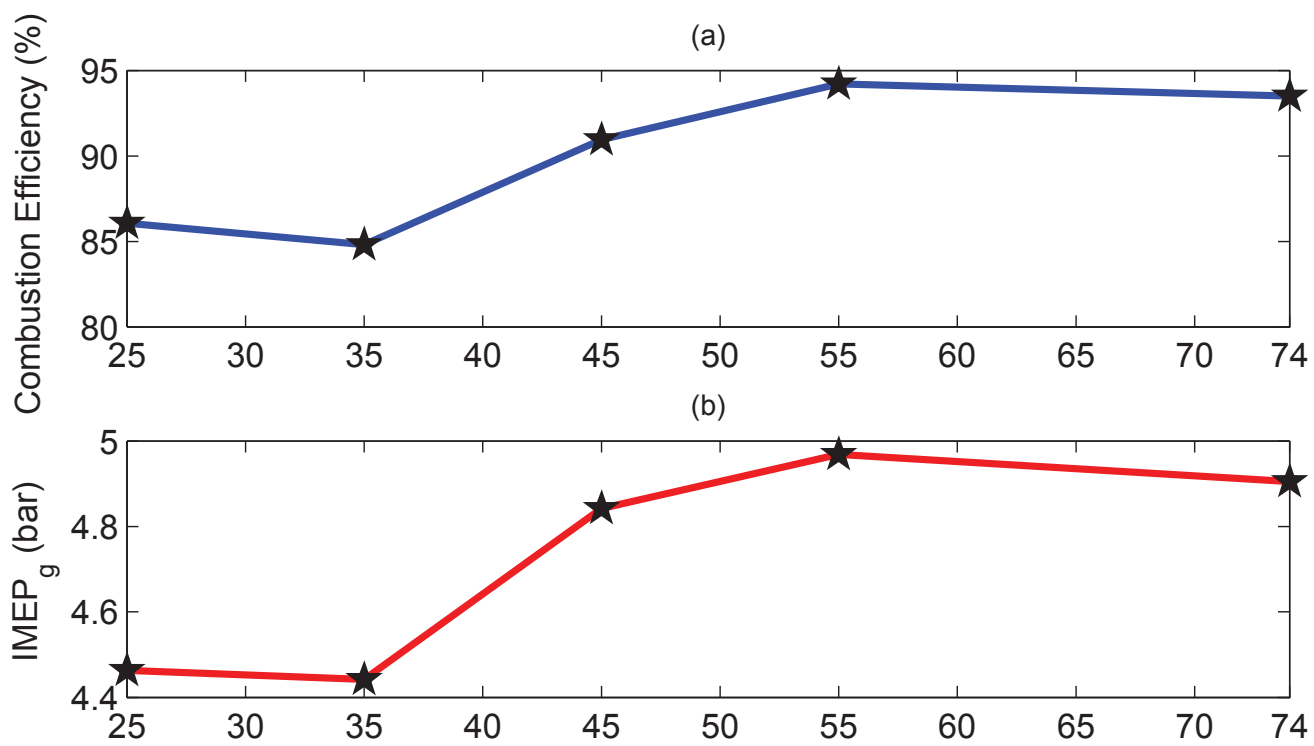

(c)

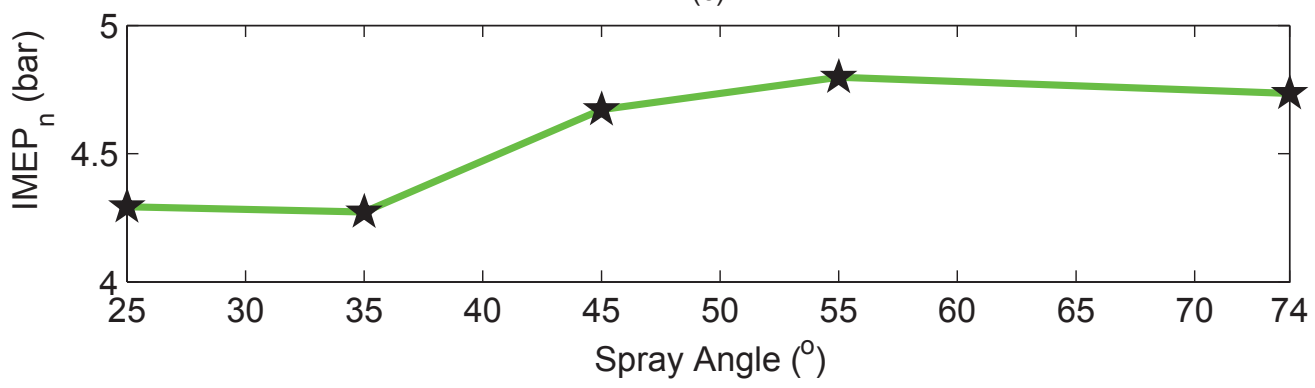

Figure 4.37: Effects of spray angle on combustion efficiency, $\mathrm{IMEP}_{\mathrm{g}}$ and $\mathrm{IMEP}_{\mathrm{n}}$ for engine operating condition corresponding to case $a$ in Table 2.3

The similar trend to that of Figure 4.37 is observed in Figure 4.38 for gross and net indicated efficiencies. The case with spray angle of $55^{\circ}$ has the highest gross and net indicated efficiencies (around $43 \%$ and $41 \%$, respectively), while the case with spray angle of $35^{\circ}$ has the lowest ones (around 38\% and 36.5\%, respectively). It is clearly seen that changing 
spray angle causes a significant variation $(\approx 5 \%)$ in gross and net indicated efficiency.

(a)

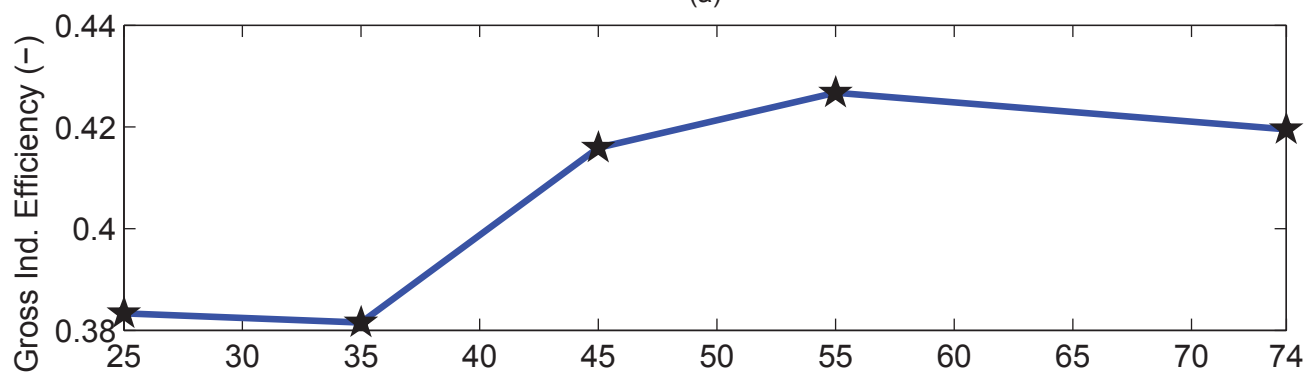

(b)

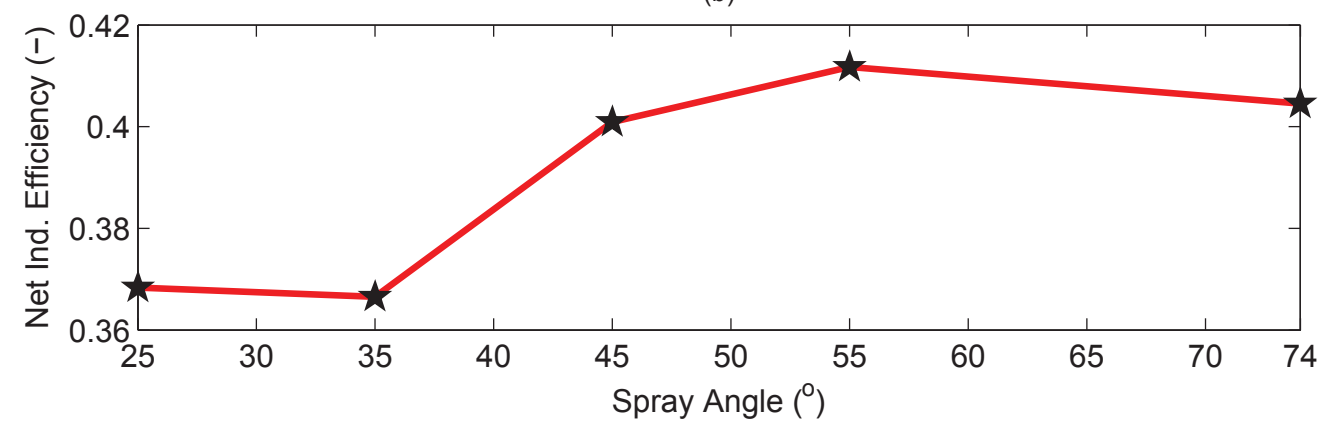

Figure 4.38: Effects of spray angle on $\eta_{\text {ind.-g }}$ and $\eta_{\text {ind.- } n}$ for engine operating condition corresponding to case $a$ in Table 2.3

Figure 4.39 shows PPRR and ringing intensity as a function of spray angle. It is observed that by increasing spray angle PPRR decreases. The case with spray angle of $74^{\circ}$ has the lowest PPRR around $3.3 \mathrm{bar} / \mathrm{deg}$ and the case with spray angle of $25^{\circ}$ has the maximum PPRR around 9 bar/deg. Similarly the ringing intensity decreases as spray angle increases. For all spray angle sweep except for spray angle of $25^{\circ}$, the values of ringing intensities are less than the standard value $5 \mathrm{MW} / \mathrm{m}^{2}$ of combustion free of noise and knock. Considering all combustion and performance characteristics of engine for different spray angles, it is concluded that the case with spray angle of $55^{\circ}$ is the optimum spray angle for the RCCI 
engine operation with the baseline SOI and injection pressure in this study.

(a)

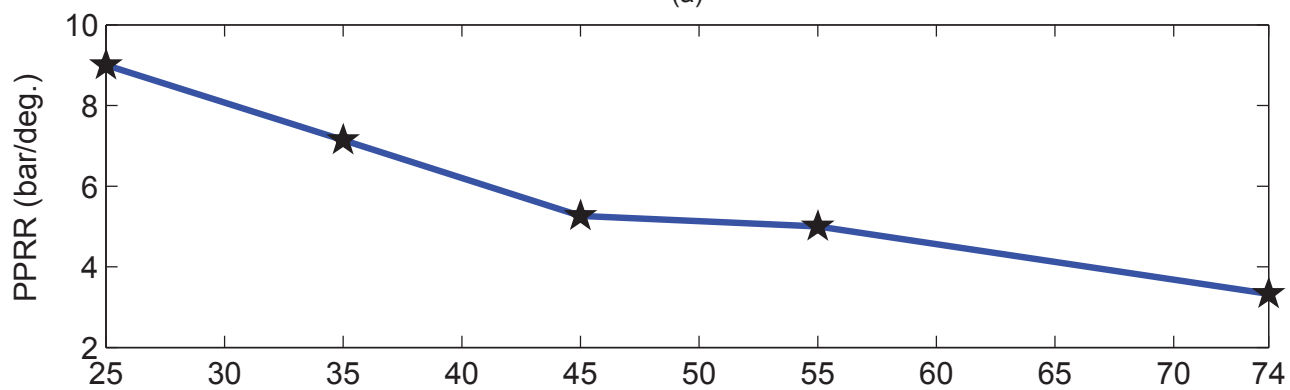

(b)

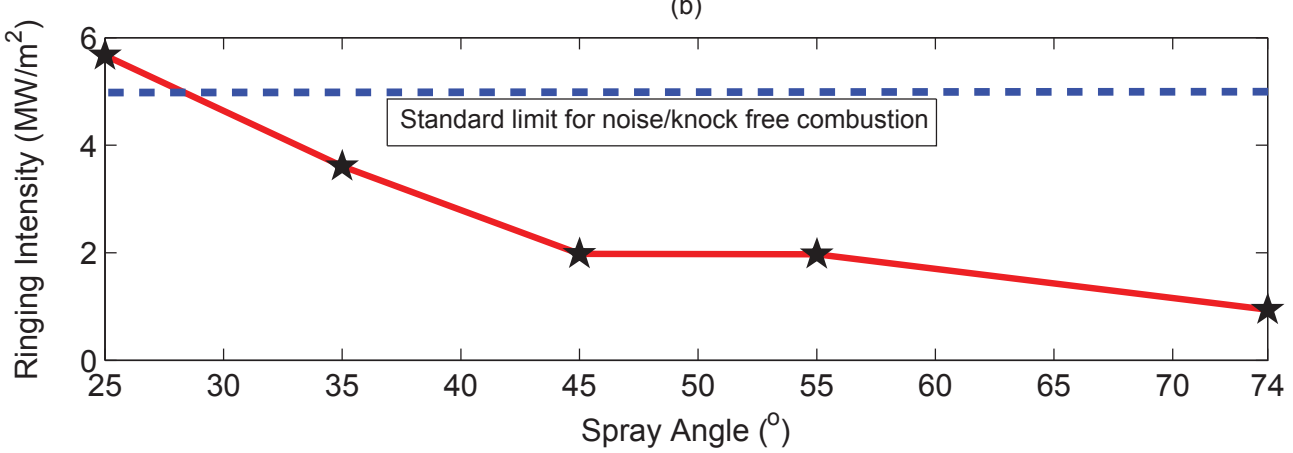

Figure 4.39: Effects of spray angle on PPRR and ringing intensity for engine operating condition corresponding to case a in Table 2.3

Given diesel fuel is injected far before TDC in typical RCCI strategies; therefore, the injected diesel fuel will impinge the wall and creates fuel film on cylinder walls. In addition, part of injected fuel will be trapped in the crevice region where the temperature is significantly lower than other regions in the combustion chamber. Decreasing the spray angle by $19^{\circ}$ avoids the wall impingement of the diesel fuel, as a result more fuel is burned during the combustion process and combustion efficiency will increase. 


\subsection{Summary of injection system parameters}

In this section, the summary of optimum injection system parameters to achieve desirable RCCI engine performance is presented. To compare operating points, all the simulation data points are grouped into three categories in Table 4.1. Group 1/dark green indicates the best engine performance while group 3/yellow shows the worst engine performance. Engine performance points are ranked based on obtained gross indicated and combustion efficiencies, minimum engine-out emissions and ringing intensity. As mentioned previously, $2010 \mathrm{EPA}$ limits for $\mathrm{NO}_{\mathrm{x}}$ and soot are 1 and $0.25 \mathrm{~g} / \mathrm{kg}$-fuel, respectively and the standard limit for combustion free of noise and knock is $5 \mathrm{MW} / \mathrm{m}^{2}$. These limits have been considered in dividing the points into three categories in Table 4.1.

Table 4.1

Classification of RCCI engine points to find optimum injection system parameters.

\begin{tabular}{lccccccc}
\hline \hline Category & $\eta_{c}$ & $\eta_{\text {ind }-g}$ & $\mathrm{HC}$ & $\mathrm{CO}$ & soot & $\mathrm{NO}_{\mathrm{x}}$ & $\mathrm{RI}$ \\
$\#$ & $(\%)$ & $(\%)$ & & $(\mathrm{g} / \mathrm{kg}-$ fuel $)$ & & $\left(\mathrm{MW} / \mathrm{m}^{2}\right)$ \\
\hline \hline 1/dark green & $94-95$ & $42-43$ & $<48$ & $<42$ & $<0.25$ & $<1$ & $<5$ \\
2/light green & $90-94$ & $40-42$ & $<57$ & $<120$ & $<0.25$ & $<4$ & $<5$ \\
3/yellow & $84-90$ & $38-40$ & $<87$ & $<243$ & $<0.25$ & $<17$ & $<6$ \\
\hline
\end{tabular}




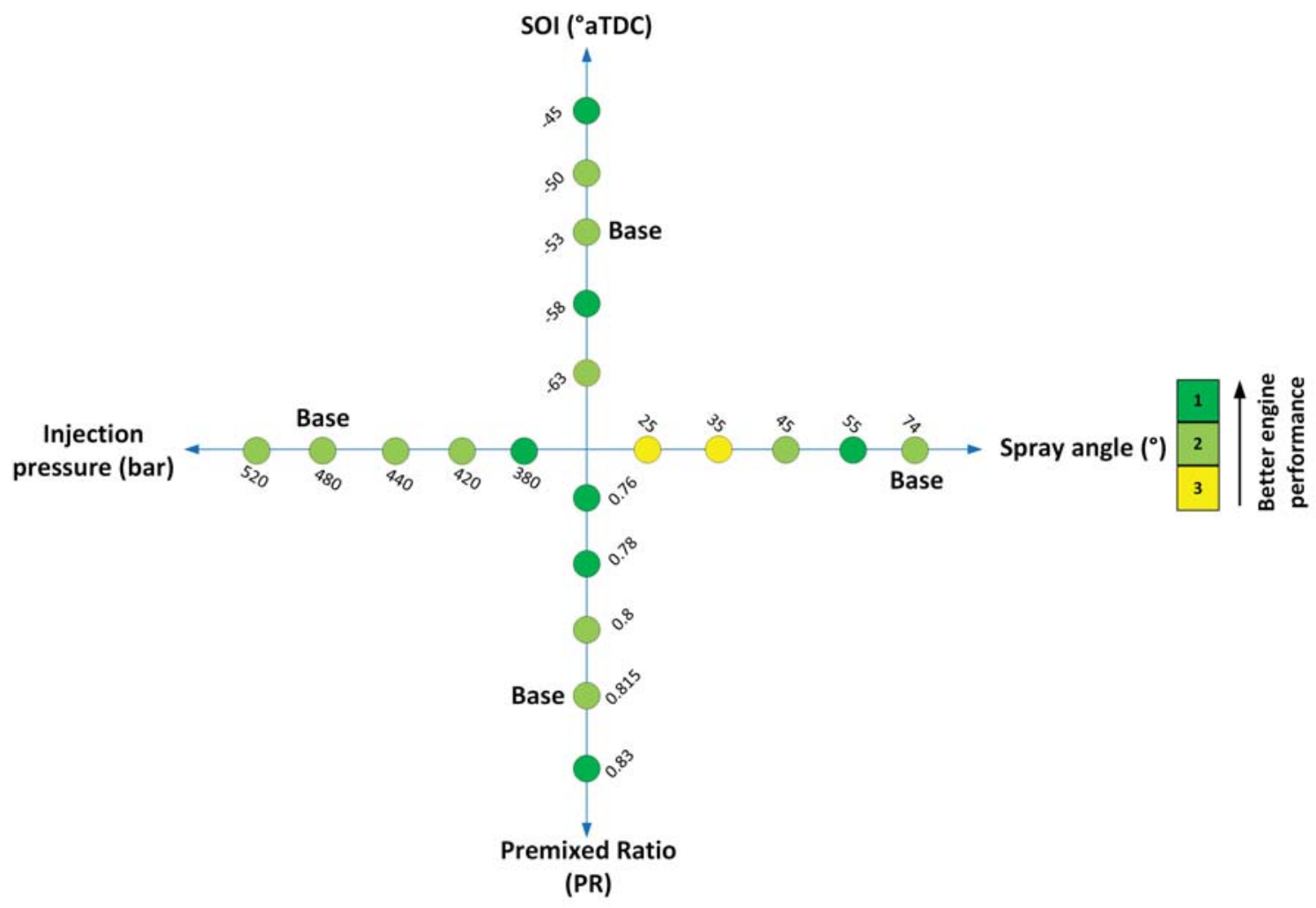

Figure 4.40: Classification of fuel injection system parameters based on engine performance metrics in Table 4.1.

Figure 4.40 shows optimum fuel injection system parameters based on three categories for engine performance metrics in Table 4.1. It is important to note that Figure 4.40 looks into individual parameters and does not consider inter effects of the injection system parameters on each other. Future work may include use of Design of Experiment (DOE) methods to define simulation test matrix in order to find an optimum combination of injection system parameters. 


\section{Chapter 5}

\section{Summary and Conclusion}

Three major areas are focused upon, which are considered to be the core parts of this thesis. First is the development of the zero-dimensional single zone combustion model

in CHEMKIN ${ }^{\circledR}-\mathrm{PRO}$ which was validated against the experimental data for predicting SOC in the RCCI engine. Second is the development of 3D/CFD combustion model in commercial CFD code called CONVERGE which was validated with experimental data to predict performance and emission characteristics of the RCCI engine. Finally, the effects of key fuel injection system parameters on the combustion and performance of the RCCI engine were studied and discussed in detail. 


\subsection{Summary of thesis contributions}

The summary of thesis contributions is as follows:

* A computationally efficient 0-D single zone combustion model was developed in CHEMKIN $^{\circledR}$ - PRO and validated against the experimental data. The model is capable to predict SOC (i.e., CA10) with an average error around $1 \mathrm{CAD}$. The processing time of the model is around 2 minutes in an Intel Core i5 processor with 4 GB RAM. This model assumed that the mixture is homogeneous and all combustion chamber is considered as one uniform zone, and consequently all air-fuel mixture is combusted spontaneously. Therefore, this model overpredicts peak in-cylinder pressure and underpredicts BD. Overall, the developed 0-D model is accurate and computationally efficient in predicting SOC, but a detailed CFD model is required to predict CA50, BD and emissions.

* A detailed 3D/CFD combustion model was developed and validated against the experimental data. The results showed that the model is capable to predict combustion phasing (CA10 and CA50) with error less than 1 CAD. The model average errors in predicting CA90 and BD are around 4 CAD. The difference in experiment and simulation for predicting CA90 and BD can be due to uncertainties exist in the heat transfer model utilized in the detailed CFD model. It was observed that the model is capable to predict $\mathrm{HC}$ and $\mathrm{CO}$ emissions for case (a) in Table 2.3 with an average error around 16.5 
g/kg-fuel. High $\mathrm{HC}$ and $\mathrm{CO}$ emissions were observed for cases (b) and (c) due to injecting high amount of diesel fuel and its impingement with cylinder wall. Due to uncertainties exist for choosing cylinder wall temperature and ignoring blow-by gas in simulation, the amounts of $\mathrm{HC}$ and $\mathrm{CO}$ emissions for cases (b) and (c) are greater than experimental values. Moreover, it was found that the model was unable to predict $\mathrm{NO}_{\mathrm{x}}$ emission accurately. This is because the extended Zel'dovich mechanism utilized for predicting $\mathrm{NO}_{\mathrm{x}}$ is mainly useful for diesel engines with high combustion temperatures. Therefore for our cases of study with maximum cylinder temperature less than $1800 \mathrm{~K}$, the predicted values are less than experimental ones.

* The effects of PR, injection pressure, SOI timing and spray angle on the combustion and performance of the RCCI engine were studied. It was observed that by increasing PR, peak in-cylinder pressure and HRR decrease and combustion phasing is retarded. In addition, increasing PR causes $\mathrm{HC}$ and $\mathrm{CO}$ emissions to increase. Considering all emission and performance parameters, $\mathrm{PR}=0.76$ was found the optimal value for the operating condition studied where $\mathrm{HC}$ and $\mathrm{CO}$ emissions decrease by 6 and $25 \mathrm{~g} / \mathrm{kg}$-fuel, respectively, and combustion efficiency improves by $1.5 \%$ compared to the base point with $\mathrm{PR}=0.815$.

It was understood that for this RCCI engine with existing injection system, decreasing injection pressure from the base case (480 bar) by 100 bar will slightly improve the combustion efficiency by around $1 \%$ and $\mathrm{HC}$ and $\mathrm{CO}$ emissions will decrease 10 and 20 $\mathrm{g} / \mathrm{kg}$-fuel, respectively. It was also observed that advancing SOI timing is beneficial 
for the engine due to increase in mixing time of diesel fuel with premixed air and gasoline where combustion and gross indicated efficiency improve by around 1\%, load (IMEP) increases by 0.17 bar and $\mathrm{HC}$ and $\mathrm{CO}$ emissions decrease 9 and $18 \mathrm{~g} / \mathrm{kg}$-fuel, respectively.

It was shown that decreasing spray angle from the base case (i.e., $74^{\circ}$ ) to $55^{\circ}$ causes $\mathrm{HC}$ and $\mathrm{CO}$ emissions to decrease 8 and $11 \mathrm{~g} / \mathrm{kg}$-fuel, respectively. In addition, combustion and gross indicated efficiency will improve by around 0.7 percent. Overall, spray angle is found as the dominant parameter affecting RCCI combustion and engine performance, while injection pressure has less effects on RCCI combustion and performance for the operating conditions studied in this thesis.

\subsection{Future Work}

Suggestions for future work include:

* A detailed chemical mechanism [75] can be utilized for better prediction of $\mathrm{HC}$ and $\mathrm{CO}$ emissions. In addition, a more accurate submodel can be developed and incorporated into CONVERGE for better prediction of $\mathrm{NO}_{\mathrm{x}}$ in LTC combustion regime.

* Turbulence models such as LES [76] and DNS [76] can be used for improving the accuracy of the CFD model for modeling the turbulent flow in the cylinder. 
* Fuels with larger reactivity gradient compared to gasoline and diesel can be studied for RCCI engine as this provides stronger control knob for shaping heat release rate. Candidate fuels include natural gas and diesel.

* The effects of multiple direct injections instead of using single injection can be explored.

* A new injector with specifications based on the outcomes from chapter 4 can be designed and implemented on the engine.

* An open cycle simulation can be done to reduce the modeling uncertainties. In particular, estimation of IVC temperature and estimation of species in external EGR and residual gases can be improved. Moreover, open cycle simulation gives the opportunity to study the VVT effects on RCCI combustion.

* Factorial design method in Design of Experiment (DOE) [77] can be used to determine optimized injection system parameters for the RCCI engine operation based on maximum thermal efficiency and minimum engine-out emissions, while meeting maximum allowable combustion noise. This method is useful to study the joint effects of the fuel injection parameters on performance of the RCCI engine. 


\section{References}

[1] G. D. Neely, S. Sasaki, Y. Huang, J. A. Leet, and D. W. Stewart. "New diesel emission control strategy to meet US tier 2 emissions regulations”. 2005. SAE Technical Paper 2005-01-1091.

[2] H. Saigaonkar. "An Investigation Of Variable Valve Timing Effects on HCCI Engine Performance”. Master's thesis, Michigan Technological University, 2014.

[3] Y. Wu, R. Hanson, and R. D. Reitz. "Investigation of Combustion Phasing Control Strategy During Reactivity Controlled Compression Ignition (RCCI) Multicylinder Engine Load Transitions". Journal of Engineering for Gas Turbines and Power, 136(9), 2014.

[4] R. W. Bilger, P. A. Libby, and F. A. Williams. “Turbulent Reacting Flows”. Springer Verlag, 1980.

[5] J. H. Kim, R. D. Reitz, and S. W. Park. "Improvements in the performance and pollutant emissions for stoichiometric diesel combustion engines using a 
two-spray-angle nozzle". Proceedings of the Institution of Mechanical Engineers, Part D: Journal of Automobile Engineering, 224(8):1113-1122, 2010.

[6] J. R. Theis, J. A. Ura, J. J. Li, G. G. Surnilla, J. M. Roth, and C. T. Goralski. "NOx release characteristics of lean NOx traps during rich purges". 2003. SAE Technical Paper 2003-01-1159.

[7] T. V. Johnson. "Diesel emissions in review". 2011. SAE Technical Paper 2011-01-0304.

[8] S. Onishi, S. H. Jo, K. Shoda, P. Do Jo, and S. Kato. "Active thermo-atmosphere combustion (ATAC)-a new combustion process for internal combustion engines". 1979. SAE Technical paper 790501.

[9] P. M. Najt and D. E. Foster. "Compression-ignited homogeneous charge combustion". 1983. SAE Technical paper 830264.

[10] R. H. Thring. "Homogeneous-charge compression-ignition (HCCI) engines". 1989. SAE Technical paper 892068 .

[11] D. Nieman. "Computational study and optimization of heavy-duty natural gas/diesel RCCI Operation”. Master's thesis, University of Wisconsin-Madison, 2012.

[12] J.-O. Olsson, P. Tunestål, and B. Johansson. "Closed-loop control of an HCCI engine”. SAE Transactions, Journal of Engines, 110(3):1076-1085, 2001. 
[13] J.-O. Olsson, P. Tunestål, G. Haraldsson, and B. Johansson. "A turbocharged dual-fuel HCCI engine”. SAE Special Publications, 2001(1627), 2001.

[14] J.-O. Olsson, P. Tunestål, J. Ulfvik, and B. Johansson. "The effect of cooled EGR on emissions and performance of a turbocharged HCCI engine”. 2003. SAE Technical paper 2003-01-0743.

[15] C. Noehre, M. Andersson, B. Johansson, and A. Hultqvist. "Characterization of partially premixed combustion”. 2006. SAE Technical Paper 2006-01-3412.

[16] V. Manente, P. Tunestål, B. Johansson, and W. Cannella. "Effects of ethanol and different type of gasoline fuels on partially premixed combustion from low to high load”. 2010. SAE Technical Paper 2010-01-0871.

[17] V. Manente, C.-G. Zander, B. Johansson, P. Tunestal, and W. Cannella. "An advanced internal combustion engine concept for low emissions and high efficiency from idle to max load using gasoline partially premixed combustion”. 2010. SAE Technical Paper 2010-01-2198.

[18] V. Manente, B. Johansson, and P. Tunestal. "Partially premixed combustion at high load using gasoline and ethanol, a comparison with diesel”. 2009. SAE Technical Paper 2009-01-0944.

[19] A. B. Dempsey and R. D. Reitz. "Computational optimization of a heavy-duty compression ignition engine fueled with conventional gasoline”. 2011. SAE Technical Paper 2011-01-0356. 
[20] K. Inagaki, T. Fuyuto, K. Nishikawa, K. Nakakita, and I. Sakata. "Dual-fuel PCI combustion controlled by in-cylinder stratification of ignitability". 2006. SAE Technical Paper 2006-01-0028.

[21] P. W. Bessonette, C. H. Schleyer, K. P. Duffy, W. L. Hardy, and M. P. Liechty. "Effects of fuel property changes on heavy-duty HCCI combustion". 2007. SAE Technical Paper 2007-01-0191.

[22] S. L. Kokjohn, R. M. Hanson, D. A. Splitter, and R. D. Reitz. "Experiments and modeling of dual-fuel HCCI and PCCI combustion using in-cylinder fuel blending”. 2009. SAE Technical Paper 2009-01-2647.

[23] D. Splitter, S. Kokjohn, K. Rein, R. Hanson, S. Sanders, and R. D. Reitz. “An optical investigation of ignition processes in fuel reactivity controlled PCCI combustion". 2010. SAE Technical Paper 2010-01-0345.

[24] R. M. Hanson, S. L. Kokjohn, D. A. Splitter, and R. D. Reitz. “An experimental investigation of fuel reactivity controlled PCCI combustion in a heavy-duty engine". 2010. SAE Technical Paper 2010-01-0864.

[25] S. Kokjohn. "Reactivity Controlled Compression Ignition (RCCI) Combustion”. PhD thesis, University of Wisconsin-Madison, 2012.

[26] B. D. Adhikary, Y. Ra, R. D. Reitz, and S. C. "Numerical optimization of a light-duty compression ignition engine fuelled with low-octane gasoline”. 2012. SAE Technical Paper 2012-01-1336. 
[27] J. Kaddatz, M. Andrie, R. D. Reitz, and S. Kokjohn. "Light-duty reactivity controlled compression ignition combustion using a cetane improver". 2012. SAE Technical Paper 2012-01-1110.

[28] D. Splitter, R. Hanson, S. Kokjohn, and R. D. Reitz. "Reactivity controlled compression ignition (RCCI) heavy-duty engine operation at mid-and high-loads with conventional and alternative fuels". 2011. SAE Technical Paper 2011-01-0363.

[29] J. U. Eichmeier, R. D. Reitz, and C. Rutland. "A zero-dimensional phenomenological model for RCCI combustion using reaction kinetics". 2014. SAE Technical Paper 2014-01-1074.

[30] J. Brakora and R. D. Reitz. "A comprehensive combustion model for biodiesel-fueled engine simulations". 2013. SAE Technical Paper 2013-01-1099.

[31] S. L. Kokjohn and R. D. Reitz. "Reactivity controlled compression ignition and conventional diesel combustion: A comparison of methods to meet light-duty NOx and fuel economy targets". International Journal of Engine Research, 14(5):452-468, 2013.

[32] D. Splitter, M. Wissink, S. Kokjohn, and R. Reitz. "Effect of compression ratio and piston geometry on RCCI load limits and efficiency". 2012. SAE Technical Paper 2012-01-0383.

[33] D. E. Nieman, A. B. Dempsey, and R. D. Reitz. "Heavy-duty RCCI operation using natural gas and diesel”. 2012. SAE Technical Paper 2012-01-0379. 
[34] S. Curran, R. Hanson, and R. Wagner. "Reactivity controlled compression ignition combustion on a multi-cylinder light-duty diesel engine”. International Journal of Engine Research, 13(3):216-225, 2012.

[35] H. J. Curran, P. Gaffuri, W. J. Pitz, and C. K. Westbrook. “A comprehensive modeling study of iso-octane oxidation”. Combustion and Flame, 129(3):253-280, 2002.

[36] G. Woschni. "A universally applicable equation for the instantaneous heat transfer coefficient in the internal combustion engine”. 1967. SAE Technical paper 670931.

[37] J. B. Heywood. “Internal combustion engine fundamentals”. McGraw-Hill New York, 1988.

[38] S. Aceves, D. Flowers, C. Westbrook, J. Smith, W. Pitz, R. Dibble, M. Christensen, and B. Johansson. "A Multi-Zone Model for Prediction of HCCI Combustion and Emissions”. 2000. SAE Technical Paper 2000-01-0327.

[39] R. W. Carling and G. Singh. "Review of heavy-duty engine combustion research at sandia national laboratories”. 2000. SAE Technical Paper 2000-01-2199.

[40] R. Chen and N. Milovanovic. "A computational study into the effect of exhaust gas recycling on homogeneous charge compression ignition combustion in internal combustion engines fuelled with methane". International Journal of Thermal Sciences, 41(9):805-813, 2002. 
[41] R. D. Reitz and R. Diwakar. "Structure of high-pressure fuel sprays". 1987. SAE Technical Paper 870598.

[42] P. J. O'Rourke and A. A. Amsden. "The TAB method for numerical calculation of spray droplet breakup”. 1987. SAE Technical Paper 872089.

[43] P. K. Senecal, K. J. Richards, E. Pomraning, T. Yang, M. Z. Dai, R. M. McDavid, M. A. Patterson, S. Hou, and T. Shethaji. "A new parallel cut-cell Cartesian CFD code for rapid grid generation applied to in-cylinder diesel engine simulations”. 2007. SAE Technical Paper 2007-01-0159.

[44] L. M. Ricart, J. Xin, G. R. Bower, and R. D. Reitz. "In-cylinder measurement and modeling of liquid fuel spray penetration in a heavy-duty diesel engine". 1997. SAE Technical Paper 971591.

[45] D. P. Schmidt and C. J. Rutland. "A new droplet collision algorithm". Journal of Computational Physics, 164(1):62-80, 2000.

[46] P. J. O’Rourke. “Collective Drop Effects on Vaporizing Liquid Sprays”. PhD thesis, Princeton University, 1981.

[47] S. L. Post and J. Abraham. "Modeling the outcome of drop-drop collisions in diesel sprays". International Journal of Multiphase Flow, 28(6):997-1019, 2002.

[48] P. J. O’Rourke and A. A. Amsden. “A spray/wall interaction submodel for the KIVA-3 wall film model". 2000. SAE Technical Paper 2000-01-0271. 
[49] A. A. Amsden, P. J. O’Rourke, and T. D. Butler. “KIVA-II: A computer program for chemically reactive flows with sprays". Technical report, 1989. Los Alamos National Lab., NM (USA).

[50] G. M. Faeth. "Current status of droplet and liquid combustion”. Progress in Energy and Combustion Science, 3(4):191-224, 1977.

[51] P. K. Senecal, E. Pomraning, K. J. Richards, T. E. Briggs, C. Y. Choi, R. M. McDavid, and M. A. Patterson. "Multi-dimensional modeling of direct-injection diesel spray liquid length and flame lift-off length using CFD and parallel detailed chemistry". 2003. SAE Technical Paper 2003-01-1043.

[52] Y. Ra and R. D. Reitz. "A reduced chemical kinetic model for IC engine combustion simulations with primary reference fuels". Combustion and Flame, 155(4):713-738, 2008.

[53] M. Jia and M. Xie. "A chemical kinetics model of iso-octane oxidation for HCCI engines". Fuel, 85(17):2593-2604, 2006.

[54] A. Patel, S.-C. Kong, and R. D. Reitz. "Development and validation of a reduced reaction mechanism for HCCI engine simulations". 2004. SAE Technical Paper 2004-01-0558.

[55] A. Babajimopoulos, D. N. Assanis, D. L. Flowers, S. M. Aceves, and R. P. Hessel. "A fully coupled computational fluid dynamics and multi-zone model with 
detailed chemical kinetics for the simulation of premixed charge compression ignition engines”. International Journal of Engine Research, 6(5):497-512, 2005.

[56] H. Hiroyasu and T. Kadota. "Models for combustion and formation of nitric oxide and soot in direct injection diesel engines". 1976. SAE Technical Paper 760129.

[57] V. Yakhot and S. A. Orszag. "Renormalization group analysis of turbulence. I. Basic theory". Journal of scientific computing, 1(1):3-51, 1986.

[58] P. J. O'Rourke and A. A. Amsden. "Implementation of a conjugate residual iteration in the KIVA computer program". Technical report, Los Alamos National Lab., NM (USA), 1986.

[59] S. R. Turns. “An Introduction to Combustion”. McGraw-Hill New York, Third Ed.,2011.

[60] S. Kokjohn, R. Hanson, D. Splitter, J. Kaddatz, and R. D. Reitz. "Fuel reactivity controlled compression ignition (RCCI) combustion in light-and heavy-duty engines". 2011. SAE Technical Paper 2011-01-0357.

[61] S. Kokjohn, R. Hanson, D. Splitter, and R. D. Reitz. "Fuel reactivity controlled compression ignition (RCCI): a pathway to controlled high-efficiency clean combustion”. International Journal of Engine Research, 12(3):209-226, 2011. 
[62] R. Hanson, S. Kokjohn, D. Splitter, and R. D. Reitz. "Fuel effects on reactivity controlled compression ignition (RCCI) combustion at low load". 2011. SAE Technical Paper 2011-01-0361.

[63] R. D. Reitz and G. Duraisamy. "Review of high efficiency and clean reactivity controlled compression ignition (RCCI) combustion in internal combustion engines". Progress in Energy and Combustion Science, 46:12-71, 2015.

[64] US EPA. 2011 News Releases. http://yosemite.epa.gov/ opa/admpress.nsf/1e5ab1124055f3b28525781f0042ed40/ 0019c092ccae8ac2852578dc0056ded0! OpenDocument, accessed on September 30, 2014.

[65] R. Opat, Y. Ra, R. Krieger, R. D. Reitz, D. E. Foster, R. P. Durrett, and R. M. Siewert. "Investigation of mixing and temperature effects on $\mathrm{HC} / \mathrm{CO}$ emissions for highly dilute low temperature combustion in a light duty diesel engine". 2007. SAE Technical Paper 2007-01-0193.

[66] H. Zhao. HCCI and CAI engines for the automotive industry. Elsevier, 2007.

[67] "Bedoya, I. and Francisco, C. and Saxena, S. and Dibble, R. and Aceves,S. and Flowers, D.”. “A Sequential Chemical Kinetics-CFD-Chemical Kinetics Methodology to Predict HCCI Combustion and Main Emissions". 2012. SAE Technical Paper 2012-01-1119. 
[68] J. E. Dec, Y. Yang, and N. Dronniou. "Boosted HCCI-controlling pressure-rise rates for performance improvements using partial fuel stratification with conventional gasoline”. 2011. SAE Technical Paper 2011-01-0897.

[69] T. Hariprasad. "Effect of Injection Pressure on Performance of Dual Fuel Diesel Engine”. 2013. SAE Technical Paper 2013-01-2887.

[70] J. Liu, A. Yao, and C. Yao. "Effects of diesel injection pressure on the performance and emissions of a HD common-rail diesel engine fueled with diesel/methanol dual fuel". Fuel, 140:192-200, 2015.

[71] M. M. Roy, E. Tomita, N. Kawahara, Y. Harada, and A. Sakane. "Effect of fuel injection parameters on engine performance and emissions of a supercharged producer gas-diesel dual fuel engine”. 2009. SAE Technical Paper 2009-01-1848.

[72] C. Leermakers, B. Van den Berge, C. Luijten, L. Somers, L. de Goey, and B. Albrecht. “Gasoline-Diesel Dual Fuel: Effect of Injection Timing and Fuel Balance”. 2011. SAE Technical Paper 2011-01-2437.

[73] J. Lim and K. Min. "The effects of spray angle and piston bowl shape on diesel engine soot emissions using 3-D CFD simulation". 2005. SAE Technical Paper 2005-01-2117.

[74] S. Wei, K. Ji, X. Leng, F. Wang, and X. Liu. "Numerical simulation on effects of spray angle in a swirl chamber combustion system of DI (direct injection) diesel engines". Energy, 75:289-294, 2014. 
[75] S. M. Sarathy, C. K. Westbrook, M. Mehl, W. J. Pitz, C. Togbe, P. Dagaut, H. Wang, M. A. Oehlschlaeger, U. Niemann, K. Seshadri, P. S. Velooe, C. Jie, F. N. Egolfopoulose, and Lu T. "Comprehensive chemical kinetic modeling of the oxidation of 2-methylalkanes from C7 to C20". Combustion and flame, 158(12):2338-2357, 2011.

[76] M. Germano, U. Piomelli, P. Moin, and W. H. Cabot. "A dynamic subgrid-scale eddy viscosity model". Physics of Fluids A: Fluid Dynamics (1989-1993), 3(7):1760-1765, 1991.

[77] D. C. Montgomery. "Design and analysis of experiments". John Wiley \& Sons, Eighth Ed., 2013.

[78] D. Kothari. "Experimental Setup And Controller Design For An HCCI Engine". Master's thesis, Michigan Technological University, 2014.

[79] V. Thakkar. “Modeling And Experimental Setup Of An HCCI Engine”. Master's thesis, Michigan Technological University, 2014.

[80] "Fuel Economy Guide". Technical report, 2015. EPA. 



\section{Appendix A}

\section{Calculations of gross and net work}

The CONVERGE simulations only consider the closed portion of the cycle (i.e., from IVC to EVO). Parameters including IMEP and indicated efficiency require full engine cycle data. To this end, experimental pressure traces were used to calculate the open valve portion of the engine cycle. Sample experimental and simulation pressure traces for case (c) in Table 2.3 are shown in Figure A.1. 


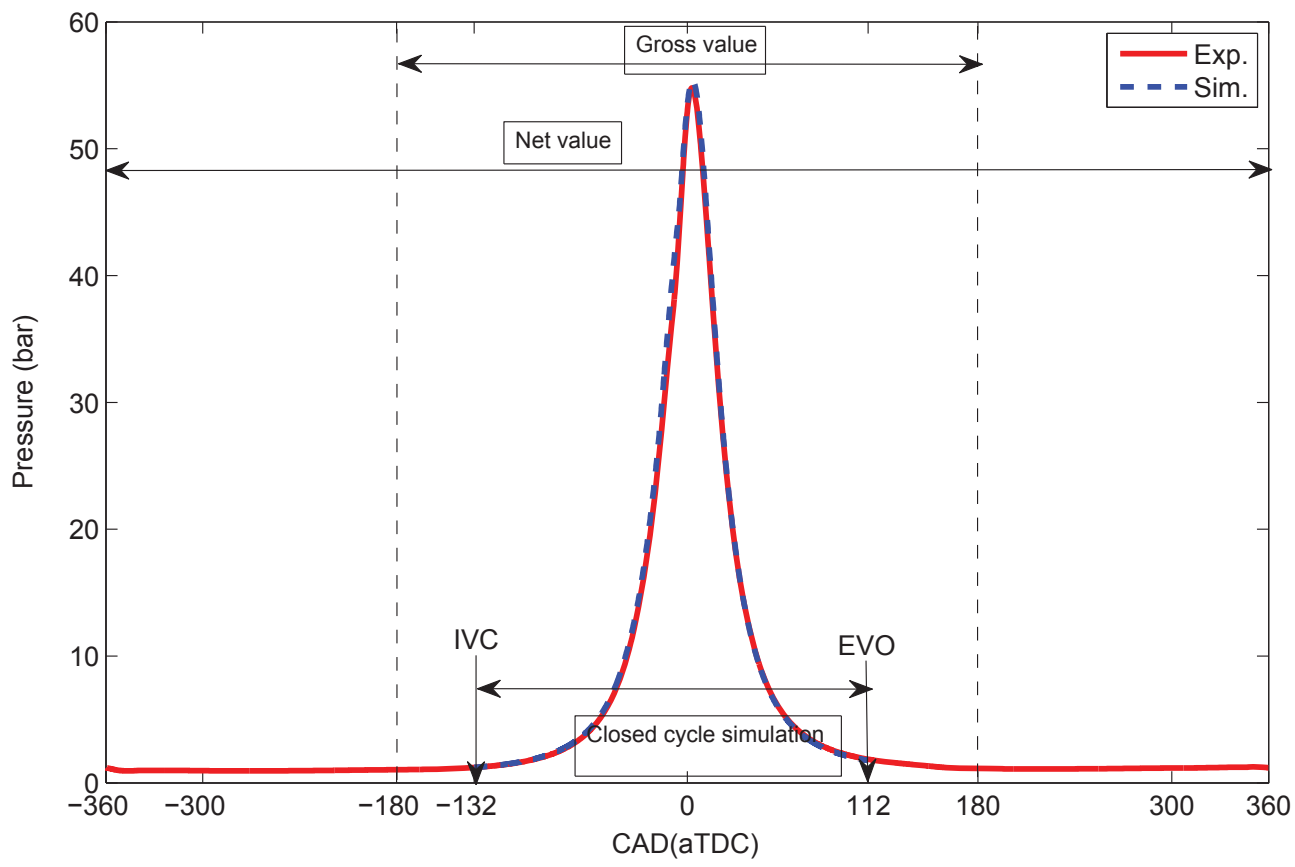

Figure A.1: Pressure trace validation for the engine operating condition corresponding to case $c$ in Table 2.3 


\section{Appendix B}

\section{MS Publications}

\section{Conference papers}

* H. Saigaonkar, M. Nazemi, M. Shahbakhti, "Sequential Model for Residual Affected HCCI with Variable Valve Timing”, 15 pages, 2015 SAE World Congress, SAE Paper No. 2015-01-1748, Apr. 21-23, 2015, Detroit, MI, USA.

* M. Nazemi, H. Saigaonkar, M. Shahbakhti, "Thermo-kinetic Modeling of Variable Valve Timing Effects on HCCI Engine Combustion", Int. Conference on Advanced Technology \& Sciences (ICATS), 6 pages, August 12-15, 2014, Antalya, Turkey.

\section{Journal paper}

The following paper was automatically selected by 2014 ICATS conference for journal publication. 
* M. Nazemi, H. Saigaonkar, M. Shahbakhti, "Thermo-kinetic Modeling of Variable Valve Timing Effects on HCCI Engine Combustion", Int. Journal of Automotive Engineering and Technologies, Vol. 4, Issue 1, pp. 54-62, 2015.

\section{Technical presentation}

* M. Nazemi, S. Polat, M. Shahbakhti, "Advanced combustion model of RCCI Engine" CONVERGE User Group Meeting, September 23-25, 2014, Madison, USA. 


\section{Appendix C}

\section{Geometric/CFD Model of EML's LTC}

engine

A group of students [78, 2, 79] have been working in Energy Mechatronics Laboratory (EML) to make an LTC engine setup at Michigan Tech's Advanced Power System Research Center (APSRC). Future and on-going works include testing and simulating engine performance.

This thesis includes the first step of CFD simulations for the LTC engine by developing a geometric/CFD model of the engine.

A GM 2.0L Gasoline Direct Injection (GDI) Ecotec LHU Gen 1 engine at APSRC is modified and instrumented in order to run in different modes of LTC regime (i.e., HCCI, 
PCCI and RCCI). The engine specifications are presented in Table C.1.

The stock piston Compression Ratio (CR) is 9.2. However, A high $\mathrm{CR}$ is beneficial to broaden the engine operating range in the LTC mode. Therefore CR is increased to 12.3.

The original and new pistons are shown in Figure C.1.

Table C.1

Engine specifications (GM Ecotec LHU A20NFT)

\begin{tabular}{cc}
\hline \hline Parameter & Value \\
\hline Bore & $86(\mathrm{~mm})$ \\
Stroke & $86(\mathrm{~mm})$ \\
Connecting rod length (center to center) & $145.5(\mathrm{~mm})$ \\
Compression Ratio & $9.2: 1$ \\
Displacement Volume & $2.0 \mathrm{~L}$ \\
Max Power@ RPM & 270kW@6000 rpm \\
Measured IVO/IVC @ 1mm lift & $24.5 / 228$ aTDC \\
Measured EVO/EVC @ 1mm lift & $36 /-158 \mathrm{bBDC}$ \\
Fuel injection system & Direct injection with 31 bar @ idle, 155 bar \\
Valvetrain & DOHC 4 valves/cylinder \\
Cam phasing mechanism & Hydraulically actuated internal vane type \\
\hline
\end{tabular}

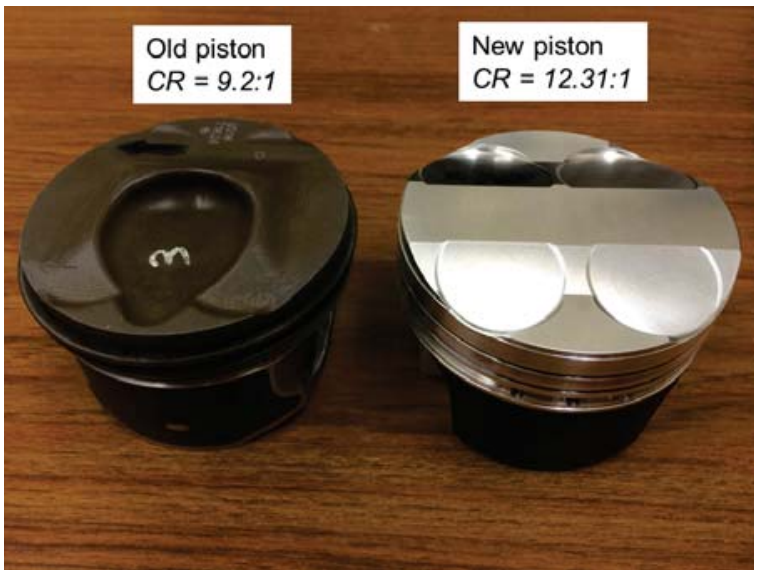

Figure C.1: Stock and new piston top designs [2] 
The 3D models of both pistons were developed in SolidWorks software to be able to import them into CONVERGE software for LTC engine modeling.

The 3D model of the engine with stock piston with $\mathrm{CR}=9.2$ in Solidworks and CONVERGE software is shown in Figure C.2. 
a) Engine model in SolidWorks

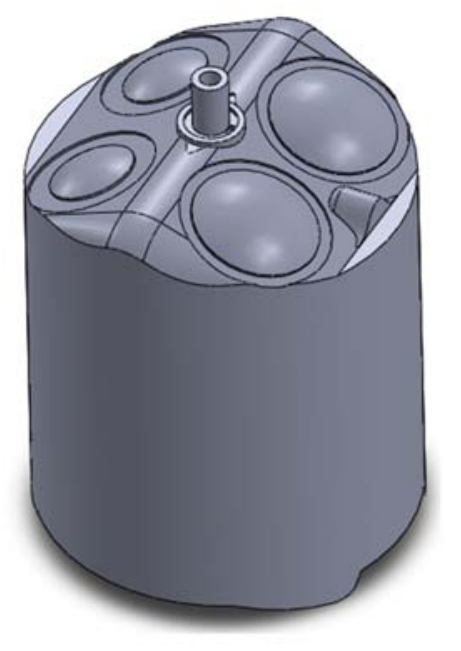

c) Stock piston in SolidWorks

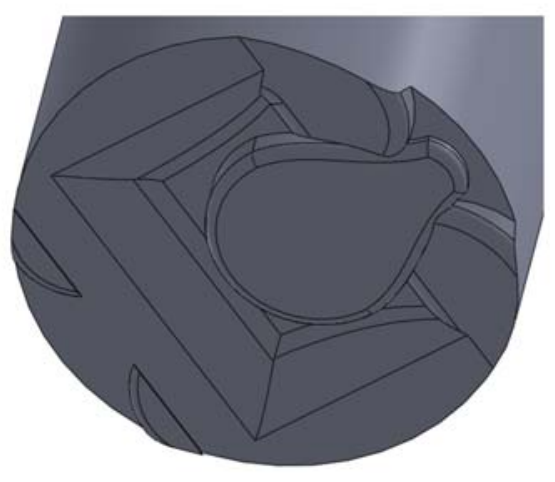

e) Cylinder head

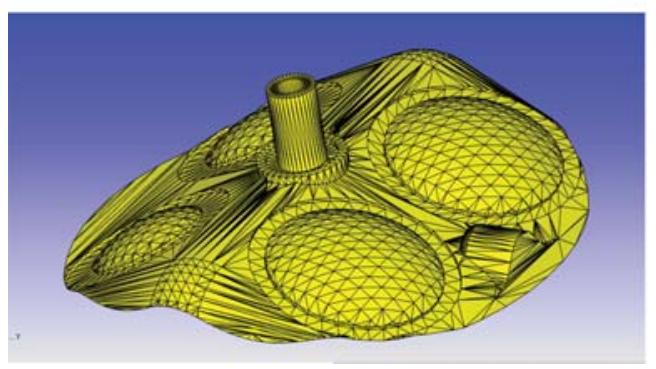

b) Engine model in CONEVRGE

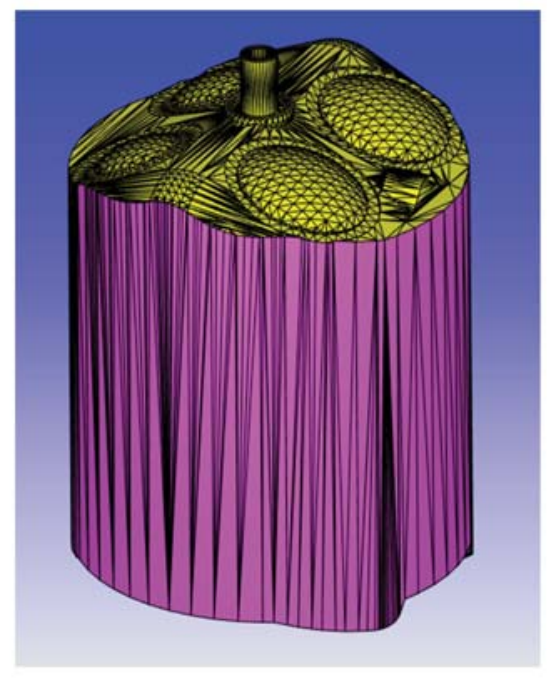

d) Stock Piston in CONVERGE

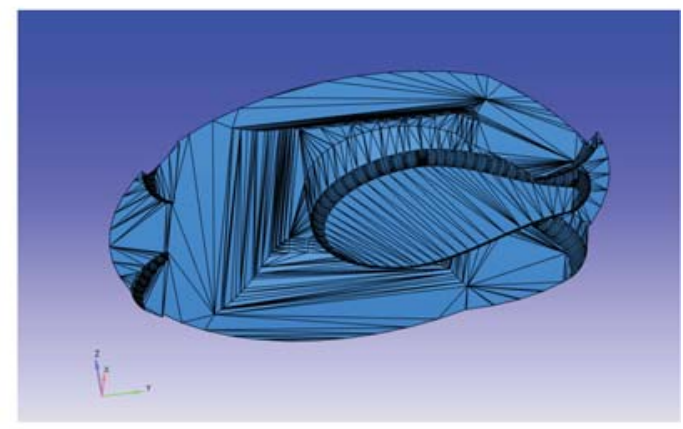

\section{f) Spark Plug}

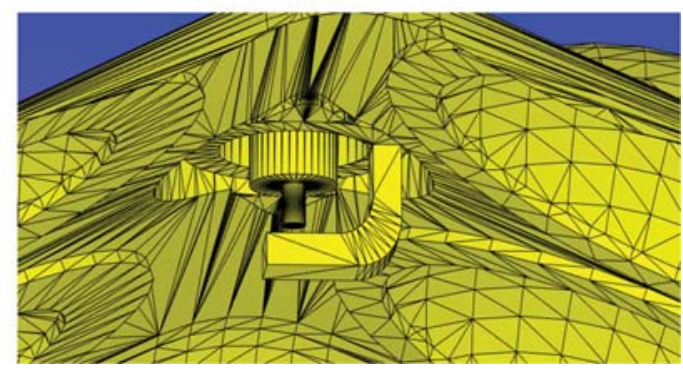

Figure C.2: 3D model of the GM Ecotec LHU engine with stock piston. 
The motoring in-cylinder pressure in the CONVERGE simulation is shown in Figure C.3.

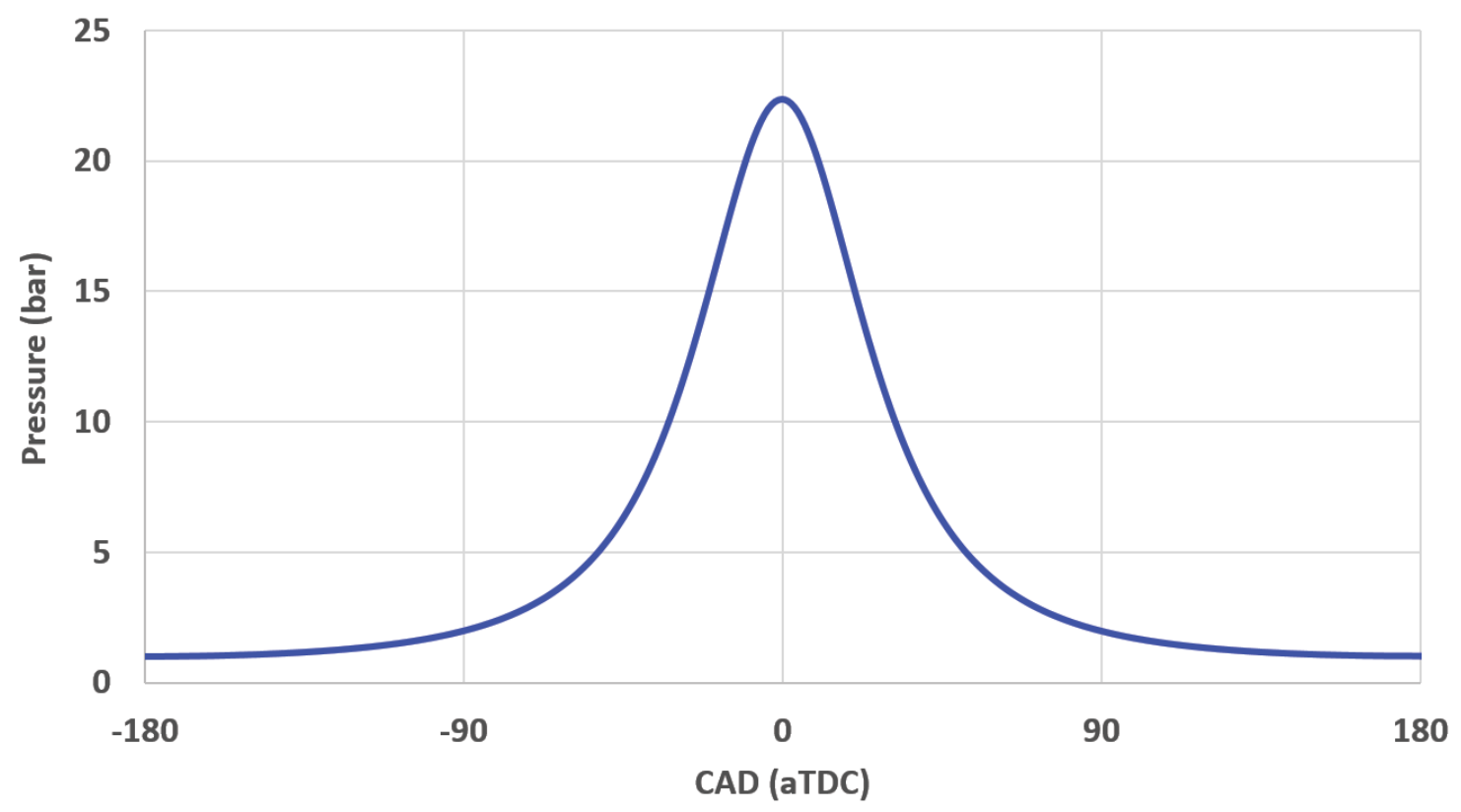

Figure C.3: Motoring in-cylinder pressure with stock piston in simulation

The differences involve in creating the $3 \mathrm{D}$ model and the actual values from experiment is presented in Table C.2

Table C.2

Differences in creating the geometric/3D model of the engine with stock piston

\begin{tabular}{cccc}
\hline \hline Parameter & Experiment & Simulation & Difference \\
\hline \hline Bore $\times$ stroke $(\mathrm{mm})$ & $86 \times 86$ & $86 \times 86$ & - \\
Compression ratio & 9.22 & 9.22 & - \\
Displacement volume $\left(\mathrm{cm}^{3}\right)$ & 499.55 & 499.01 & $0.1 \%$ \\
Clearance volume $\left(\mathrm{cm}^{3}\right)$ & 60.77 & 60.64 & $0.2 \%$ \\
Total cylinder volume $\left(\mathrm{cm}^{3}\right)$ & 560.32 & 559.65 & $0.1 \%$ \\
\hline
\end{tabular}

In addition, the $3 \mathrm{D}$ model of the engine with new piston with $\mathrm{CR}=12.3$ is shown in 
Figure C.4.

a) Engine model in SolidWorks

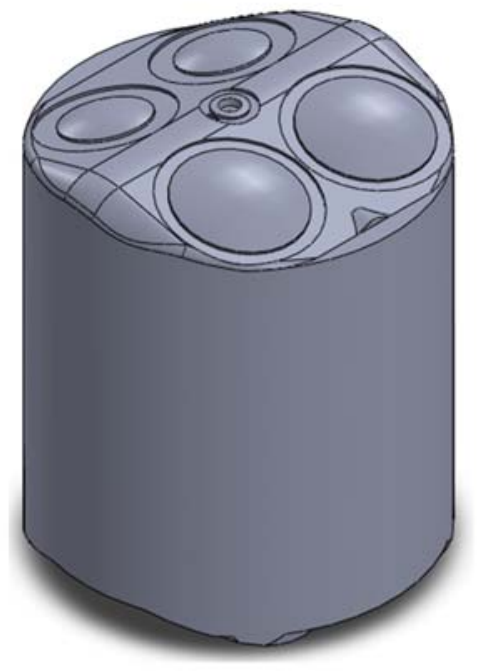

c) New piston in SolidWorks

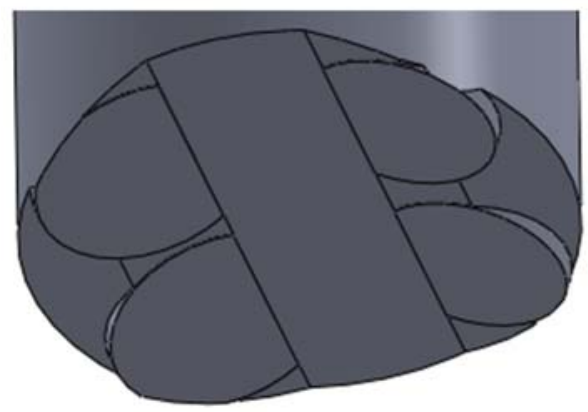

b) Engine model in CONVERGE

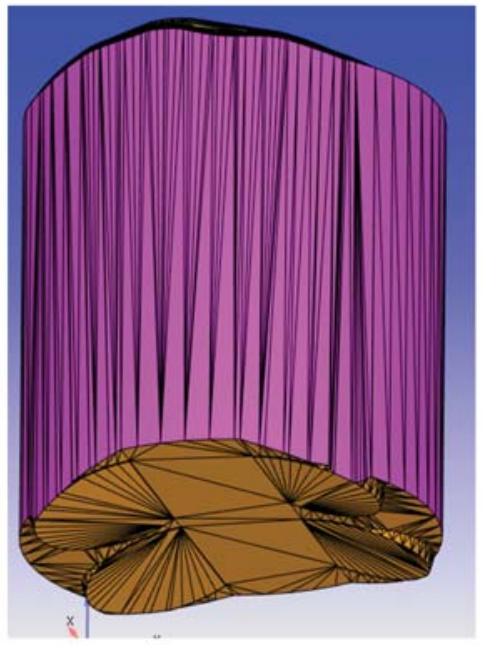

d) New piston in CONVERGE

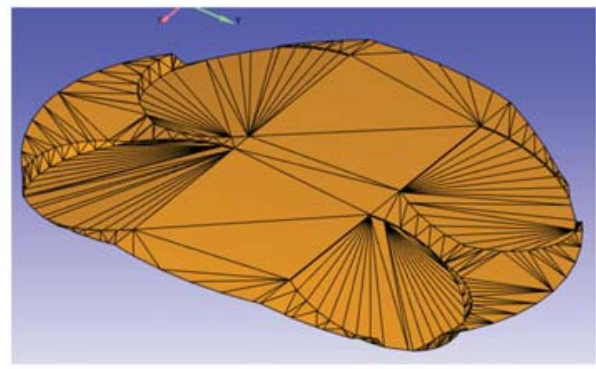

Figure C.4: 3D model of the GM Ecotec LHU engine with new piston.

The motoring in-cylinder pressure in the CONVERGE simulation with new piston is shown in Figure C.5. 


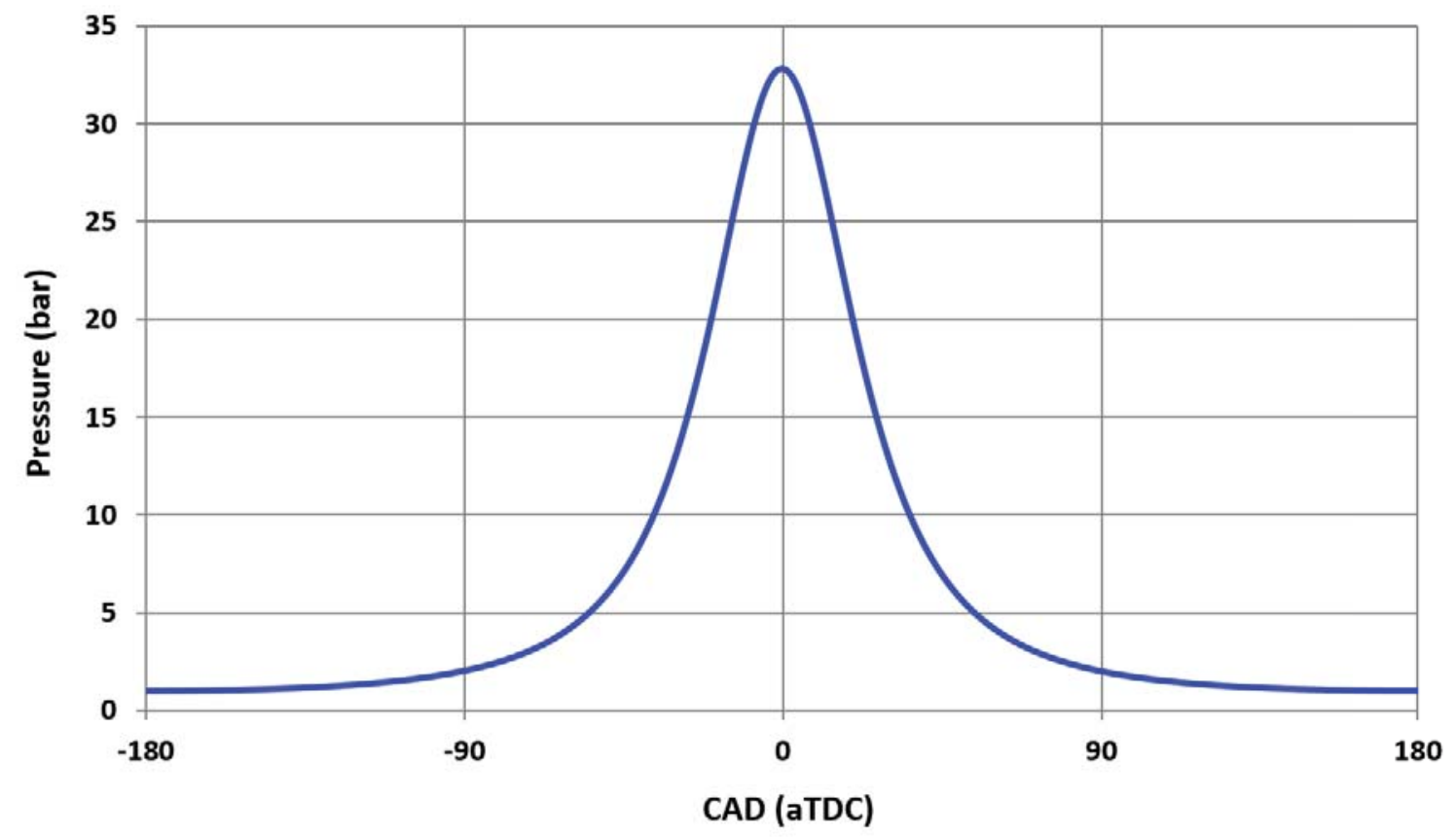

Figure C.5: Motoring in-cylinder pressure with new piston in simulation

The differences involve in creating the 3D model with new piston and the actual values from experiment is presented in Table C.3

Table C.3

Differences in creating the geometric/3D model of the engine with new piston

\begin{tabular}{cccc}
\hline \hline Parameter & Experiment & Simulation & Difference \\
\hline \hline Bore $\times$ stroke $(\mathrm{mm})$ & $86 \times 86$ & $86 \times 86$ & - \\
Compression ratio & 12.31 & 12.23 & $0.6 \%$ \\
Displacement volume $\left(\mathrm{cm}^{3}\right)$ & 499.55 & 498.7 & $0.1 \%$ \\
Clearance volume $\left(\mathrm{cm}^{3}\right)$ & 44.1 & 44.4 & $0.6 \%$ \\
Total cylinder volume $\left(\mathrm{cm}^{3}\right)$ & 543.7 & 543.1 & $0.1 \%$ \\
\hline
\end{tabular}




\section{Appendix D}

\section{Calculations for standard limit of HC}

\section{and CO emissions}

EPA 2010 Standard limit for HC and CO emissions [64] are 0.8 and $4.2 \mathrm{~g} / \mathrm{mile}$, respectively. All emissions unit in chapters 3 and 4 are $\mathrm{g} / \mathrm{kg}$-fuel. Therefore it is necessary to convert unit from $\mathrm{g} / \mathrm{mile}$ to $\mathrm{g} / \mathrm{kg}$-fuel.

Based on EPA report for fuel economy in 2015 [80], a fuel economy range of 27 to 46 MPG is found for over 10 different vehicles operated with diesel engines which have similar size as the engine in this thesis. The following example shows how emission limit is converted from "g/mile" to "g/kg-fuel":

$4.2\left[\frac{\mathrm{g}}{\text { mile }}\right] \times 27\left[\frac{\text { mile }}{\text { Gallon }}\right] \times\left[\frac{1 \text { Gallon }}{3.78541 \text { Liter }}\right] \times\left[\frac{1 \text { Liter }}{0.77 \mathrm{~kg}-\text { fuel }}\right]=38.9 \mathrm{~g} / \mathrm{kg}$-fuel 
As a result, the ranges of standard $\mathrm{HC}$ and $\mathrm{CO}$ emissions based on EPA 2010 emissions regulations are [7.41-12.62] and [38.90-66.28] g/kg-fuel, respectively. 


\section{Appendix E}

\section{Thesis files summary}

Following files were used for this thesis. Data is arranged in form of tables.

Table E.1

Experimental data files

\begin{tabular}{|c|c|c|}
\hline Sr. \# & File Name & Description \\
\hline 1 & ExperimentalData_case A & $\begin{array}{c}\text { Experimental data for case (a) } \\
\text { in Table } 2.3\end{array}$ \\
\hline 2 & ExperimentalData_caseB & $\begin{array}{c}\text { Experimental data for case (b) } \\
\text { in Table } 2.3\end{array}$ \\
\hline 3 & ExperimentalData_caseC & $\begin{array}{c}\text { Experimental data for case (c) } \\
\text { in Table } 2.3\end{array}$ \\
\hline 4 & Summary_OperatingConditions & $\begin{array}{l}\text { Specifications of three operating } \\
\text { conditions in Table } 2.3\end{array}$ \\
\hline 5 & Wisconsin-Madison_Geometry & $\begin{array}{l}\text { Geometric models for stock piston } \\
\text { and new piston with } C R=16.7\end{array}$ \\
\hline 6 & EML_Geometry & $\begin{array}{l}\text { Geometric models for stock piston } \\
\text { and new piston with } \mathrm{CR}=12.3\end{array}$ \\
\hline
\end{tabular}


Table E.2

CHEMKIN $^{\circledR}$ - PRO and CONVERGE ${ }^{\mathrm{TM}}$ files

\begin{tabular}{|c|c|c|}
\hline Sr. \# & File Name & Description \\
\hline 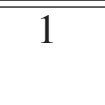 & CONVERGE Validation Input Files & $\begin{array}{l}\text { CONVERGE input files for validation } \\
\text { of three operating conditions in Table } 2.3\end{array}$ \\
\hline 2 & CONVERGE Parametric Study & $\begin{array}{c}\text { Input files for four fuel injection } \\
\text { system parameters sweep in chapter } 4 \text {. }\end{array}$ \\
\hline 3 & CHEMKIN-Pro Files & $\begin{array}{l}\text { CHEMKIN }{ }^{\circledR}-\text { PRO model } \\
\text { files for validation of SOC in chapter } 2 .\end{array}$ \\
\hline
\end{tabular}

Table E.3

Matlab figure (.fig) files for Chapter 3

\begin{tabular}{ccc}
\hline \hline Sr. \# & File Name & Description \\
\hline \hline 1 & RateShape & Figure 3.3 \\
2 & ValPreCaseA & Figure 3.4 \\
3 & ValHRCaseA & Figure 3.5 \\
4 & ValPreCaseB & Figure 3.6 \\
5 & ValHRCaseB & Figure 3.7 \\
6 & ValPreCaseC & Figure 3.8 \\
7 & ValHRCaseC & Figure 3.9 \\
\hline
\end{tabular}


Table E.4

Matlab figure (.fig) files for Chapter 4 and Appendix A

\begin{tabular}{|c|c|c|}
\hline Sr. \# & File Name & Description \\
\hline 1 & PrePreMix & Figure 4.1 \\
\hline 2 & HRR & Figure 4.2 \\
\hline 3 & CombustionPhasing & Figure 4.3 \\
\hline 4 & Emissions & Figure 4.4 \\
\hline 5 & TempPreMix & Figure 4.5 \\
\hline 6 & ComEffiPreMix & Figure 4.6 \\
\hline 7 & GroEffiPreMix & Figure 4.7 \\
\hline 8 & RIPreMix & Figure 4.8 \\
\hline 9 & PresInjPre & Figure 4.9 \\
\hline 10 & HRInjPre & Figure 4.12 \\
\hline 11 & ComPhasInjPre & Figure 4.13 \\
\hline 12 & EmiInjPre & Figure 4.14 \\
\hline 13 & ComEffInjPre & Figure 4.15 \\
\hline 14 & GroEffiInjPre & Figure 4.16 \\
\hline 15 & RIInjPre & Figure 4.17 \\
\hline 16 & PreSOI & Figure 4.18 \\
\hline 17 & HRSOI & Figure 4.20 \\
\hline 18 & TempSOI & Figure 4.21 \\
\hline 19 & ComPhasSOI & Figure 4.23 \\
\hline 20 & EmiSOI & Figure 4.24 \\
\hline 21 & MaxTempSOI & Figure 4.25 \\
\hline 22 & ComEffSOI & Figure 4.26 \\
\hline 23 & GroEffSOI & Figure 4.27 \\
\hline 24 & RISOI & Figure 4.28 \\
\hline 25 & PreSpAn & Figure 4.31 \\
\hline 26 & HRSpAn & Figure 4.32 \\
\hline 27 & ComPhasSpAn & Figure 4.34 \\
\hline 28 & EmSpAn & Figure 4.35 \\
\hline 29 & MaxTempSP & Figure 4.36 \\
\hline 30 & ComEffSpAn & Figure 4.37 \\
\hline 31 & GroEffSpAn & Figure 4.38 \\
\hline 32 & RISpAn & Figure 4.39 \\
\hline 33 & Appendix & Figure A.1 \\
\hline
\end{tabular}


Table E.5

Image files for Chapters 1, 3 and Appendix C

\begin{tabular}{ccc}
\hline \hline Sr. \# & File Name & Description \\
\hline \hline 1 & LTC & Figure 1.1 \\
2 & PisGeo & Figure 3.2 \\
3 & OldNewPistons & Figure C.1 \\
4 & MotoringP_stockPiston & Figure C.3 \\
5 & MotoringP_newPiston & Figure C.5 \\
\hline
\end{tabular}

Table E.6

Visio figures

\begin{tabular}{ccc}
\hline \hline Sr. \# & File Name & Description \\
\hline \hline 1 & FuelInjectionSystem_Litreview & Figure 1.2 \\
2 & ThesisOrganization_Nazemi & Figure 1.3 \\
3 & Thermokinetic & Figure 2.1 \\
4 & SeqModSZM & Figure 2.2 \\
5 & SeqModelCFD & Figure 3.1 \\
6 & EnInjPre & Figure 4.10 \\
7 & EnInjPrePhi & Figure 4.11 \\
8 & SOIPhi & Figure 4.19 \\
9 & EnSOI & Figure 4.22 \\
10 & SpAn & Figure 4.29 \\
11 & SpAn_2 & Figure 4.30 \\
12 & EnSpAn & Figure 4.33 \\
13 & InjectionSummary & Figure 4.40 \\
14 & OldPiston & Figure C.2 \\
15 & NewPiston & Figure C.4 \\
\hline
\end{tabular}




\section{Appendix F}

\section{Permission}

This permission is for Figure C.1.

Hello Mohammadreza,

I hereby grant permission to you for using the Figure from the thesis entitled: "An Investigation Of Variable Valve Timing Effects on HCCI Engine Performanc". Master's thesis, Michigan Technological University 2014, in your M.S. thesis.

Best regards, Hrishikesh Saigaonkar

Performance Development Engineer, Cummins Power Generation

Phone: 906-231-2835 , Email: hsaigaon@mtu.edu 